\title{
DESEMPENHO DO MODELO DE PENMAN-MONTEITH E DE DOIS EVAPORÍMETROS NA ESTIMATIVA DA EVAPOTRANSPIRAÇÃO DE REFERÊNCIA (ETo) EM RELAÇÃO A UM LISÍMETRO DE PESAGEM
}

\section{FRANCISCO ADRIANO DE CARVALHO PEREIRA \\ Engenheiro Agrônomo}

Orientador : Prof. Dr. MARCOS VINÍCIUS FOLEGATTI

Co-orientador : Prof. Dr. NILSON AUGUSTO VILLA NOVA

Tese apresentada à Escola Superior de Agricultura "Luiz de Queiroz", Universidade de São Paulo, para obtenção do título de Doutor em Agronomia, Área de concentração em Irrigação e Drenagem.

P I R A C I C A B A

Estado de São Paulo - Brasil

Agosto de 1998 
Dados Internacionais de Catalogação na Publicação (CIP) DIVISÃO DE BIBLIOTECA E DOCUMENTAÇÃO - Campus "Luiz de Oueiroz"/USP

Pereira, Francisco Adriano de Carvalho

Desempenho do modelo de Penman-Monteith e de dois evaporimetros na estimativa da evapotranspiração de referência (ETo) em relação a um lisimetro de pesagem / Francisco Adriano de Carvalho Pereira. - - Piracicaba, 1998.

$87 \mathrm{p}$.

Tese (doutorado) - - Escola Superior de Agricultura Luiz de Queiroz, 1998.

Bibliografia.

1. Atmômetro 2. Evaporimetro 3. Evapotranspiraçao 4. Lisímetro 5. Modelo de Penman-Monteith 6. Tanque evaporimétrico I. Titulo 
Ao meu querido e amado pai Valter Pereira (In memorian) incansável lutador pela minha formação profissional

\section{DEDICO}

A Mirella e Celininha A minha mãe Leda

Aos meus irmãos 


\section{AGRADECIMENTOS}

A Deus, presença constante nos momentos de dificuldades, tristezas e alegrias.

Ao Departamento de Engenharia Agrícola, da Escola de Agronomia da Universidade Federal da Bahia, pela confiança depositada e oportunidade oferecida a realização deste Curso.

Ao programa CAPES-PICDT, pela ajuda financeira concedida na forma de bolsa de estudo, sem a qual se tornaria impossível a realização deste Curso.

Ao Prof. Dr. Marcos Vinícius Folegatti, pelo constante apoio, incentivo e orientação a realização deste trabalho.

Ao Prof. Dr. Nilson Augusto Villa Nova, pelos constantes ensinamentos, orientação, amizade e incentivos, o meu profundo agradecimento.

Ao Prof. Dr. Antônio Roberto Pereira, por todas as sugestões, orientação e ensinamentos prestados ao longo do desenvolvimento deste trabalho.

Aos Professores Valter Barbieri, José Geanini Peres, Gilberto Chohaku Sediyama pelas valiosas correções e sugestões apresentadas.

Aos Departamentos de Engenharia Rural e Física e Meteorologia da ESALQ/USP pelo apoio e por todas as facilidades oferecidas a realização deste trabalho.

A Lucieta Guerreiro Martorano, Pesquisadora da EMBRAPA-CNPS, amiga e colega pela oportunas sugestões apresentadas, serenidade e apoio durante a realização deste trabalho.

Aos funcionários, Hélio, César, Zezinho e Gilmar do Departamento de Engenharia Rural ESALQ/USP e Robson Tuon, Edivaldo Modesto, Vanderlino, Francisco Bernardino, Fernando e Ana do Departamento de Física e Meteorologia da ESALQ-USP, pelo grande apoio durante o transcorrer do Curso.

Aos colegas Luis Fernando, Sérgio Antônio Veronez, Clóvis Peixoto, Fátima Peixoto, Carlos Alfredo, Rosa Maria, Zilda Mariano, Antônio M. Saad pela convivência hormoniosa e amiga.

A todos as pessoas que anonimamente ajudaram direta ou indiretamente a realização deste trabalho. 


\section{SUMÁRIO}

LISTA DE FIGURAS

Página

vii

LISTA DE TABELAS

$\mathrm{x}$

LISTA DE QUADRO

xiii

RESUMO

xiv

SUMMARY

$\mathrm{xvi}$

1 INTRODUÇÃO

2 REVISÃO DE LITERATURA

2.1 Definições

2.2 Classificação dos métodos de estimativa da evapotranspiração

2.2.1 Lisimetria

2.2.2 Balanço hídrico de campo

2.2.3 Evaporímetros

2.2.3.1 Tanque Classe A

2.2.3.2 Atmômetros

2.2.4 Métodos combinados

2.2.4.1 Modelo de Penman-Monteith

3 MATERIAL E MÉTODOS 12

$\begin{array}{ll}3.1 \text { Material } & 12\end{array}$

3.1.1 Localização da área experimental 12

3.1.2 Caracterização da área experimental 12

3.1.3 Instalação e condução do experimento 13

3.1.4 Lisímetro de Pesagem 14

3.1.5 Dados meteorológicos 15

3.2 Métodos 17

$\begin{array}{ll}\text { 3.2.1 Determinação da evapotranspiração } & 17\end{array}$ 
3.2.2 Estimativa da evapotranspiração de referência utilizando o modelo de Penman-Monteith parametrizado pela FAO/91

3.2.3 Tanque Classe A

3.2.4 Atmômetro modificado SEEI 31

3.3 Coleta e seleção dos dados para análise 31

3.4 Análise dos resultados $\quad 32$

4 RESULTADOS E DISCUSSÃO 34

4.1 Condições meteorológicas durante o período experimental 34

4.2 Evapotranspiração de referência nos períodos de 24 horas e de luz 37

4.3 Evapotranspiração de referência estimada pelo modelo de Penman- $\quad 40$

Monteith, para o período de luz.

4.4 Evapotranspiração de referência estimada pelo modelo de Penman-

Monteith, para o periodo de 24 horas

4.5 Estimativa da resistência do dossel da grama 44

4.5.1 Resistência do dossel durante o período de luz 45

4.5.2 Resistência do dossel durante o período de 24 horas 46

4.6 Estimativa da evapotranspiração de referência, utilizando os dados 48 meteorológicos medidos em uma estação convencional

4.7 Evapotranspiração de referência estimada por meio da evaporação do tanque Classe A, utilizando diferentes modelos de coeficiente de tanque

4.8 Estimativa da evapotranspiração de referência a partir da evaporação de um atmômetro modificado SEEI

5 CONCLUSÕES

ANEXOS 62

REFERÊNCIAS BIBLIOGRÁFICAS $\quad 79$ 


\section{LISTA DE FIGURAS}

Página

1 Visão geral da estação lisimétrica da Fazenda Areão

2 Temperatura média do ar $\left({ }^{\circ} \mathrm{C}\right)$ e umidade relativa média do ar $(\%)$ no 35 período de 24 horas ao longo da fase experimental.

3 Temperatura média do ar $\left({ }^{\circ} \mathrm{C}\right)$ e umidade relativa média do ar $(\%)$ no 35 período de luz, ao longo da fase experimental.

4 Radiação liquida no período de luz e 24 horas ao longo da fase 36 experimental.

5 Evapotranspiração de referência no período de luz (p.luz), medida no lisímetro de pesagem (EToLP) versus a estimada pelo modelo de Penman-Monteith (EToPM), para a resistência do dossel de 69 s.m. ${ }^{-1}$.

6 Evapotranspiração de referência no período de luz (p.luz), medida no lisímetro de pesagem (EToLP) versus a estimada pelo modelo de Penman-Monteith (EToPM), para a resistência do dossel de $80 \mathrm{s.m}$.

7 Evapotranspiração de referência no período de 24 horas, medida no lisímetro de pesagem (EToLP) versus a estimada pelo modelo de Penman-Monteith (EToPM), para a resistência do dossel de $69 \mathrm{~s} . \mathrm{m}^{-1}$

8 Evapotranspiração de referência no período de 24 horas, medida no 43 lisímetro de pesagem (EToLP) versus a estimada pelo modelo de Penman-Monteith (EToPM), para a resistência do dossel de $80 \mathrm{s.m}$ 
9 Resistência do dossel da grama ( $\left.\mathrm{rc}_{\mathrm{res}}\right)$ para o período de luz, estimada como valor residual do modelo de Penman-Monteith ao longo do período experimental.

10 Resistência do dossel da grama ( $\left.\mathrm{sc}_{\mathrm{res}}\right)$ para o período de 24 horas, estimada como valor residual do modelo de Penman-Monteith ao longo do período experimental.

11 Evapotranspiração de referência no período de 24 horas, medida no lisímetro de pesagem (EToLP) versus a estimada pelo modelo de Penman-Monteith (EToPM), para a resistência do dossel de $40 \mathrm{~s} . \mathrm{m}^{-1}$

12 Evapotranspiração de referência no período de 24 horas, medida no lisímetro de pesagem (EToLP) versus a estimada pelo modelo de Penman-Monteith (EToPM), para a resistência do dossel de $69{\mathrm{~s} . \mathrm{m}^{-1}}^{-1}$ utilizando dados medidos em uma estação meteorológica convencional.

13 Relação entre a radiação líquida medida por um radiômetro líquido $\mathrm{Rn}$ med $\left(\mathrm{MJ} \mathrm{m} \mathrm{m}^{-2} \operatorname{dia}^{-1}\right)$ e estimada $\mathrm{Rn}$ est $\left(\mathrm{MJ} \mathrm{m}^{-2} \operatorname{dia}^{-1}\right)$ conforme parametrização proposta pela FAO.

14 Relação entre a temperatura do ar medida em uma estação 50 meteorológica automática Tar EA $\left({ }^{\circ} \mathrm{C}\right)$ e em uma estação convencional $\operatorname{Tar} \mathrm{EC}\left({ }^{\circ} \mathrm{C}\right)$.

15 Relação entre a umidade relativa do ar mediada em uma estação meteorológica automática UR EA (\%) e em uma estação convencional UR EC (\%). 
16 Evapotranspiração de referência no período de 24 horas, medida no lisímetro de pesagem (EToLP) versus a estimada pelo modelo de Penman-Monteith (EToPM), para a resistência do dossel de $40{\mathrm{~s} . \mathrm{m}^{-1}}^{-1}$ utilizando dados medidos em uma estação meteorológica convencional.

17- Evapotranspiração de referência no período de 24 horas, medida no 54 lisímetro de pesagem (EToLP) versus a estimada pelo tanque Classe A (EToECA), utilizando o Kp proposto por Pereira et al. (1995).

18- Evapotranspiração de referência no período de 24 horas, medida no 54 lisímetro de pesagem (EToLP) versus a estimada pelo tanque Classe A (EToECA), utilizando o Kp proposto pela FAO (1977).

19- Evapotranspiração de referência no período de 24 horas, medida no 56 lisímetro de pesagem (EToLP) versus a estimada pelo atmômetro modificado SEEI (EToA).

20- Evapotranspiração de referência no período de 24 horas, medida no lisímetro de pesagem (EToLP) versus a estimada pelo atmômetro modificado SEEI (EToA), com agrupamento dos dados em períodos de três dias.

21 Evapotranspiração de referência no período de 24 horas, medida no 58 lisímetro de pesagem (EToLP) versus a estimada pelo atmômetro modificado SEEI (EToA), com agrupamento dos dados em períodos de cinco dias. 


\section{LISTA DE TABELAS}

Página

1 Evapotranspiração de referência medida no lisímetro de pesagem, para o 38 período de 24 horas e de luz e o percentual da ETo que ocorre fora do período de radiação líquida positiva.

2 Indicadores estatísticos de desempenho para a evapotranspiração medida no lisímetro de pesagem e estimada pelo modelo de Penman-Monteith para o período de luz utilizando dados meteorológicos coletados em uma estação automática.

3 Indicadores estatísticos de desempenho para a evapotranspiração medida no lisímetro de pesagem e estimada pelo modelo de Penman-Monteith para o período de 24 horas utilizando dados meteorológicos coletados em uma estação automática.

4 Indicadores estatísticos de desempenho para a evapotranspiração medida no lisímetro de pesagem e estimada pelo modelo de Penman-Monteith para o período de 24 horas utilizando dados meteorológicos coletados uma estação automática.

5 Indicadores estatísticos de desempenho para a evapotranspiração medida no lisímetro de pesagem e estimada pelo modelo de Penman-Monteith para o período de 24 horas utilizando dados meteorológicos coletados em uma estação convencional com a velocidade do vento corrigida para 2 metros. 
6 Indicadores estatísticos de desempenho para a evapotranspiração medida

no lisímetro de pesagem e estimada pela evaporação do tanque Classe, para diferentes valores de $\mathrm{Kp}$.

7 Indicadores estatísticos de desempenho para a evapotranspiração medida no lisímetro de pesagem e estimada pela atmômetro modificado SEEI em base diária.

8 Indicadores estatísticos de desempenho para a evapotranspiração medida no lisímetro de pesagem e estimada pela atmômetro modificado SEEI média de três dias.

9 Indicadores estatísticos de desempenho para a evapotranspiração medida 59 no lisímetro de pesagem e estimada pela atmômetro modificado SEEI média de cinco dias.

10 Dados meteorológicos médios para o período de 24 horas medidos na estação meteorológica automática e no lisímetro de pesagem.

11 Dados meteorológicos médios para o período de luz medidos na estação meteorológica automática e no lisímetro de pesagem.

12 Dados meteorológicos médios no período de 24 horas, estimados e medidos em um estação meteorológica convencional.

13 Valores de evapotranspiração de referência medidos no lisímetro de pesagem e estimados pelo modelo de Penman-Monteith utilizando os dados meteorológicos medido em uma estação automática, para diferentes valores de resistência de dossel no período de 24 horas. 
14 Valores de evapotranspiração de referência medidos no lisímetro de pesagem e estimados pelo modelo de Penman-Monteith utilizando os dados meteorológicos medido em uma estação automática, para diferentes valores de resistência do dossel no período de luz.

15 Valores de evapotranspiração de referência medidos no lisímetro de 73 pesagem e estimados pelo modelo de Penman-Monteith utilizando os dados meteorológicos medidos em uma estação convencional, para diferentes valores de resistência do dossel no período de 24 horas.

16 Valores de evaporação em tanque classe A e evapotranspiração de 75 referência estimados por meio de coeficientes de tanque (Kp), propostos por Pereira et al. (1995) e FAO (1977) e medida em lisímetro de pesagem.

17 Valores de evapotranspiração de referência estimada em atmômetro modificado SEEI e medida em lisímetro de pesagem. 


\section{LISTA DE QUADRO}

Página

1 Valores médios, máximos e mínimos de radiação líquida $(\mathrm{Rn})$, densidade 37 de fluxo de calor no solo $(G)$, temperatura do ar $(T)$, umidade relativa (UR) e velocidade do vento (U), no curso da fase experimental, nos períodos de $24 \mathrm{~h}$ e de luz. 


\title{
DESEMPENHO DO MODELO DE PENMAN-MONTEITH E DE DOIS EVAPORÍMETROS NA ESTIMATIVA DA EVAPOTRANSPIRAÇÃO DE REFERÊNCIA (ETo) EM RELAÇÃO A UM LISÍMETRO DE PESAGEM
}

\author{
Autor : FRANCISCO ADRIANO DE C. PEREIRA \\ Orientador : Prof. Dr. MARCOS VINÍCIUS FOLEGATTI \\ Co-orientador : Prof. Dr. NILSON AUGUSTO VILLA NOVA
}

\section{RESUMO}

Este trabalho teve como objetivos, avaliar o desempenho do modelo de PenmanMonteith e de dois evaporimetros na estimativa da evapotranspiração de referência em relação a um lisímetro de pesagem, bem como estudar a relação de dependência do coeficiente de tanque $(\mathrm{Kp})$, com os elementos meteorológicos. O experimento foi realizado na Fazenda Areão da Escola Superior de Agricultura Luiz de Queiroz ESALQ/USP, em Piracicaba, SP ( $22^{\circ} 42^{\prime} 30^{\prime \prime} \mathrm{S}$ e $\left.47^{\circ} 30^{\prime} 00^{\prime \prime} \mathrm{W}\right)$, durante o período de agosto a dezembro do ano de 1996. A evapotranspiração de referência foi determinada em um lisímetro de pesagem dotado de células de carga, vegetado com grama batatais (Paspalum notatum Flugge). Os dados meteorológicos foram coletadas por uma estação automática, contendo os sensores de: temperatura e umidade relativa do ar, velocidade do vento a $2 \mathrm{~m}$, radiação líquida e densidade de fluxo de calor no solo. A estimativa da evapotranspiração de referência foi realizada utilizando-se o modelo de Penman-Monteith nos períodos de luz e de $24 \mathrm{~h}$ e com os evaporímetros tanque Classe A e atmômetro modificado SEEI. Os dados foram coletados diariamente e analisados, estatisticamente, mediante análise de regressão. Com base nos resultados, verificou-se que no período de luz para uma resistência de dossel (re) de 80 s. $\mathrm{m}^{-1}$, o modelo de Penman-Monteith superestimou a evapotranspiração de referência, com um erro médio de $0,65 \% \mathrm{em}$ relação aos valores medidos em um lisímetro de pesagem. No período de 24 horas o 
modelo subestima a evapotranspiração de referência na ordem de 12 a $15 \%$, para os valores de (rc) de 69 e $80 \mathrm{s.m}^{-1}$, respectivamente. O melhor desempenho entre os valores medidos e estimados da evapotranspiração de referência no período de 24 horas, foi obtido quando se utilizou a resistência do dossel de $40 \mathrm{s.m} \mathrm{m}^{-1}$, com um erro médio da ordem de 4,4\% em subestimar a ETo. A resistência de dossel da grama, estimada como resíduo da utilização do modelo de Penman-Monteith, apresentou um valor médio de 92 $\mathrm{s} . \mathrm{m}^{-1}$ para o período de luz e $41 \mathrm{~s} . \mathrm{m}^{-1}$ no período de 24 horas. A utilização do coeficiente de tanque (Kp) proposto por Pereira et al. (1995) para estimativa da evapotranspiração de referência a partir da evaporação do tanque Classe A, possibilitou uma boa correlação e uma excelente concordância em relação as medidas efetuadas no lisímetro de pesagem, com um erro médio relativo da ordem de $0,08 \%$ em subestimar a ETo. O atmômetro modificado apresentou uma excelente correlação com a evapotranspiração de referência, medida em um lisímetro de pesagem, para o agrupamento dos dados em períodos de tempo igual ou superior a três dias, em função do amaciamento das flutuações diárias. 


\title{
PENMAN-MONTEITH AND TWO EVAPORIMETERS PERFORMANCE ON THE ESTIMATION OF THE REFERENCE EVAPOTRANSPIRATION (ETO) IN RELATION TO A WEIGHING LISIMETER MEASUREMENTS
}

\author{
Author : FRANCISCO ADRIANO DE C. PEREIRA \\ Adviser : Prof. Dr. MARCOS VINÍCIUS FOLEGATTI \\ Co-Adviser : Prof. Dr. NILSON AUGUSTO VILLA NOVA
}

\section{SUMMARY}

This aim of this work was to evaluate the Penman-Monteith and two evaporimeters on the estimation of the reference evapotranspiration (ET) in relation to weighing lysimeter measurements and also to study how the Kp coefficient is affected by the meteorological parameters. The experiment is carried out at Areão`s Farm of the Agricultural College Luiz de Queiroz - University of São Paulo, in Piracicaba - SP $\left(22^{\circ}\right.$ $42^{\prime} 30^{\prime \prime} \mathrm{S}$ e $47^{\circ} 30^{\prime} 00^{\prime \prime} \mathrm{W}$ ), from august to december of the year 1996. The reference evapotranspiration was measured by a weighing lysimeter using a strain gauge, with grass (Paspalum notatum Flugge). The meteorological parameters were collected by an automatic weather station, with sensor of temperature, relative humidity, wind speed at 2 $\mathrm{m}$, net radiation and soil heat flux. The reference evapotranspiration was estimated using a Penman-Monteith model, the evaporimeter Class A Pan and the modified atmometer, during the light period and for 24 hours. The data were collected daily and the statistical analysis was done using regression equations. Based on the results, it was verified that during the light period the canopy diffusion resistance (rc) of $80 \mathrm{~s} / \mathrm{m}$, the Penman Monteith model overestimates the reference evapotranspiration with an error of $0,65 \%$ in relation to the lysimeter measurements. During the period of $24 \mathrm{~h}$ the model underestimate the reference evapotranspiration, from to 12 to $15 \%$ for values of rc from 
69 to $80 \mathrm{~s} / \mathrm{m}$. The best performance among measured and estimated values of reference evapotranspiration during periods of 24 hours was obtained, when rc of $40 \mathrm{~s} / \mathrm{m}$ was considered, with an error of $4,4 \%$ underestimating ET. The canopy diffusion resistance of grass estimated as a residue of the Penman Monteith model, resulted mean values of 92 $\mathrm{s} / \mathrm{m}$ for light period and $41 \mathrm{~s} / \mathrm{m}$ for $24 \mathrm{~h}$ period. The pan coefficient $(\mathrm{Kp})$ proposed by Pereira et al. (1995) in order to estimate the reference evapotranspiration using Class A pan evaporation data, resulted in a good correlation with lysimeter measurements. The modified atmometer showed a good correlation with reference evapotranspiration measured by the lysimeter periods of three days. 


\section{INTRODUÇ̃̃O}

A produção agrícola é intensamente influenciada pelas condições edafoclimáticas locais, sendo a água e os nutrientes elementos essenciais à obtenção de elevadas produtividades.

É fato reconhecido que a escassez de água por longos períodos, principalmente pela distribuição irregular das chuvas, tem sido um dos principais fatores limitantes à produção agrícola, tornando a irrigação um prática indispensável para suprir as deficiências hídricas das culturas. Para que a irrigação seja eficiente no aumento e na manutenção da produtividade agrícola, torna-se necessário o conhecimento da demanda hídrica das culturas, nas suas diferentes fases fenológicas.

A evapotranspiração tem sido, há muito, objeto de estudo de diversos pesquisadores trabalhando nas mais diferentes localidades. Estas pesquisas têm procurado estudar o consumo de água pelas plantas, lançando mão das mais variadas metodologias. Cada uma delas apresentam vantagens e desvantagens quanto a sua utilização, bem como quanto as variáveis necessárias a sua implementação. Entretanto, as diferenças encontradas na estimativa da evapotranspiração, pelos vários métodos utilizados em diferentes regiões, têm preocupado os especialistas no assunto, que vem desenvolvendo estudos para avaliar e ajustar estes métodos a estimativas mais precisa Silva (1989).

Entre os pesquisadores, Thornthwaite (1948) foi o primeiro a introduzir o termo evapotranspiração potencial, enquanto Penman (1956) definiu a evapotranspiração potencial como sendo o processo de transferência de água para a atmosfera, por unidade 
de tempo, de uma superficie totalmente coberta por uma vegeteção resteira, em pleno desenvolvimento vegetativo e sem restrições hídricas.

Segundo Tanner (1968), o evapotranspiração pode ser determinada por meio de três métodos classificados em: os de balanço hídrico, os micrometeorológicos e os empíricos. Mais recentemente, Burman et al. (1980) subdividem a determinação da evapotranspiração em dois grupos: 1) os de medidas diretas, representado pelos lisímetros e pelo balanço hídrico de campo que utiliza um volume de solo controlado, e 2) de medidas indiretas, ou seja, aquele que lança mão de equações empíricas, semiempiricas, e evaporímetros para a estimativa da evapotranspiração.

Atualmente, as pesquisas na área de evapotranspiração apontam para a necessidade de se avaliar do modelo de Penman-Monteith-FAO, uma vez que ele tem apresentado melhor desempenho na estimativa da evapotranspiração de referência ETo de uma cultura hipotética, atendendo mais de perto, a definição de ETP de Penman e o conceito adotado pela FAO-24 para ETo. Estas demandas de pesquisa foram referendadas em encontro promovido pela FAO (1990) em Roma, com especialistas da área de evapotranspiração, quanto a necessidade de se avaliar o modelo de PenmanMonteith-FAO, com a finalidade de valida-lo em locais de climas mais amenos e, ou sub-úmidos, bem como de promover uma análise mais rigorosa dos termos de resistência da equação, visando conhecer melhor os mecanismos físicos e biológicos envolvidos na evapotranspiração, facilitando assim a introdução do conceito de evapotranspiração da cultura em uma só etapa.

Com base nesta linha de ação, o presente trabalho teve como objetivos:

a) avaliar o desempenho do modelo de Penman-Monteith em relação a um lisímetro de pesagem e a determinação da resistência do dossel da grama para as condições de evapotranspiração potencial em Piracicaba-São Paulo nos períodos de luz (radiação líquida positiva) e de 24 horas.

b) estudar a relação de dependência do coeficiente de tanque (Kp), com os elementos meteorológicos. 
c) realizar uma analise comparativa da evapotranspiração de referência, padrão grama, utilizando os métodos: lisimétrico (pesagem), evaporimetricos (tanque Classe A e atmômetro modificado SEEI), confrontando-os quanto a precisão, tempo de resposta e praticidade. 


\section{REVISÃO DE LITERAURA}

\subsection{Definições}

A evapotranspiração é definida como sendo a soma da quantidade de água evaporada e transpirada por uma superficie vegetada, de maneira simultânea, durante um determinado período de tempo. Thornthwaite \& Holzman (1944) conceituaram a evapotranspiração como sendo a perda de água de uma superfície completamente vegetada, em fase de desenvolvimento ativo e com extensão suficiente para minimizar o efeito-oásis.

Visando padronizar a evapotranspiração, como elemento climatólogico de uma dada região, surgiu a necessidade de se definir a evapotranpiração potencial para uma cultura de referência $\left(\mathrm{ET}_{\mathrm{O}}\right.$ ) esta segundo Doorenbos \& Pruitt (1977), corresponde a quantidade de água perdida para a atmosfera, por uma superficie de solo totalmente coberta por grama, de altura uniforme entre oito a quinze centímetros, em crescimento ativo e sem restrições hídricas.

Desta maneira, quando as condições de contorno acima mencionadas não forem atendidas, tem-se a evapotranspiração real $\left(\mathrm{ET}_{\mathrm{r}}\right)$, que é a que ocorre numa superficie vegetada, independente de sua área, do seu porte e das condições de umidade do solo Pereira et al. (1997).

As plantas apresentam diferentes necessidades hídricas, em função do seu estádio de desenvolvimento, sendo então introduzido o conceito de evapotranspiração da cultura $\left(\mathrm{ET}_{\mathrm{C}}\right)$, que segundo Doorenbos \& Pruitt (1977), caracteriza a evapotranspiração de uma 
cultura qualquer, desenvolvendo-se em uma área sob ótimas condições de umidade e fertilidade. Na prática, a determinação da $\mathrm{ET}_{\mathrm{c}}$ é dificil e sujeita a muitos erros.

Para contornar este problema, Jensen (1968) recomenda a estimativa da evapotranspiração da cultura $\left(\mathrm{ET}_{\mathrm{C}}\right)$ a partir de evapotranspiração de referência, corrigida por um coeficiente de cultivo $(\mathrm{Kc})$.

- Ferreira (1988) ressalta que o coeficiente de cultura $(\mathrm{Kc})$ é a razão entre a $\mathrm{ET}_{\mathrm{c}}$ e a $\mathrm{ET}_{\mathrm{O}}$, ou a percentagem de demanda evapotranspirométrica das culturas, enquanto não existir limitações de água no solo. Segundo Doorenbos \& Pruitt (1977), o valor deste coeficiente é afetado, principalmente, pelas características da cultura, estádio de desenvolvimento, extensão do ciclo da cultura e condições climáticas.

\subsection{Classificação dos métodos de estimativa da evapotranspiração}

A estimativa da evapotranpiração potencial de referência pode ser realizada de diferentes maneiras. Burman et al. (1980), classificam os métodos de estimativa da evapotranspiração potencial em dois grupos: os de medida direta e os indiretos: Os métodos diretos são representados pelos lisímetros e balanço hídrico de campo, enquanto que os métodos indiretos são subdivididos em dois grupos: os evaporímetros e aqueles que empregam equações empíricas. Pereira et al. (1997), por sua vez subdividem os métodos de estimativa da evapotranspiração em cinco categorias, em função dos princípios envolvidos no seu desenvolvimento, ou seja: empíricos; aerodinâmicos; balanço de energia; combinados e correlação dos turbilhões.

\subsubsection{Lisimetria}

Os lisímetros ou evapotranspirômetros são equipamentos que consistem de um caixa impermeável, cheia de solo, e que permitem conhecer detalhadamente todos os termos do balanço hídrico. Segundo Aboukhaled et al (1982), os lisímetros podem ser de pesagem (mecânica, eletrônica, hidráulica e de flutuação) e volumétricos (drenagem e compensação de lençol freático constante). 
Angelocci \& Minami (1992) citam que os de maior uso, pela sua simplicidade, são os do grupo volumétrico, embora não estejam isentos de críticas e discussão sobre qual dos dois representantes desse grupo seria o mais adequado.

Encarnação (1980), Barbieri (1981), Cury \& Villa Nova (1987) e Encarnação et al. (1987), utilizando o evapotranpirômetro de lençol frático de nível constante na determinação da evapotranspiração máxima das culturas do feijoeiro, cana-de-açúcar, repolho e batatinha, respectivamente, têm dado preferência a esse, em detrimento ao de drenagem, pela sua simplicidade e maior automação.

Entretanto, Aboukhaled (1982) chama a atenção para os lisímetros de pesagem, como os que possuem maior precisão, porém por apresentarem custos elevados, seu uso tem ficado restrito as instituições de pesquisa.

Silva (1996), instalando um lisímetro de pesagem utilizando células de carga, em Piracicaba-SP, verificou que o mesmo apresenta um excelente desempenho na medida da ETo, permitindo realizar medidas num espaço de tempo inferior a uma hora.

Apesar da lisímetria ser considerada padrão, no estudo de calibração de outros métodos em uma região qualquer, eles não estão isentos de críticas. Sediyama (1995) afirma que os lisímetros não são representativos das condições de campo, gerando uma grande inconsistência nas medições, quando as condições do meio ambiente não forem bem caracterizadas no manejo do lisímetro.

\subsubsection{Balanço hídrico de campo}

Como alternativa, para uma melhor representatividade das condições de campo, pode-se lançar mão do método do balanço hídrico, que utiliza um determinado volume de solo cultivado e não confinado para estimativa da evapotranpiração.

Segundo Guandique (1993), o balanço hídrico realizado diretamente em condições de campo, permite um acompanhamento das relações hídricas de uma cultura durante suas distintas fases de desenvolvimento. Entretanto, segundo ainda o mesmo autor, alguns dos seus componentes como a evapotranspiração e drenagem profunda, são de dificil determinação, levando a erros que prejudicam o valor final obtido. 
O balanço hídrico no solo, determinado através de um volume controle, utiliza a equação geral de conservação de massa na forma integral ou diferencial, para a determinação dos seus componentes (precipitação, irrigação, escoamento superficial, drenagem profunda, variação no armazenamento e evapotranspiração), sendo esta equação utilizada em trabalhos como os de Luchiari Junior (1978), Reichardt et al. (1979), Sakai (1989), Saad (1991), e que tem sido recomendada por Rose \& Stern (1967), Barrada (1971) e Reichardt (1985).

Um outro fator que também deve ser considerado na determinação do balanço hídrico é o intervalo de tempo utilizado. Jensen (1967), verificou que a utilização de períodos de 3 a 5 dias, provocaram erros na ordem de 15 a $30 \%$ na evapotranspiração. Costa (1986), aponta os períodos chuvosos como limitantes, dada a dificuldade de determinação na variação da água armazenada no solo com precisão maior de 2,0 mm.

\subsubsection{Evaporímetros}

Entre os métodos empíricos, os evaporímetros são bastante utilizados pela simplicidade e baixo custo, sendo classificados em dois tipos: os que a superficie da água fica livremente exposta (tanques de evaporação) e aqueles em que a evaporação se dá através de uma superficie porosa (atmômetros) (Berlato \& Molion, 1981; Bernardo, 1989).

\subsubsection{1 - Tanque Classe A}

Entre os tanques de evaporação, o classe A tem sido recomendado por muitos autores para a estimativa da evapotranspiração de referência, principalmente quando se deseja utilizá-lo na estimativa da evapotranspiração das culturas, para manejo da água em projetos de irrigação. (Vieira, 1989; Bernardo, 1989; Sediyama, 1987; Reichardt, 1987).

A estimativa da evapotranspiração de referência a partir da evaporação medida no tanque Classe $\mathrm{A}$, requer a correção por um coeficiente $(\mathrm{Kp})$, que depende do tamanho e da natureza da área de bordadura, da velocidade do vento e da umidade relativa do ar. Doorenbos \& Pruitt (1977), apresentam uma tabela que sistematiza o valor de Kp, em 
função desses fatores, após exautiva análise de dados experimentais obtidos em diferentes regiões do globo. Amorim et al. (1997) relatam que esta tabela foi, por muito tempo, o principal elemento para conversão dos registros de evaporação em (ETo), entretanto, diversos fatores de ordem técnica e micrometeorológica limitam o seu uso. Entre estes fatores pode-se citar: diferenças da reflectância da água e das culturas, diferenças entre o comportamento do perfil do vento sobre uma cultura e um tanque de evaporação, o elevado calor específico da água possibilita que o processo de evaporação continue durante a noite, o evaporímetro não considera a resistência estomática presente nas plantas quando submétidas a déficit hídrico, Withers \& Vipond (1974). Propondo contornar estas limitações, Pereira et al. (1995) estabeleceram um modelo alternativo para a determinação de $\mathrm{Kp}$, que leva em consideração a resistência do dossel de um gramado (rc) e a resistência aerodinâmica ao transporte do vapor da água (ra). Este modelo indica que o coeficiente do tanque é dependente do razão (rc/ra) e da temperatura do ar, que por sua vez determina o valor da tangente à curva de pressão de saturação do vapor da água.

\subsubsection{2- Atmômetros}

Os atmômetros são instrumentos de medida da demanda evaporativa da atmosfera, onde a evaporação se processa através de uma superficie porosa. Entre os diversos modelos existentes pode-se citar o evaporímetro de Piche, que utiliza um papel de filtro como superficie evaporante e o atmômetro de Livingstron, que consiste de uma cápsula porosa esférica, ligada a um reservatório de água para medida da evaporação.

Objetivando aperfeiçoar os evaporímetros de superficie porosa, Altenhofen (1985), desenvolveu um equipamento que recebeu a denominação de atmômetro modificado. Este aparelho consiste em uma cápsula porosa, coberta com uma lona especial de cor verde, interligada a um reservatório de água destilada por um tubo de sucção. O nível da água no reservatório é lido numa escala graduada em milímetros, colocada sob tubo plástico transparente. A quantidade de água evaporada é determinada pela variação do nível da água. Entre os objetivos de utilização da cobertura da cápsula porosa, está em se 
conseguir um albedo similar a um dossel vegetativo e uma resistência ao fluxo de vapor da água, similar aos oferecidos pelos estomatos das folhas da alfafa, cultivada sem restrições hídricas (Altenhofen, 1985; Law e Israeli, 1988).

Pereira \& Coelho (1992) relatam que o atmômetro modificado tem sido um dos mais promissores aparelhos para o controle da irrigação, entre os agricultores amaricanos, apresentando as seguintes vantagens em relação ao tanques de evaporação: baixo custo, melhor portabilidade e operacionalidade no campo, menor acúmulo de energia durante o dia, o que pode alterar as medidas do tanque devido a evaporação no período noturno.

Pereira (1993), utilizando o tanque Classe A e atmômetro modificado, para a estimativa da evapotranspiração de referência, verificou que os dois evaporímetros apresentaram um comportamento bastante semelhante e uma pequena variação entre si.

Erthal (1994), avaliando a utilização do atmômetro modificado na estimativa da evapotranspiração de referência na região de Viçosa - MG, constatou que o aparelho simula adequadamente a ETo, quando comparado ao tanque classe $\mathrm{A}$ e a equação de Penman, para períodos de sete dias ou mais longos, entretanto não apresentou uma boa correlação com o evapotranspirômetro de drenagem.

Atualmente, no mercado nacional, são comercializados dois tipos de atmômetros modificados, sob as desiguinações de: atmômetro modificado SEEI, com dimensões semelhantes ao modelo desenvolvido por Altenhofen (1985) e o fabricado pela SOILCONTROL, com dimensões inferiores ao SEEI, apresentando superficie evaporante em formato cônico (Pereira, 1997).

\subsubsection{Métodos combinado}

\subsubsection{1- Modelo de Penman-Monteith}

Entre os diversos modelos existentes para a estimativa da evapotranspiração de referência, o de Penman (1948) é considerado por muitos como sendo um método padrão, por ser o primeiro a combinar os efeitos do balanço vertical de energia (termo energético) com aqueles do poder evaporante do ar (termo aerodinâmico). O poder 
evaporante do ar é baseado no déficit de pressão de vapor associado a uma função empírica do vento. Esse modelo foi desenvolvido na Grã-Bretanha, utilizando dados de uma região úmida e de clima moderado, tendo sido utilizado nas mais diferentes regiões da Terra. Pereira (1997) alerta que apesar do método estar alicerçado em princípios fisicos corretos, a utilização de inúmeras aproximações o torna também empiríco. Para contornar algumas dessas desvantagens observadas no modelo original, Monteith (1965), incorporou modificações no termo aerodinâmico da equação de Penman, incluindo dois valores de resistência ao fluxo de vapor da água. A resistência do dossel da cultura (rc), decorrente das carcterísticas fisiológicas da planta, e a resistência aerodinâmica (ra), que inclue o papel do vento na difusão turbulenta de calor sensível e do vapor da água (Oke, 1992). Portanto, esse modelo, incorpora a ação do clima e da fisiologia da planta, permitindo sua utilização em qualquer tipo de cultura. Entretanto, a sua operacionalidade fica limitada a obtenção de valores confiáveis de (rc) e (ra).

Segundo Monteith (1985), os problemas encontrados na estimativa da resistência de dossel, são decorrentes da sua associação com os fatores ambientais e biológicos, cujos efeitos individuais, são dificeis de serem separados.

A estimativa da resistência de dossel, pode se realizada diretamente, por meio de medidas da resistência estomática média, com o uso de porômetros de difusão, associado ao índice de área foliar. Como esta prática é bastante árdua, recorre-se, dentro dos limites permitidos dos erros experimentais, a determinação de (rc), como resíduo da aplicação do modelo de Penman-Monteith, conhecendo-se a evapotranspiração, medida em lisímetros ou estimada pela razão de Bowen e as variáveis meteorológicas envolvidas no processo (Monteith, 1980; Sharma, 1983; Luchiari Jr. \& Riha, 1991; Oke, 1992).

A literatura apresenta diversos resultados de pesquisa, que relaciona a resistência de dossel da cultura com os elementos do solo e do clima, cujos valores são bastante variados. Entre estes trabalhos, Hatfield (1988) relata que a maioria das culturas apresenta valores de (rc) em torno de $20 \mathrm{s.m}^{-1}$ para solos em capacidade de campo, com tendência a aumentar a medida que a umidade do solo diminui. 
Monteith (1985) por sua vez, sugere a adoção de um valor de rc de $50 \mathrm{~s} . \mathrm{m}^{-1}$ para a maioria das plantas cultivadas, quando se deseja conhecer a sua evapotranspiração potencial.

Peres (1994), trabalhando com dados de três localidades do estado de São Paulo, verificou que o modelo de Penman-Monteith, desenvolvido segundo a parametrização da FAO, estimou a evapotranspiração de referência de forma consistente e bem correlocionada com os valores medidos em evapotranspirômetros de drenagem, na escala de tempo decendial e mensal. Verificou ainda, que a resistência de dossel que melhor representa as condições de evapotranspiração potencial, situa-se na faixa de $60 \mathrm{a} 80 \mathrm{sm}^{-1}$.

Maggiotto (1996), estimando os valores de resistência de dossel, como resíduo de utilização do modelo de Penman-Monteith, a partir da variáveis meteorológicas médias no período de 24 horas, utilizando a ETo medida em um lisímetro de pesagem, encontrou valores que variaram de 53 a $256 \mathrm{~s} . \mathrm{m}^{-1}$, com valor médio de $144 \mathrm{~s} . \mathrm{m}^{-1}$.

- Silva (1996) verificou alta correlação do modelo de Penman-Monteith FAO, na estimativa da evapotranspiração de referência, em relação a um lisímetro de pesagem, recomendando a sua utilização como método de avaliação do desempenho de outros modelos, ou mesmo de dispositivos de determinação direta da ETo.

- Apesar das limitações de ordem operacional, apresentadas quando da utilização do modelo de Penman-Monteith, Smith (1991) recomenda o seu uso, por ser um método que tem se mostrado superior aos demais na estimativa da evapotranspiração potencial, para uma ampla diversidade de climas e locais. - 


\section{MATERIAL E MÉTODOS}

\section{1. - Material}

\subsection{1 - Localização da área experimental}

O experimento foi realizado na área experimental do Departamento de Engenharia Rural, localizada na Fazenda Areão, da Escola Superior de Agricultura "Luiz de Queiroz", situada no município de Piracicaba, Estado de São Paulo, a uma altitude de $576 \mathrm{~m}$ acima do nivel do mar, com as coordenadas geográficas de $22^{\circ} 42^{\prime} 30^{\prime \prime}$ de latitude Sul e $47^{\circ} 30^{\prime} 00$ " de longitude Oeste.

\subsection{2 - Caracterização da área experimental}

Segundo a classificação climática de Köppen, o clima na região de Piracicaba é do tipo Cwa, isto é, clima subtropical úmido, com verão chuvoso, inverno seco e temperatura do mês mais frio inferior a $18^{\circ} \mathrm{C}$. Os dados climáticos médios da região apresentam as seguintes médias anuais: precipitação $1259 \mathrm{~mm}$, temperatura do ar $21,4^{\circ}$ C, umidade relativa do ar $74 \%$ e velocidade do vento de $2,2 \mathrm{~m} / \mathrm{s}$. (Martorano et al. 1997; Ometto,1989).

O solo da área experimental é classificado como Terra Roxa Estruturada (Alfisol), série Luiz de Queiroz, apresentando uma declividade e média de 2,3\%. 
No local do experimento, toda á área encontra-se vegetada com grama battatàis (Paspalum notatum Flugge) mantida com altura entre 8 a $12 \mathrm{~cm}$, por meio de cortes periódicos. Apresenta as dimensões de $35 \times 90 \mathrm{~m}$, com área de $3150 \mathrm{~m}^{2}$, tendo instalados na sua parte central um bateria de cinco lisímetros, uma estação automática de coleta de dados meteorológicos, tanque classe A, e atmômetro modificado SEEI, (Figura 1).

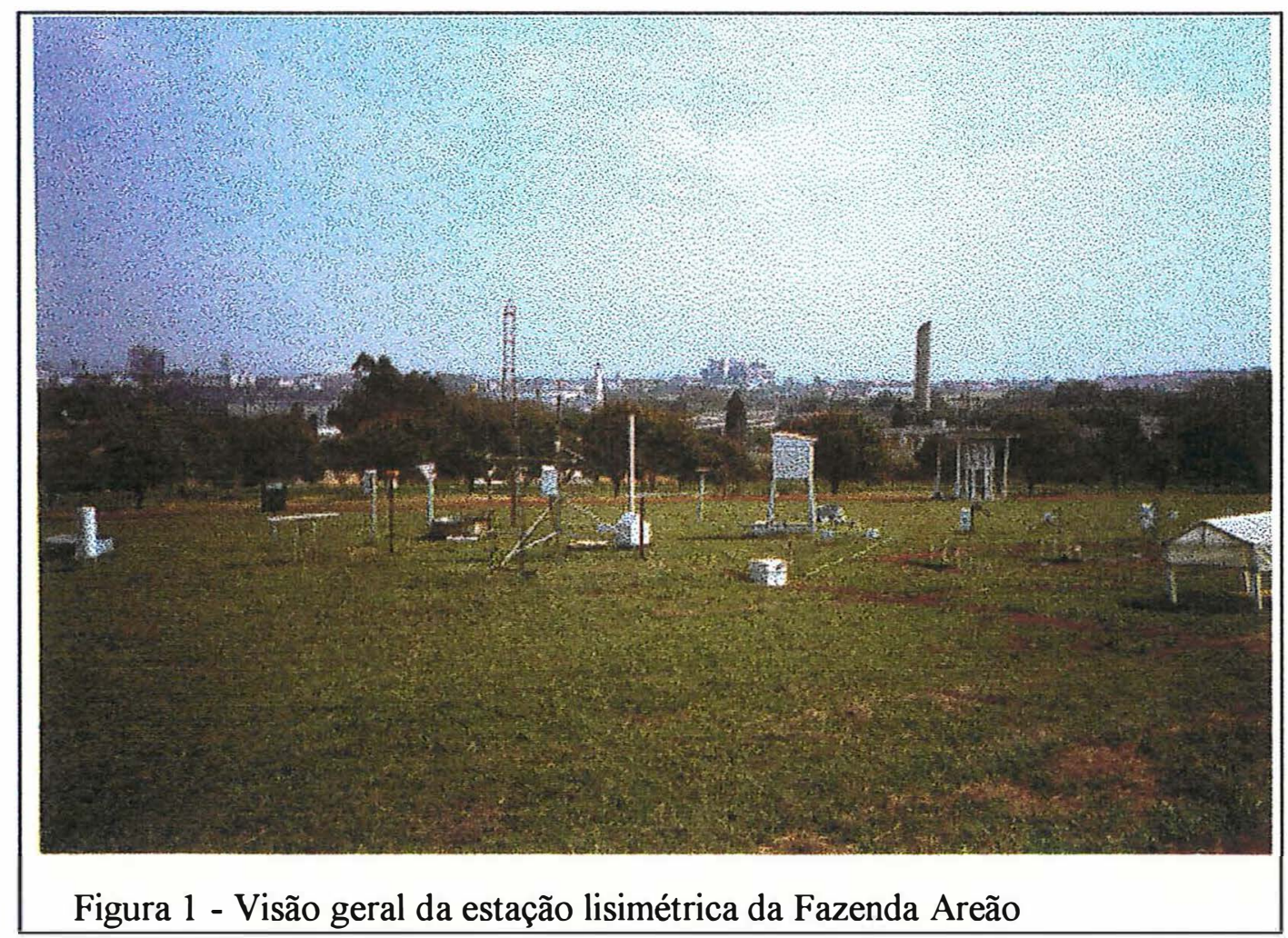

\subsection{3 - Instalação e condução do experimento}

O experimento para a determinação da evapotranspiração de referência, foi conduzido em um lisímetro de pesagem, utilizando células de carga. $O$ equipamento foi montado em uma caixa de cimento amianto com as dimensões de $1,20 \times 0,20 \times 0,65 \mathrm{~m}$, fornecendo uma área de cultivo de $0,92 \mathrm{~m}^{2}$, apresentando uma borda lateral de $5 \mathrm{~cm}$ 
acima da superficie do solo, afim de evitar a entrada de água. A descrição completa dos detalhes construtivos deste lisímetro encontra-se em SILVA (1996).

A estimativa da evapotranspiração de referência foi realizada utilizando o modelo de Penman Monteith e os evaporímetros: tanque classe A e atmômetro modificado SEEI.

\subsection{4 - Lisímetro de pesagem}

Neste sistema, o tanque lisimétrico encontra-se apoiado sobre uma placa de compensado naval de dimensões $1,25 \times 0,90 \times 0,03 \mathrm{~m}$, que por sua vez apoia-se sobre um conjunto formado por três células de carga que se acham em disposição triangular. As células de carga foram montadas sobre pilares, que se encontram fixados a uma base de cimento armado. Toda esta estrutura de sustentação, tem como objetivo evitar o deslocamento do sistema de pesagem devido as deformações do solo. As paredes laterais do solo foram contidas com placas de compensado naval de $0,015 \mathrm{~m}$ de espessura, sendo a parte inferior do fosso revestida com uma camada de brita, para facilitar a drenagem da água de chuva que pudesse vir a se armazenar.

A mensuração do peso do conjunto evapotranspirométrico, foi realizada por meio de células de carga fabricadas pela Omega Engeerring, modelo LCCA-2K, com capacidade de $910 \mathrm{~kg}$ e precisão de $0,037 \%$ da sua capacidade total.

O sistema de drenagem do lisímetro é constituido de um tubo de $0,05 \mathrm{~m}$ de diâmetro, que se comunica com um outro, disposto em forma retangular e perfurado em toda a sua extensão sob uma camada de brita zero de 0,02 $\mathrm{m}$ de espessura localizado na parte inferior do tanque. Quando o peso do lisímetro ultrapassava $930 \mathrm{~kg}$, realizava-se a drenagem por meio de um tubo venturi acionado por uma fonte de água de baixa pressão, sendo a água de drenagem aspirada por um tubulação de saída vertical e eliminada sobre a superficie do solo exterior ao lisímetro. Dessa maneira, pode-se realizar o acompanhamento e manutenção do lençol freático no nível desejado. 
Visando manter e acompanhar o potencial matricial da água no solo, numa faixa de valores que possibilitasse a cultura evapotranspirar potencialmente, foram instalados tensiômetros de câmara de ar, nas profundidades de 0,15 e $0,35 \mathrm{~m}$. As leituras foram realizadas por meio de um tensímetro digital, com valores pontuais fornecidos diretamente em mbar. O potencial matricial da água no solo foi mantido na faixa entre -60 e -70 mbar correspondente a umidade à capacidade de campo.

\subsection{5 - Dados meteorológicos}

Os elementos meteorológicos utilizados neste trabalho foram coletados por uma estação meteorológica automática instalada na área experimental, e por uma estação convencional instalada no Posto Meteorológico pertencente ao Departamento de Física e Meteorologia da ESALQ- USP.

A estação meteorológica automática encontrava-se equipada com os seguintes sensores:

- temperatua do ar e umidade relativa do ar a $2 \mathrm{~m}$ de altura (modelo: HMP35C Temperature/RH Probe - Campebell Scientific, Inc; exatidão: temperatura $= \pm 0,1{ }^{\circ} \mathrm{C}$; umidade relativa $= \pm 3 \%$ );

- radiação solar global a 3 m de altura (modelo: LI200X Pyranometer - Licor Inc.)

- radiação líquida a $1 \mathrm{~m}$ de altura da cobertura vegetal (modelo: Q7.1 Net Radiometer - REBS; espectro: 025 a $60 \mu \mathrm{m}$ );

- velocidade do vento a 2 m de altura (modelo: 014A Wind Speed Sensor - Met One Instruments; limiar de medida $=0,45 \mathrm{~m} \cdot \mathrm{s}^{-1}$ );

- direção do vento a $2 \mathrm{~m}$ de altura (modelo: 024A Wind Direction Sensor - Met One Instruments; limiar de medida $=0,45 \mathrm{~m} \cdot \mathrm{s}^{-1}$; exatidão $\left.= \pm 5^{\circ}\right)$;

- precipitação a 1,5 m de altura (modelo: TE525 Tipping Bucket Rain Gauge Weather Bureau; precisão = 0,1 mm ); 
- densidade de fluxo de calor no solo, instalado a $2 \mathrm{~cm}$ de profundidade na área evaporante do lisímetro de célula de carga (modelo: HFT-3 Soil Heat Flux Plate REBS).

Todos os sensores encontravam-se conectados a um datalogger modelo CR 10 da Campbell Scientific, com armazenamento dos dados médios a cada 30 minutos, a partir das leituras feitas a cada segundo.

A estação meteorológica convencional encontrava-se equipada com os seguintes instrumentos de medida:

- termômetros de máxima e mínima;

- conjunto psicrométrico composto por termômetros de bulbo úmido e bulbo seco;

- higrógrafo de cabelo;

- termógrafo;

- evaporimetro de Piche;

- heliógrafo Campbell-Stokes;

- actinógrafo bimetálico Robitzch;

- anemômetro totalizador de conchas;

- anemômetro universal;

- pluviômetro stand;

- pluviógrafo Hellmann;

- tanque de evaporação Classe A e

- barômetro de mercúrio.

Os observações meteorológicas na estação convencional foram realizadas diáriamente em dois horários, às 7:00 e 18:00 horas respectivamente. 


\section{2.- Métodos}

\subsection{1 - Determinação da evapotranspiração}

A evapotranspiração de referência, foi mensurada por meio da diferença de peso médio das três células de carga, a cada $30 \mathrm{~min}$, cujos valores foram armazenados num datalogger modelo CR 10 da Campbell Scientific, a partir de dados medidos a cada segundo. A determinação da lâmina total evapotranspirada, para o período de luz (radiação líquida positiva) e de 24 horas, foi obtida por meio do somatório das variações negativas de peso, dividido pela superfície evaporante do lisímetro de $0,92 \mathrm{~m}^{2}$.

\subsection{2- Estimativa da evapotranspiração de referência utilizando o modelo de Penman-Monteith parametrizado pela FAO/91.}

A estimativa da evapotranspiração de referência utilizando o modelo de Penman Monteith, foi realizada para o período de luz (radiação líquida positiva) e para o período de 24 horas por meio da sua equação escrita como:

$$
\lambda E T o=\frac{s \cdot(R n-G)+\rho \cdot c p \cdot \frac{(e s-e a)}{r a}}{s+\gamma \cdot\left(1+\frac{r c}{r a}\right)}
$$

em que: $\lambda E T o=$ fluxo de calor latente de evaporação $\left(\mathrm{MJm}^{-2} \mathrm{~s}^{-1}\right)$;

$$
\begin{aligned}
& \mathrm{Rn}=\text { radiação líquida }\left(\mathrm{MJ} \mathrm{m}^{-2} \mathrm{~s}^{-1}\right) ; \\
& \mathrm{G}=\text { fluxo de calor no solo }\left(\mathrm{MJ} \mathrm{m}^{-2} \mathrm{~s}^{-1}\right) ;
\end{aligned}
$$




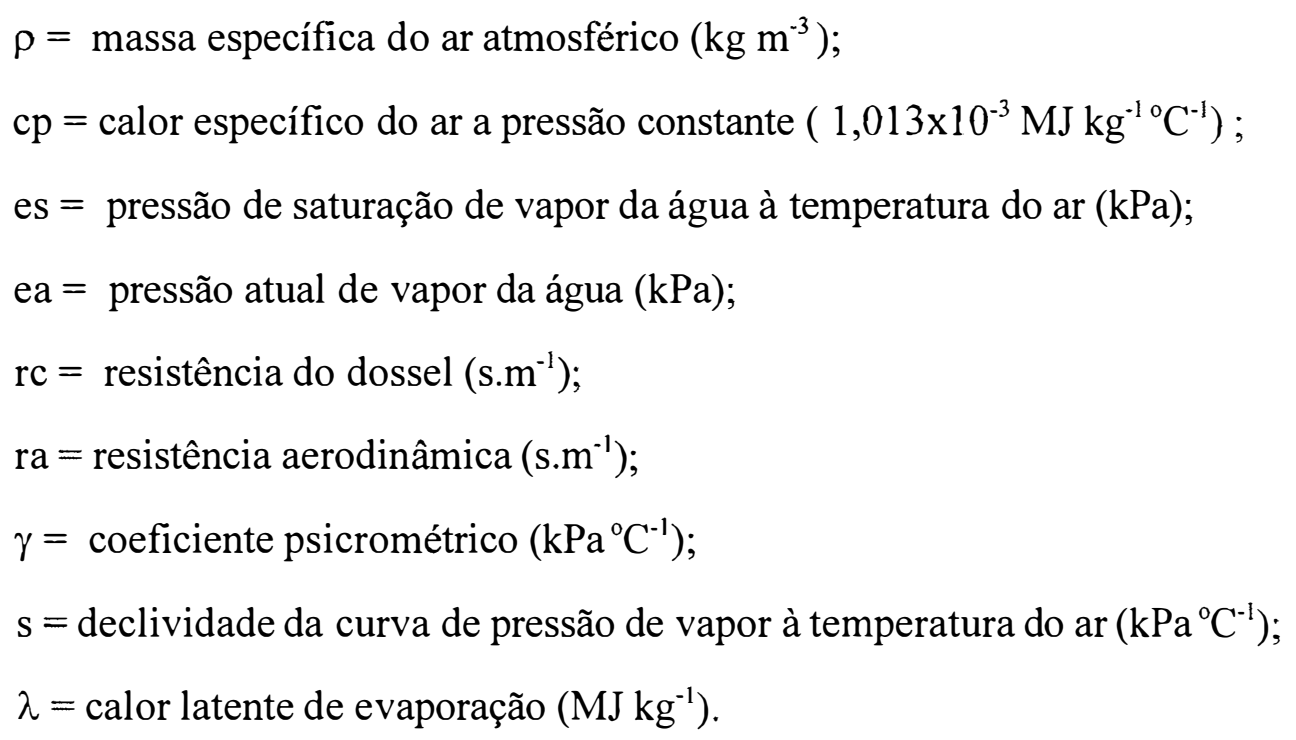

Afim de avaliar a potencialidade do modelo, em função da disponibilidade dos elementos meteorológicos, estimou-se a evapotranspiração, utilizando dados coletados em uma estação automática instalada na área experimental e em outra convencional localizada no Posto Meteorológico da ESALQ - Departamento de Física e Meteorologia .

Visando padronizar o cálculo dos diferentes elementos climáticos, utilizou-se os algorítimos apresentados por SMITH (1991), tomando por base sua aceitação geral e simplicidade de uso, assumindo para alguns elementos valores fixos, a partir de sua validade global.

\subsubsection{1 - Calor latente de evaporação $(\lambda)$}

O calor latente de evaporação é a quantidade de energia necessária para evaporar a massa de $1 \mathrm{~g}$ de água estando esta à temperatura $\mathrm{T}$, sendo uma função linear da sua temperatura : 


$$
\lambda=2,501-\left(2,361 \times 10^{-\hat{3}}\right) \cdot T
$$

em que : $\lambda=$ calor latente de evaporação $\left(\mathrm{MJ} \mathrm{kg}^{-1}\right)$;

$$
\mathrm{T}=\text { temperatura } \operatorname{do} \operatorname{ar}\left({ }^{\circ} \mathrm{C}\right) \text {. }
$$

Como $\lambda$ é uma função fraca da temperatura, foi utilizado um valor constante de $2,45 \mathrm{MJ} \mathrm{kg}^{-1}$, para $\mathrm{T}=20^{\circ} \mathrm{C}$.

\subsubsection{2- Massa específica do ar atmosférico $(\rho)$}

A massa específica do ar atmosférico foi calculada por meio da equação dos gases ideais :

$$
\rho=\frac{P}{T v \cdot R}
$$

em que : $\rho=$ massa específica do ar atmosférico $\left(\mathrm{kg} \mathrm{m}^{-3}\right)$;

$\mathrm{P}=$ pressão atmosférica média local $(95,310 \mathrm{kPa})$;

$\mathrm{R}=$ constante universal dos gases $\left(0,287 \mathrm{~kJ} \mathrm{~kg}^{-1} \mathrm{~K}^{-1}\right)$;

$\mathrm{T}_{\mathrm{v}}=$ temperatura virtual do ar $(\mathrm{K})$.

SMITH (1991) propõe que a temperatura virtual do ar seja estimada pela expressão:

$$
T_{v}=T+275
$$

em que : T $=$ temperatura média do ar no período $\left({ }^{\circ} \mathrm{C}\right)$; substituindo-se os valores de $P, R$ e $T_{v}$ na equação (3), obtem-se a expressão: 


$$
\rho=\frac{332,091}{T+275}
$$

3.2.2.3 - Pressão de saturação do vapor da água à temperatura do ar (es)

A pressão de saturação do vapor da água em função da temperatura do ar, foi estimada pela equação:

$$
e s=0,6108 \exp \left(\frac{17,27 \cdot T}{T+237,3}\right)
$$

em que : es = pressão de saturação do vapor da água $(\mathrm{kPa})$;

$\mathrm{T}=$ temperatura do ar $\left({ }^{\circ} \mathrm{C}\right)$.

\subsubsection{4 - Pressão atual do vapor da água (ea)}

A pressão atual de vapor foi calculada, conhecendo-se a pressão de saturação de vapor da água e a umidade relativa do ar, pela equação:

$$
e a=e s \cdot \frac{U R}{100}
$$

em que : ea = pressão atual do vapor da água $(\mathrm{kPa})$;

$\mathrm{UR}=$ umidade relativa do ar $(\%)$. 


\subsubsection{5- Coeficiente psicrométrico $(\gamma)$}

Para psicrômetros sem ventilação forçada a equação que permite o cálculo do coeficiente psicrométrico é expressa por:

$$
\gamma=10^{-3} \frac{c p \cdot P}{\varepsilon \cdot \lambda}
$$

em que: $\gamma=$ coeficiente psicrométrico $\left(\mathrm{kPa}^{\circ} \mathrm{C}^{-1}\right)$;

$\mathrm{cp}=$ calor específico do ar seco à pressão constante $\left(\mathrm{cp}=1,013 \mathrm{MJ} \mathrm{kg}^{-1}{ }^{0} \mathrm{C}^{-1}\right)$;

$\mathrm{P}=$ pressão atmosférica média local $(\mathrm{P}=95,310 \mathrm{kPa})$;

$\varepsilon=$ razão entre o peso molecular do vapor da água e do ar atmosférico seco $(\varepsilon=0,622)$;

$\lambda=$ calor latente de evaporação $\left(\lambda=2,45 \mathrm{MJ} \mathrm{kg}^{-1}\right)$.

Aplicando-se os valores de cp, $\mathrm{P}, \varepsilon$ e $\lambda$ na equação (8), obtém-se $\gamma=0,063\left(\mathrm{kPa}^{\circ} \mathrm{C}^{-1}\right)$.

\subsubsection{6 - Declividade da curva de pressão de vapor da água (s)}

O valor da declividade da curva de pressão de vapor da água, à temperatura do ar, foi calculada pela seguinte equação:

$$
s=\frac{4098 \cdot e s}{(T+237,3)^{2}}
$$

em que : $\mathrm{s}=$ declividade da curva de pressão de vapor à temperatura do ar $\left(\mathrm{kPa}^{\circ} \mathrm{C}^{-1}\right)$; $\mathrm{T}=$ temperatura do ar $\left({ }^{\circ} \mathrm{C}\right) ;$ es $=$ pressão de saturação do vapor da água $(\mathrm{kPa})$. 


\subsubsection{7- Radiação líquida (Rn)}

Foram utilizados dados de radiação líquida obtidos por dois procedimentos:

3.2.2.7.1- Medida em radiômetro líquido (modelo: Q7.1 REBS; espectro: 25 a $60 \mu \mathrm{m}$ ) colocado $1 \mathrm{~m}$ de altura da superficie vegetal.

3.2.2.7.2- Estimada por meio das equações de Angström e Brunt, conforme parametrização proposta pela FAO-91.

\subsection{1- Radiação no topo da atmosfera (Ra)}

$$
R a=37,586 . d_{r}\left(\omega_{s} \operatorname{sen} \varphi \operatorname{sen} \delta+\cos \varphi \cos \delta \operatorname{sen} \omega_{s}\right)
$$

em que: $\mathrm{Ra}=$ radiação no topo da atmosfera $\left(\mathrm{MJm}^{-2} \mathrm{~d}^{-1}\right)$;

$\mathrm{dr}=$ distância relativa Terra-Sol;

$\omega_{\mathrm{s}}=$ ângulo horário do pôr do sol (rad);

$\varphi=$ latitude local (rad);

$\delta=$ declinação solar (rad).

\subsection{2- Declinação solar $(\delta)$}

$$
\delta=0,4093 \operatorname{sen}\left(\frac{2 \pi}{365} D J-1,405\right)
$$

em que: DJ $=$ dia juliano, Janeiro $1=1 ;$ Fevereiro $1=32 ; \ldots$. Dezembro $31=365$. 
3.2.2.7.2.3- Ângulo horário do pôr do sol $\left(\omega_{\mathrm{s}}\right)$

$$
\omega_{s}=\arccos (-\tan \varphi \tan \delta)
$$

3.2.2.7.2.4- Distância relativa Terra-Sol $\left(d_{r}\right)$

$$
d_{r}=1+0,033 \cos \left(\frac{2 \pi}{365} D J\right)
$$

3.2.2.7.2.5- Número máximo de horas de brilho solar (N)

$$
N=\frac{24}{\pi} \omega_{s}
$$

em que: $\mathrm{N}=$ número máximo de horas de brilho solar (h).

$$
\begin{aligned}
& \text { 3.2.2.7.2.6. - Radiação solar incidente }\left(\mathbf{R}_{\mathbf{s}}\right) \\
& R_{s}=\left(a+b \frac{n}{N}\right) R_{a}
\end{aligned}
$$

em que: $R_{s}=$ radiação solar incidente $\left(\mathrm{MJm}^{-2} \mathrm{~d}^{-1}\right)$;

$\mathrm{n}=$ número de horas de brilho solar registrada em heliógrafos CampbellStokes (h).

a e b $=$ coeficientes da equação de Angström. 


\subsection{7. - Coeficientes da equação de Angström}

$\mathrm{Na}$ ausência de coeficientes ajustados para um local de estudo, recomenda-se a aproximação proposta por GLOVER \& McCULLOCH (1958):

$$
\begin{aligned}
& a=0,29 \cos \varphi, \quad \varphi<60^{\circ} \\
& b=0,52
\end{aligned}
$$

3.2. 2. 2.8. - Saldo de Radiação de Ondas Curtas $\left(R_{n s}\right)$

$$
R_{n s}=(1-r) R_{s}
$$

em que: $R_{n s}=$ saldo de radiação de ondas curtas $\left(\mathrm{MJm}^{-2} \mathrm{~d}^{-1}\right)$;

$r=$ coeficiente de reflexão para cultura da grama $(r=0,23)$.

\subsection{9- Saldo de Radiação de Ondas Longas $\left(R_{b}\right)$}

$$
R_{b}=-\left(0,9 \frac{n}{N}+0,1\right) \cdot\left(c-d \cdot \sqrt{e_{a}}\right) \cdot \sigma\left(T_{k x}^{4}+T_{k n}^{4}\right) \frac{1}{2}
$$

em que: $\mathrm{R}_{\mathrm{b}}=$ saldo de radiação de ondas longas $\left(\mathrm{MJm}^{-2} \mathrm{~d}^{-1}\right)$;

$\sigma=$ constante de Stefan - Boltzmann $\left(4,903 \cdot 10^{-9} \mathrm{MJ} \mathrm{m}^{-2} \mathrm{~d}^{-1} \mathrm{~K}^{-4}\right)$

$\mathrm{e}_{\mathrm{a}}=$ pressão atual do vapor da água $(\mathrm{kPa})$.

$c, d=$ coeficientes da equação de Brunt para estimativa do saldo de radiação de

ondas longas

$$
\begin{array}{ll}
\text { período seco } & c=0,34, d=0,14 \\
\text { período úmido } & c=0,56, d=0,25
\end{array}
$$




\subsection{0- Temperatura virtual máxima diária $\left(\mathrm{T}_{\mathrm{kx}}\right)$}

$$
T_{k x}=T_{\max }+273
$$

em que: $T_{k x}=$ temperatura virtual máxima diária $(K)$;

$\mathrm{T}_{\max }=$ temperatura máxima $\left({ }^{\circ} \mathrm{C}\right)$.

\subsection{1- Temperatura virtual mínima diária $\left(\mathrm{T}_{\mathrm{kn}}\right)$}

$$
T_{k n}=T_{\text {min }}+273
$$

em que: $\mathrm{T}_{\mathrm{kn}}=$ temperatura virtual mínima diária $(\mathrm{K})$;

$\mathrm{T}_{\min }=$ temperatura mínima $\left({ }^{\circ} \mathrm{C}\right)$.

\subsection{2- Radiação líquida (Rn)}

$$
R_{n}=R_{n s}+R_{b}
$$

em que: $R_{n}=$ radiação líquida $\left(\mathrm{MJm}^{-2} \mathrm{~d}^{-1}\right)$;

\subsubsection{8. - Resistência aerodiâmica (ra)}

Para a estimativa da resistência aerodinâmica, Allen et al. (1989) recomendam a utilização da equação (22), para períodos de um dia ou mais longos.

$$
r a=\frac{\ln \left(\begin{array}{c}
z m-d \\
z o m
\end{array}\right) \ln \left(\begin{array}{c}
z h-d \\
z o h
\end{array}\right)}{k^{2} U z}
$$


em que : ra = resistência aerodinâmica à transferência de calor sensível e vapor de água $\left(\mathrm{s} . \mathrm{m}^{-1}\right)$;

$\mathrm{zm}=$ altura de medida da velocidade do vento $(\mathrm{m}) ;$

$\mathrm{zh}=$ altura em que é feita a medida da temperatura e umidade relativa do ar $(\mathrm{m})$;

$\mathrm{d}=$ deslocamento do plano zero do perfil do vento $(\mathrm{m})$;

zom $=$ comprimento de rugosidade equivalente para tranferência de momentum $(\mathrm{m})$;

zoh $=$ comprimento de rugosidade equivalente para tranferência de calor sensível e calor latente (m);

$\mathrm{k}=$ constante de von $\operatorname{Karman}(\mathrm{k}=0,41)$;

$\mathrm{Uz}=$ velocidade do vento medida a altura $\mathrm{z}\left(\mathrm{m} \mathrm{s}^{-1}\right)$.

Monteith (1981) e Brutsaert (1982) recomendam o cálculo de d, zom e zoh, por meio das equações:

$$
\begin{aligned}
& d=\frac{2}{3} \cdot h c \\
& z o m=0,123 \cdot h c \\
& z o h=0,1 \cdot z o m \\
& \text { ou } \\
& z o h=0,0123 \cdot h c
\end{aligned}
$$


Padronizando-se a medida da velocidade do vento (zm), temperatura e umidade relativa do ar (zh) à altura de $2,0 \mathrm{~m}$ e assumindo-se altura da cultura hc $=0,12 \mathrm{~m}$, conforme sugestões de Allen et al. (1989) e Smith (1991) nas equações (23), (24), (25) e aplicando-os na (22), chega-se a uma equação simplificada para a estimativa da resistência aerodinâmica para um gramado:

$$
r a=\frac{208}{U_{z}}
$$

\subsubsection{9. - Resistência do dossel (rc)}

A resistência do dossel de uma cultura, em condições de desenvolvimento ativo e sob condições ótimas de umidade do solo, pode ser estimada por meio da resistência estomática mínima de uma folha e do índice de área foliar da vegetação, conforme sugestão de Allen et al. (1989), por meio da seguinte equação:

$$
r c=\frac{R i}{0,5 I A F}
$$

em que: $r c=$ resistência do dossel da cultura $\left(\mathrm{s} \mathrm{m}^{-1}\right)$;

$\mathrm{Ri}=$ resistência estomática mínima para uma folha $\left(\mathrm{s} \mathrm{m}^{-1}\right)$;

$\mathrm{IAF}=$ índice de área foliar.

Assumindo-se o valor de Ri $=100 \mathrm{~s} . \mathrm{m}^{-1}$, conforme recomendação de Monteith (1981) e Sharma (1983), e adotando-se a equação proposta por Allen et al. (1989), para a estimativa do IAF para hc $=0,12 \mathrm{~m}$ :

$$
I A F=24 h c
$$


obtém-se o valor da resistência do dossel padronizado para a cultura de referência, conforme sugerido por Smith (1991):

$$
\mathrm{rc}=69 \mathrm{~s} \mathrm{~m}^{-1}
$$

Objetivando avaliar o desempenho do modelo de Penman Monteith em relação a resistência do dossel, utilizou-se os valores de rc $=69 \mathrm{~s} \mathrm{~m}^{-1}$ (Smith, 1991) e rc $=80 \mathrm{~s} \mathrm{~m}^{-1}$ (Peres, 1994), no período de luz (radiação líquida positiva) e de 24 horas.

Afim de determinar a resistência de dossel média em cada período de tempo estudado, utilizou-se os elementos meteorológicos e a evapotranspiração medida no lisímetro de pesagem ( $\lambda$ EToLP), para o cálculo do re como valor residual da equação de PenmanMonteith, por meio da expressão:

$$
r c_{r e s}=\frac{r a \cdot s \cdot(R n-G)+\rho \cdot c p \cdot \Delta e \cdot N}{\gamma \cdot \lambda E T o L P}-\operatorname{ra} \cdot\left(\frac{s}{\gamma}+1\right)
$$

em que: $\lambda E T o L P=$ evapotranspiração medida no lisímetro de pesagem $\left(\mathrm{MJ} \mathrm{m}^{-2} \mathrm{~s}^{-1}\right)$;

\subsection{3- Tanque Classe $A$}

A evapotranspiração de referência foi estimada a partir da evaporação da água no tanque classe A. As medidas de evaporação foram realizadas diariamente, por meio de um parafuso micrométrico, assentado sob um poço tranquilizador. As lâminas evaporadas foram convertidas em lâminas evapotranspiradas por meio da equação: 


$$
E T o T=K p . E C A
$$

em que: $\mathrm{EToT}$ = evapotranspiração de referência estimada com o tanque classe A, $\mathrm{mm} \mathrm{d}^{-1}$;

$\mathrm{ECA}=$ evaporação da água no tanque Classe $\mathrm{A}, \mathrm{mm} \mathrm{d}^{-1}$;

$\mathrm{Kp} \quad=$ coeficiente do tanque, adimensional.

Os valores do coeficiente do tanque para as condições de Piracicaba,SP foram selecionados utilizando-se a equação de regressão ajustada por Snyder (1992), para os dados propostos por Doorenbos e Pruitt (1977):

$$
K p=0,482+0,024 \ln (F)-0,000376 . U+0,0045 . U R
$$

em que: $F$ = distância da área de bordadura em relação ao centro do tanque $(\mathrm{m})$;

$$
\begin{aligned}
& \mathrm{U}=\text { velocidade do vento }\left(\mathrm{km} \mathrm{h}^{-1}\right) ; \\
& \mathrm{UR}=\text { umidade relativa do } \operatorname{ar}(\%) .
\end{aligned}
$$

Pereira et al. (1997) advertem que essa equação só deve ser utilizada dentro dos limites de F, U e UR da tabela original, desaconselhando sempre a extrapolação.

Com o objetivo de estabelecer um significado físico ao coeficiente do tanque, Pereira et al. (1995) propuseram um modelo alternativo para a sua determinação que é obtido expressando-se (Kp) por meio da equação (32):

$$
K p=\frac{E T o}{E C A}
$$


Aplicando a equação de Penman-Monteith a um gramado:

$$
\text { ETo }=\frac{s(R n-G)+\frac{\rho \cdot c p . \Delta e}{r a}}{s+\gamma\left(1+\frac{r c}{r a}\right)}
$$

e a uma superficie de água livre em um tanque classe A:

$$
E C A=\frac{s(R n-G)^{*}+\frac{\rho . c p . \Delta e}{r a}}{s+\gamma}
$$

em que: $(R n-G)^{*}=$ balanço de energia aplicado a uma superficie de água livre.

substituindo as equações (35) e (36) em 34 obtém-se:

$$
K p=\frac{\frac{s .(R n-G)+\frac{\rho . c p . \Delta e}{r a}}{s+\gamma\left(1+\frac{r c}{r a}\right)}}{\frac{s(R n-G)^{*}+\frac{\rho \cdot c p . \Delta e}{r a}}{s+\gamma}}
$$

rearranjando os termos semelhantes na equação (37), chega-se:

$$
K p=\frac{s \cdot(R n-G)+\frac{\rho \cdot c p \cdot \Delta e}{r a}}{s .(R n-G)^{*}+\frac{\rho \cdot c p \cdot \Delta e}{r a}} \cdot \frac{s+\gamma}{s+\gamma\left(1+\frac{r c}{r a}\right)}
$$


o primeiro termo da equação recebe o nome de Kpmax, dai a equação (38) assumir a seguinte apresentação final:

$$
K p=K p \max . \frac{s+\gamma}{s+\gamma\left(1+\frac{r c}{r a}\right)}
$$

Analisando a tabela proposta por Doorenbos e Pruitt (1977), verifica-se que o Kpmax tende a 0,85 , quando a umidade relativa é alta e a velocidade do vento é baixa. Esse resultado indica que $\mathrm{Kp}$ é dependente do quociente $\mathrm{rc} / \mathrm{ra}$ e da temperatura do ar, que determina o valor de "s" (Pereira et al. 1995).

\subsection{4.- Atmômetro modificado SEEI}

A estimativa da evapotranspiração de referência, utilizando o atmômetro modificado SEEI, foi realizada pelas diferenças das leituras diárias do nível da água, na escala localizada na parte externa do aparelho.

\section{3 - Coleta e seleção dos dados para análise.}

Os dados deste trabalho foram coletados durante os meses de agosto a dezembro do ano de 1996. A partir dos dados originais, procurou-se eliminar os dias cujos valores de precipitação pluviométrica fosse superior a $1,0 \mathrm{~mm}$, bem como os dias em que foram realizados trabalhos de manutenção na área experimental, afim de não interferir nas medidas feitas pelos sensores. Desta maneira, mediu-se os elementos meteorológicos de: radiação líquida, temperatura e umidade relativa do ar, velocidade do vento, fluxo de calor no solo e evapotranspiração de referência para os períodos médios de 24 horas e de radiação líquida positiva, aqui designado como período de luz. 
A base de dados utilizada neste trabalho consta de uma série de 88 dias de medidas, cujos valores encontram-se apresentados nas Tabelas 10 e 11. (Anexos)

\section{4 - Análise dos resultados.}

Objetivando avaliar o desempenho da cada método de estimativa da evapotranspiração de referência, foram realizados estudos comparativos entre as metodologias propostas, adotando-se as medidas feitas no lisímetro de pesagem como padrão. Os dados foram coletados diariamente e analisados, estatisticamente, mediante análise de regressão.

Para cada análise realizada, obteve-se uma equação de regressão linear com seu respectivo coeficiente de determinação. Considerando, que os coeficientes de determinação $\left(r^{2}\right)$ e de correlação $(r)$, traduzem apenas o grau de precisão da análise, não revelando o seu grau de exatidão, podendo levar a interpretações equivocadas do desempenho do modelo em estudo, utilizou-se o índice de concordância "Id" proposto por Willmont (1981).

\subsection{1- Índice de concordância de Willmont (Id)}

$$
I d=1-\frac{\sum(P i-O i)^{2}}{\sum(|P i-O i|+|O i-O|)^{2}}
$$

em que: $\mathrm{Pi}=$ evapotranspiração estimada pelo modelo em estudo $(\mathrm{mm})$;

$\mathrm{Oi}=$ evapotranspiração medida pelo lisímetro de pesagem $(\mathrm{mm})$; $\mathrm{O}=$ média da evapotranspiração medida $(\mathrm{mm})$. 
Foram utilizados ainda, outros indicadores de desempenho dos modelos em estudo, descritos como se segue:

\subsection{2 - Erro sistemático (Es)}

$$
E s=\left(\frac{\sum(\operatorname{Pr} i-O i)^{2}}{N}\right)^{2}
$$

em que: Pri = calculado a partir dos parâmetros da equação de regressão entre o valor padrão (medido) e o estimado (Pri $=a+b . O i)$

$\mathrm{N}=$ número de dados analisados.

3.4.3 - Erro não sistemático (Eu)

$$
E \boldsymbol{u}=\left(\frac{\sum(\operatorname{Pi}-\operatorname{Pr} i)^{2}}{N}\right)^{2}
$$

3.4.4 - Raiz quadrada do erro médio (RQEM)

$$
R Q E M=\sqrt{(E s)^{2}+(E u)^{2}}
$$

3.4.5 - Média do erro absoluto (MAE)

$$
M A E=\frac{\sum|P \boldsymbol{i}-O \boldsymbol{i}|}{N}
$$




\section{RESULTADOS E DISCUSSÃO}

\section{1 - Condições meteorológicas durante o período experimental.}

Analisando os dados meteorológicos médios, da época em que foram realizados os estudo de campo, verificou-se que a temperatura do ar variou de 21,3 a $14,6{ }^{\circ} \mathrm{C}$ e de 17,4 a $29,7^{\circ} \mathrm{C}$ durante os períodos de 24 horas e de luz, respectivamente. A umidade relativa do ar apresentou uma variação de 55 a $88 \%$ em 24 horas e de 41 a $82 \%$ no período de luz (Figuras 2 e 3 ). Os valores médios da temperatura e umidade relativa do ar, foram carcterísticos dos meses de agosto a dezembro, próximos das normais climatológicas da região (Ometto,1991). Estas condições favoreceram o desenvolvimento ativo da grama, permitindo a sua evapotranspiração a nível potencial, dada a sua intensa atividade fisiológica e a grande disponibilidade de água no solo, tornando este período como adequado a realização de estudos em evapotranspiração.

A radiação líquida representa a energia disponível ao meio ambiente, na forma de ondas eletromagnéticas, após as trocas radiantes. Esta energia é utilizada nos processos naturais de evaporação, transpiração, evapotranspiração, aquecimento do solo e do ar e sínteses biológicas (Ometto, 1991). Na Figura 4 são apresentados os dados de radiação líquida, no curso dos dias analisados. Apesar da variação observada, verificou-se que a disponibilidade de energia aumenta progressivamente de agosto a dezembro, apresentando valores médios de 13,29 e 12,29 MJ.m. ${ }^{-2}$ nos períodos de luz de 24 horas respectivamente. 


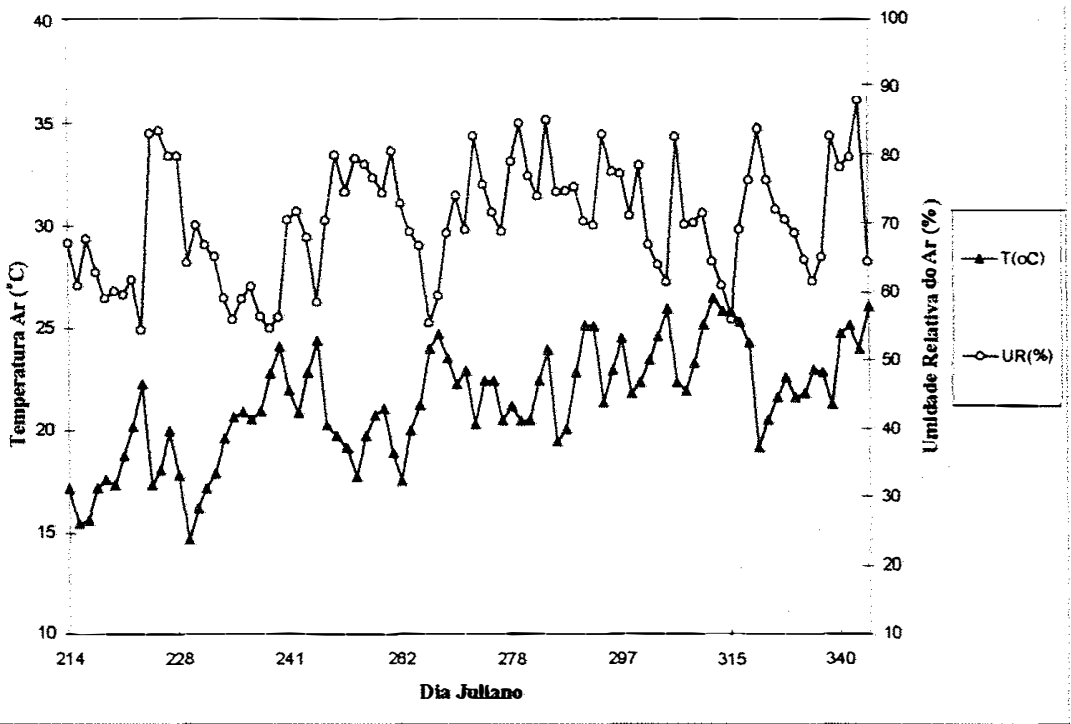

Figura 2 - Temperatura média do $\operatorname{ar}\left({ }^{\circ} \mathrm{C}\right)$ e umidade relativa média do ar $(\%)$ no período de 24 horas ao longo da fase experimental.

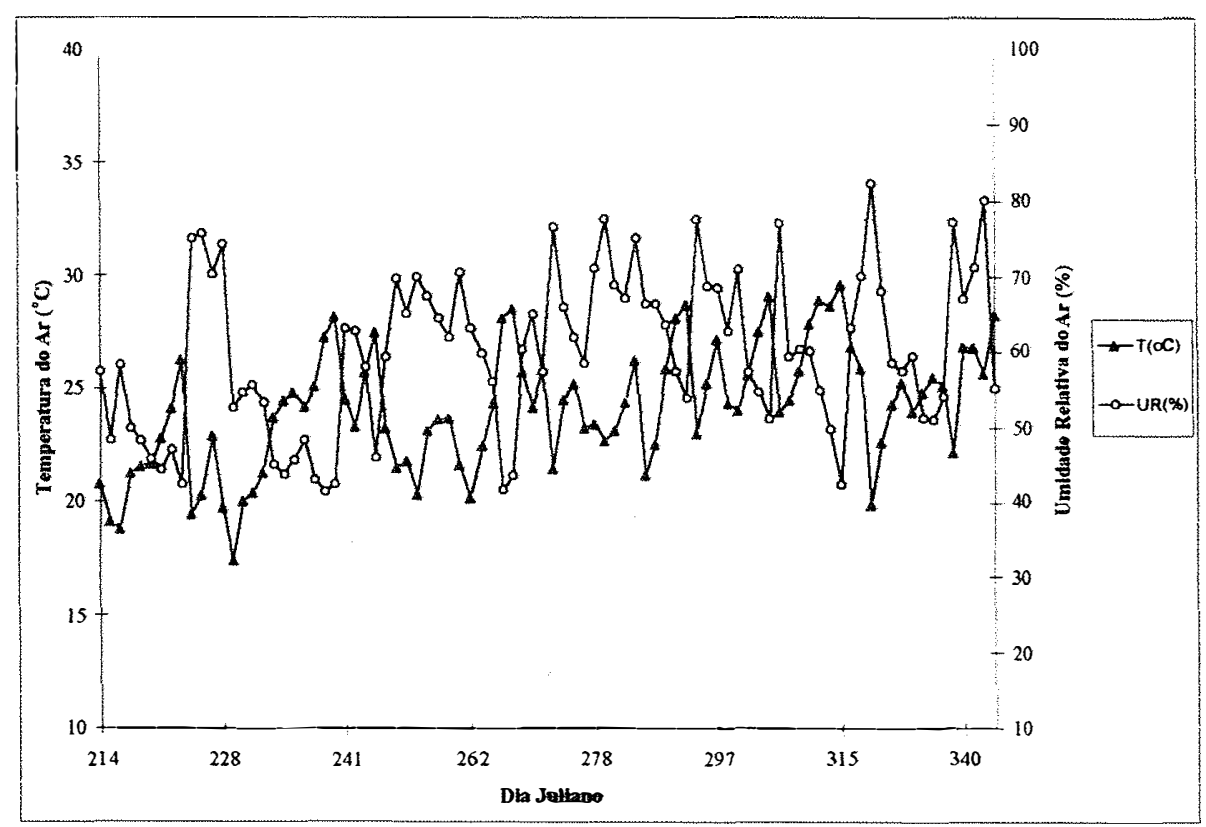

Figura 3 - Temperatura média do ar $\left({ }^{\circ} \mathrm{C}\right)$ e umidade relativa média do ar $(\%)$ no período de luz, ao longo da fase experimental. 
A presença de nuvens é um dos principais fatores responsáveis por esta variação, interferindo nas trocas de energia radiante entre o sol e a superficie do solo.

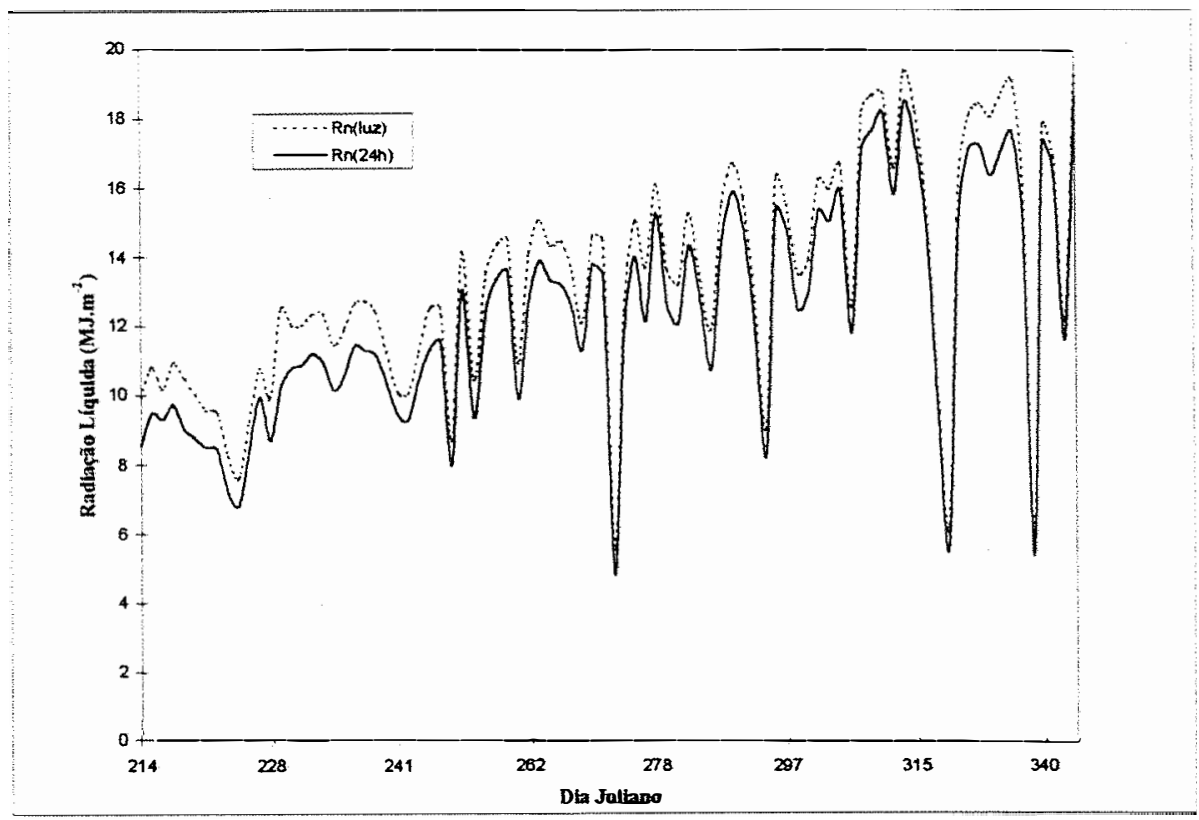

Figura 4 - Radiação liquida no período de luz e 24 horas ao longo da fase experimental.

A velocidade do vento é um elemento meteorológico muito importante no processo da evapotranspiração, estando a sua influência relacionada com a resistência aerodinâmica ao transporte de calor sensível e vapor da água. A velocidade média variou de 1,2 a $4,2 \mathrm{~m} . \mathrm{s}^{-1}$, observado-se no período de luz os valores mais elevados no curso da fase experimental. Avaliando-se o Quadro 1, pode-se verificar que o balanço de energia no período de luz é maior que em 24 horas. Desta maneira, durante a fase de luz, ocorrerá obviamente maior perda de água no sistema solo-planta para a atmosfera. 
Quadro 1 - Valores médios, máximos e mínimos de radiação líquida $(\mathrm{R} n)$, densidade de fluxo de calor no solo $(\mathrm{G})$, temperatura do ar (T), umidade relativa (UR) e velocidade do vento $(U)$, no curso da fase experimental, nos períodos de $24 \mathrm{~h}$ e de luz.

\begin{tabular}{|c|c|c|c|c|c|c|c|c|c|c|}
\hline Mês & \multicolumn{2}{|c|}{$\begin{array}{c}\text { Rn } \\
\left(\mathrm{MJ} \mathrm{m}^{-2}\right)\end{array}$} & \multicolumn{2}{c|}{$\begin{array}{c}\text { G } \\
\left(\mathrm{MJ} \mathrm{m}^{-2}\right)\end{array}$} & \multicolumn{2}{c|}{$\begin{array}{c}\text { T } \\
\left({ }^{\circ} \mathrm{C}\right)\end{array}$} & \multicolumn{2}{c|}{$\begin{array}{c}\text { UR } \\
(\%)\end{array}$} & \multicolumn{2}{c|}{$\begin{array}{c}\text { U } \\
\left(\mathrm{m} \mathrm{s}^{-1}\right)\end{array}$} \\
\hline & $24 \mathrm{~h}$ & Luz & $24 \mathrm{~h}$ & Luz & $24 \mathrm{~h}$ & Luz & $24 \mathrm{~h}$ & Luz & $24 \mathrm{~h}$ & Luz \\
\hline Ago & 9,70 & 10,86 & 0,20 & 0,76 & 19,3 & 22,7 & 65 & 53 & 1,91 & 2,19 \\
\hline Set & 11,85 & 12,84 & 0,28 & 0,67 & 20,9 & 23,7 & 73 & 62 & 2,15 & 2,39 \\
\hline Out & 13,47 & 14,39 & 0,35 & 0,79 & 22,4 & 25,1 & 74 & 65 & 2,27 & 2,41 \\
\hline Nov & 14,07 & 15,71 & 0,29 & 0,71 & 22,7 & 25,4 & 73 & 61 & 2,27 & 2,50 \\
\hline Dez & 15,90 & 16,45 & 0,23 & 0,63 & 24,8 & 26,9 & 78 & 68 & 1,71 & 2,09 \\
\hline Méd & 12,29 & 13,29 & $\mathbf{0 , 2 5}$ & $\mathbf{0 , 7 3}$ & $\mathbf{2 1 , 3}$ & $\mathbf{2 4 , 1 7}$ & $\mathbf{7 0}$ & $\mathbf{6 0}$ & $\mathbf{2 , 1 1}$ & 2,34 \\
\hline Máx & 18,54 & 19,28 & $\mathbf{0 , 7 7}$ & $\mathbf{1 , 1 4}$ & $\mathbf{2 6 , 3}$ & $\mathbf{2 9 , 6 8}$ & $\mathbf{8 8}$ & $\mathbf{8 2}$ & $\mathbf{3 , 7 9}$ & $\mathbf{4 , 2 5}$ \\
\hline Mín & $\mathbf{0 , 4 8}$ & $\mathbf{0 , 5 5}$ & $-\mathbf{0 , 4 8}$ & $\mathbf{0 , 0 4}$ & 14,6 & $\mathbf{1 7 , 3 6}$ & $\mathbf{5 5}$ & $\mathbf{4 1}$ & $\mathbf{1 , 2 3}$ & $\mathbf{1 , 4 2}$ \\
\hline
\end{tabular}

\section{2 - Evapotranspiração de referência nos períodos de 24 horas e de luz.}

A partir dos dados apresentados nas Tabelas 10 e 11, pode-se separar o fluxo evapotranspirativo para os períodos de 24 horas e de luz.

Analisando a Tabela 1, verificou-se que o maior percentual de perda de água no sistema solo-planta ocorreu no período de radiação líquida positiva, perfazendo na média, aproximadamente $85 \%$ do total. Deve-se ressaltar que a perda de água durante o período noturno está associada a ação dos ventos, os quais condicionam os fatores aerodinâmicos, influenciando desta forma a evapotranspiração e a de umidade do solo. Nas épocas de menor umidade do solo, como as que ocorre entre os meses de abril a agosto na região de Piracicaba, as perdas de água durante o período noturno, possivelmente, serão bem menores do que as observadas de setembro a março. Salientase ainda, que desse total o maior percentual cabe ao processo evaporativo do solo, haja visto que a transpiração via estômatos, é desprezível durante o período sem energia solar.

Dentro dessa análise, deve-se atentar para a importância em prever as perdas de água por evaporação em locais que utilizam sistemas de irrigação de alta freqüência, como pivô central, gotejamento, e microaspersão. 
Tabela 1- Evapotranspiração de referência medida no lisímetro de pesagem, para o período de 24 horas e de luz e o percentual da ETo que ocorre fora do período de radiação líquida positiva.

\begin{tabular}{|c|c|c|c|c|}
\hline Data & $\begin{array}{l}\text { ETOLP } \\
\mathrm{mm} \cdot \mathrm{dia}^{-1}\end{array}$ & $\begin{array}{c}\text { EToLP } \\
\text { mm.p.luz }\end{array}$ & $\begin{array}{c}\Delta \text { EToLP } \\
\mathrm{mm}\end{array}$ & $\begin{array}{c}\Delta \mathrm{ETOLP} \\
\%\end{array}$ \\
\hline $01 / 08 / 96$ & 2,59 & 2,10 & 0,49 & 18,92 \\
\hline 02/08/96 & 3,02 & 2,10 & 0,92 & 30,46 \\
\hline 03/08/96 & 2,74 & 2,05 & 0,69 & 25,18 \\
\hline 04/08/96 & 4,05 & 2,89 & 1,16 & 28,64 \\
\hline 05/08/96 & 3,50 & 2,99 & 0,51 & 14,57 \\
\hline 06/08/96 & 3,33 & 2,48 & 0,85 & 25,53 \\
\hline 07/08/96 & 3,03 & 2,42 & 0,61 & 20,13 \\
\hline 08/08/96 & 3,29 & 2,68 & 0,61 & 18,54 \\
\hline 09/08/96 & 3,35 & 2,48 & 0,87 & 25,97 \\
\hline $11 / 08 / 96$ & 2,68 & 2,21 & 0,47 & 17,54 \\
\hline $12 / 08 / 96$ & 2,99 & 2,26 & 0,73 & 24,41 \\
\hline $13 / 08 / 96$ & 3,15 & 2,32 & 0,83 & 26,35 \\
\hline $15 / 08 / 96$ & 3,09 & 2,65 & 0,44 & 14,24 \\
\hline $16 / 08 / 96$ & 4,07 & 2,85 & 1,22 & 29,98 \\
\hline $17 / 08 / 96$ & 3,83 & 3,04 & 0,79 & 20,63 \\
\hline $18 / 08 / 96$ & 3,59 & 3,05 & 0,54 & 15,04 \\
\hline 19/08/96 & 3,76 & 3,10 & 0,66 & 17,55 \\
\hline $21 / 08 / 96$ & 4,39 & 3,37 & 1,02 & 23,23 \\
\hline $22 / 08 / 96$ & 3,90 & 3,14 & 0,76 & 19,49 \\
\hline 23/08/96 & 4,18 & 3,45 & 0,73 & 17,46 \\
\hline 24/08/96 & 4,41 & 3,39 & 1,02 & 23,13 \\
\hline $25 / 08 / 96$ & 4,32 & 3,55 & 0,77 & 17,82 \\
\hline $26 / 08 / 96$ & 4,62 & 3,74 & 0,88 & 19,05 \\
\hline 27/08/96 & 4,46 & 3,97 & 0,49 & 10,99 \\
\hline 28/08/96 & 3,80 & 3,00 & 0,80 & 21,05 \\
\hline 29/08/96 & 3,20 & 2,61 & 0,59 & 18,44 \\
\hline $30 / 08 / 96$ & 4,24 & 3,72 & 0,52 & 12,26 \\
\hline $31 / 08 / 96$ & 5,11 & 4,30 & 0,81 & 15,85 \\
\hline 02/09/96 & 3,93 & 3,38 & 0,55 & 13,99 \\
\hline 04/09/96 & 3,40 & 2,72 & 0,68 & 20,00 \\
\hline 07/09/96 & 4,73 & 3,74 & 0,99 & 20,93 \\
\hline $12 / 09 / 96$ & 3,73 & 2,85 & 0,88 & 23,59 \\
\hline $13 / 09 / 96$ & 3,99 & 3,18 & 0,81 & 20,30 \\
\hline $14 / 09 / 96$ & 4,79 & 4,45 & 0,34 & 7,10 \\
\hline $15 / 09 / 96$ & 4,73 & 4,18 & 0,55 & 11,63 \\
\hline $17 / 09 / 96$ & 4,18 & 3,53 & 0,65 & 15,55 \\
\hline $18 / 09 / 96$ & 4,80 & 3,86 & 0,94 & 19,58 \\
\hline $19 / 09 / 96$ & 5,23 & 4,41 & 0,82 & 15,68 \\
\hline $20 / 09 / 96$ & 4,79 & 4,14 & 0,65 & 13,57 \\
\hline $22 / 09 / 96$ & 5,50 & 5,02 & 0,48 & 8,73 \\
\hline 23/09/96 & 5,22 & 4,52 & 0,70 & 13,41 \\
\hline 24/09/96 & 4,40 & 3,72 & 0,68 & 15,45 \\
\hline
\end{tabular}




\begin{tabular}{|c|c|c|c|c|}
\hline Data & $\begin{array}{c}\text { EToL.P } \\
\mathrm{mm} \cdot \mathrm{dia}^{-1}\end{array}$ & $\begin{array}{c}\text { EToL.P } \\
\text { mm.p.luz }\end{array}$ & $\begin{array}{c}\Delta \text { ETOLP } \\
\mathrm{mm}\end{array}$ & $\begin{array}{c}\Delta \mathrm{ETOLP} \\
\%\end{array}$ \\
\hline $26 / 09 / 96$ & 5,14 & 4,53 & 0,61 & 11,87 \\
\hline $27 / 09 / 96$ & 5,28 & 4,51 & 0,77 & 14,58 \\
\hline $28 / 09 / 96$ & 2,48 & 2,18 & 0,30 & 12,10 \\
\hline 29/09/96 & 4,24 & 3,83 & 0,41 & 9,67 \\
\hline $30 / 09 / 96$ & 5,71 & 5,03 & 0,68 & 11,91 \\
\hline 01/10/96 & 3,74 & 3,13 & 0,61 & 16,31 \\
\hline 04/10/96 & 4,57 & 4,00 & 0,57 & 12,47 \\
\hline 07/10/96 & 4,42 & 3,97 & 0,45 & 10,18 \\
\hline 08/10/96 & 4,45 & 3,84 & 0,61 & 13,71 \\
\hline 09/10/96 & 4,54 & 3,92 & 0,62 & 13,66 \\
\hline $11 / 10 / 96$ & 4,20 & 3,52 & 0,68 & 16,19 \\
\hline $15 / 10 / 96$ & 4,53 & 3,53 & 1,00 & 22,08 \\
\hline $16 / 10 / 96$ & 5,32 & 4,62 & 0,70 & 13,16 \\
\hline $17 / 10 / 96$ & 5,90 & 4,96 & 0,94 & 15,93 \\
\hline $18 / 10 / 96$ & 6,27 & 5,64 & 0,63 & 10,05 \\
\hline $19 / 10 / 96$ & 4,72 & 3,89 & 0,83 & 17,58 \\
\hline $21 / 10 / 96$ & 3,67 & 2,91 & 0,76 & 20,71 \\
\hline $22 / 10 / 96$ & 5,09 & 4,55 & 0,54 & 10,61 \\
\hline 23/10/96 & 5,38 & 4,55 & 0,83 & 15,43 \\
\hline $24 / 10 / 96$ & 4,72 & 3,91 & 0,81 & 17,16 \\
\hline $28 / 10 / 96$ & 5,03 & 4,24 & 0,79 & 15,71 \\
\hline 29/10/96 & 5,61 & 4,97 & 0,64 & 11,41 \\
\hline $30 / 10 / 96$ & 6,01 & 5,23 & 0,78 & 12,98 \\
\hline $31 / 10 / 96$ & 6,18 & 5,58 & 0,60 & 9,71 \\
\hline $04 / 11 / 96$ & 4,41 & 3,77 & 0,64 & 14,51 \\
\hline $05 / 11 / 96$ & 6,37 & 5,71 & 0,66 & 10,36 \\
\hline $06 / 11 / 96$ & 6,49 & 5,50 & 0,99 & 15,25 \\
\hline $07 / 11 / 96$ & 6,09 & 5,45 & 0,64 & 10,51 \\
\hline $08 / 11 / 96$ & 6,50 & 5,43 & 1,07 & 16,46 \\
\hline $09 / 11 / 96$ & 6,86 & 6,14 & 0,72 & 10,50 \\
\hline $10 / 11 / 96$ & 6,88 & 5,96 & 0,92 & 13,37 \\
\hline $11 / 11 / 96$ & 5,32 & 4,59 & 0,73 & 13,72 \\
\hline $12 / 11 / 96$ & 3,55 & 3,30 & 0,25 & 7,04 \\
\hline $22 / 11 / 96$ & 2,71 & 2,05 & 0,66 & 24,35 \\
\hline 23/11/96 & 4,98 & 4,50 & 0,48 & 9,64 \\
\hline $24 / 11 / 96$ & 6,40 & 5,39 & 1,01 & 15,78 \\
\hline $25 / 11 / 96$ & 5,98 & 5,37 & 0,61 & 10,20 \\
\hline $26 / 11 / 96$ & 5,46 & 4,97 & 0,49 & 8,97 \\
\hline $27 / 11 / 96$ & 6,26 & 5,37 & 0,89 & 14,22 \\
\hline $28 / 11 / 96$ & 6,10 & 5,59 & 0,51 & 8,36 \\
\hline $29 / 11 / 96$ & 5,17 & 4,85 & 0,32 & 6,19 \\
\hline $30 / 11 / 96$ & 2,22 & 1,78 & 0,44 & 19,82 \\
\hline $05 / 12 / 96$ & 5,78 & 5,34 & 0,44 & 7,61 \\
\hline $06 / 12 / 96$ & 5,73 & 5,20 & 0,53 & 9,25 \\
\hline $08 / 12 / 96$ & 3,91 & 3,70 & 0,21 & 5,37 \\
\hline $09 / 12 / 96$ & 6,99 & 6,42 & 0,57 & 8,15 \\
\hline Média & 4,58 & 3,90 & 0,69 & 15,76 \\
\hline
\end{tabular}




\section{3 - Evapotranspiração de referência estimada pelo modelo de Penman Monteith, para o período de luz.}

A partir das medidas realizadas no lisímetro de pesagem, que retratam o período de luz, como o de maior percentual de ocorrência de evapotranspiração, avaliou-se o desempenho do modelo de Penman-Monteith para esse período, utilizando-se os dados meteorológicos médios, medidos em uma estação automática apresentados na Tabela 11, para os valores de resistência do dossel de $69 \mathrm{~s} . \mathrm{m}^{-1}$ e $80 \mathrm{~s} \cdot \mathrm{m}^{-1}$.

Analisando a Figura 5, observou-se que o modelo de Penman-Monteith estimou satisfatoriamente a evapotranspiração de referência, em relação ao lisímetro de pesagem, quando adotou-se a resistência do dossel proposta pela FAO de 69 s.m ${ }^{-1}$. O bom desempenho apresentado é referenciado pela aproximação da reta de ajuste da regressão com a reta 1:1 e pelo elevado valor de coeficiente de determinação $\left(r^{2}=0,9001\right)$ retratando pequena dispersão entre os valores medidos e estimados em torno da reta de ajuste da equação de regressão. Avaliando-se a dispersão dos pontos medidos em torno da reta $1: 1$, verificou-se que o modelo em estudo superestima a evapotranspiração de referência de $3 \%$ em média.

Adotando-se o resistência do dossel de $80 \mathrm{~s} . \mathrm{m}^{-1}$, conforme proposto por Peres (1994), verificou-se que o modelo de Penman-Monteith apresentou melhores resultados quando comparado a condição que se usou a resistência de dossel proposta pela FAO, Figura 6. Avaliando-se os indicadores estatísticos de desempenho Tabela 2, constatou-se que este melhor desempenho está associado a um maior índice de concordância de Willmott e menores valores para os erros sistemáticos e não sistemáticos. 


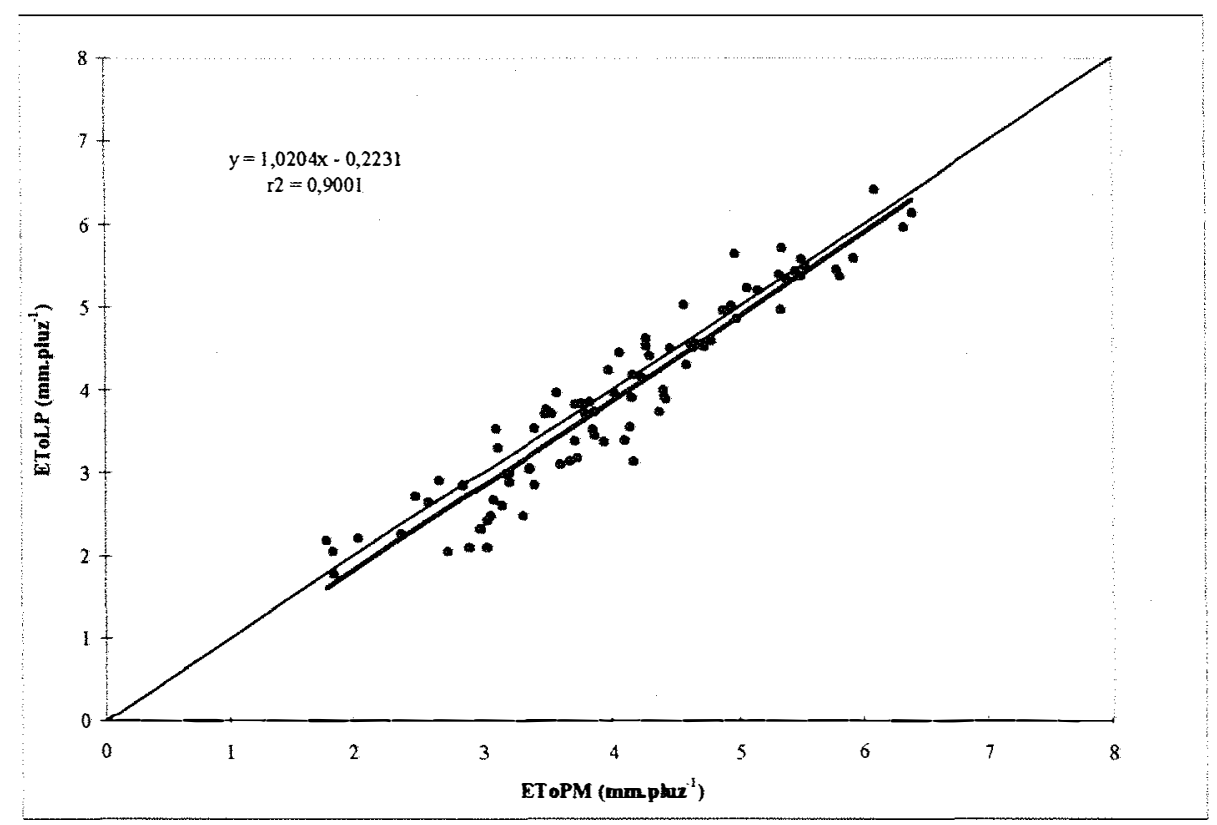

Figura 5- Evapotranspiração de referência no período de luz (p.luz), medida no lisímetro de pesagem (EToLP) versus a estimada pelo modelo de Penman-Monteith (EToPM), para a resistência do dossel de $69 \mathrm{~s} . \mathrm{m}^{-1}$.

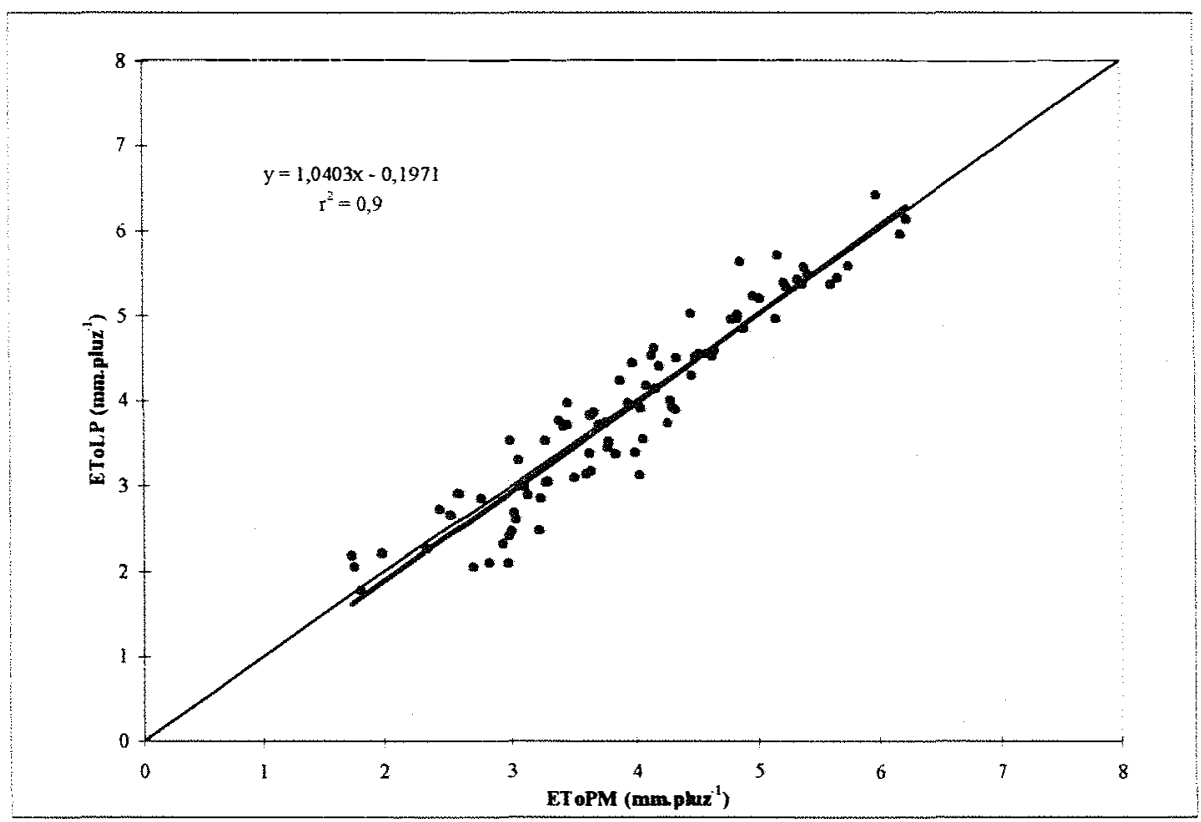

Figura 6- Evapotranspiração de referência no período de luz (p.luz), medida no lisímetro de pesagem (EToLP) versus a estimada pelo modelo de Penman-Monteith (EToPM), para a resistência do dossel de $80 \mathrm{s.m}$. 
Analisando conjuntamente a Figura 6 e a Tabela 2, constatou-se um excelente desempenho do modelo de Penman-Monteith no período de luz, com um erro médio em superestimar a evapotranspiração da ordem de $0,65 \%$.

Tabela 2- Indicadores estatísticos de desempenho para a evapotranspiração medida no lisímetro de pesagem e estimada pelo modelo de Penman Monteith para o período de luz utilizando dados meteorológicos coletados em uma estação automática.

\begin{tabular}{|c|c|c|c|c|c|c|}
\hline & $\begin{array}{c}\text { Média } \\
\text { mm }\end{array}$ & Id & $\begin{array}{c}\text { Es } \\
\text { mm }\end{array}$ & $\begin{array}{c}\mathbf{E u} \\
\mathbf{m m}\end{array}$ & $\begin{array}{c}\text { MAE } \\
\mathbf{m m}\end{array}$ & $\begin{array}{c}\text { RQEM } \\
\text { mm }\end{array}$ \\
\hline Lisímetro Pesagem & 3,90 & & & & & \\
\hline Penman-Monteith (rc $69 \mathrm{~s} \mathrm{~m}^{-1}$ ) & 4,04 & 0,968 & 0,000 & 0,046 & 0,306 & 0,046 \\
\hline Penman-Monteith (rc $80 \mathrm{~s} \mathrm{~m}^{-1}$ ) & 3,94 & 0,971 & 0,000 & 0,023 & 0,293 & 0,023 \\
\hline
\end{tabular}

\section{4 - Evapotranspiração de referência estimada pelo modelo de Penman-Monteith,} para o período de 24 horas.

Adotando-se o mesmo procedimento utilizado para o período de luz, estimou-se a evapotranspiração de referência em 24 horas utlizando-se os elementos meteorológicos médios, medidos em uma estação automática apresentados na Tabela 10.

Analisando-se as Figuras 7 e 8, verificou-se que o modelo de Penman-Monteith subestima a evapotranspiração de referência no período de 24 horas, na ordem de 12 a

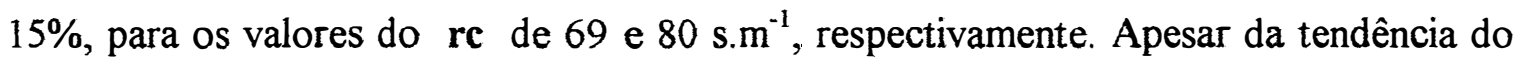
modelo em subestimar a evapotranspiração, constatou-se que o mesmo apresentou em desempenho satisfatório, tendo em vista que as estimativas e as análises foram realizadas em base diária, conforme mostra os resultados dos indicadores estatísticos na Tabela 3 . 


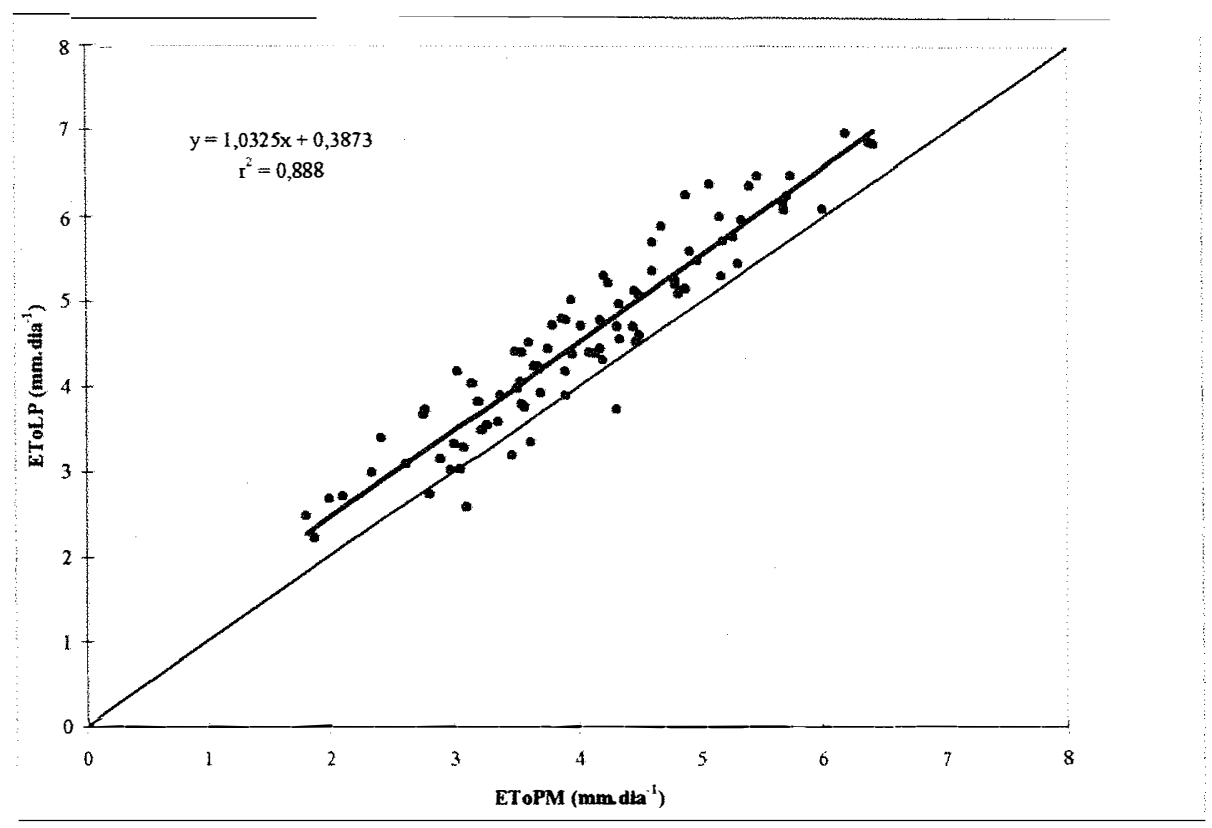

Figura 7- Evapotranspiração de referência no período de 24 horas, medida no lisímetro de pesagem (EToLP) versus a estimada pelo modelo de Penman-Monteith (EToPM), para a resistência do dossel de 69 s. $\mathrm{m}^{-1}$.

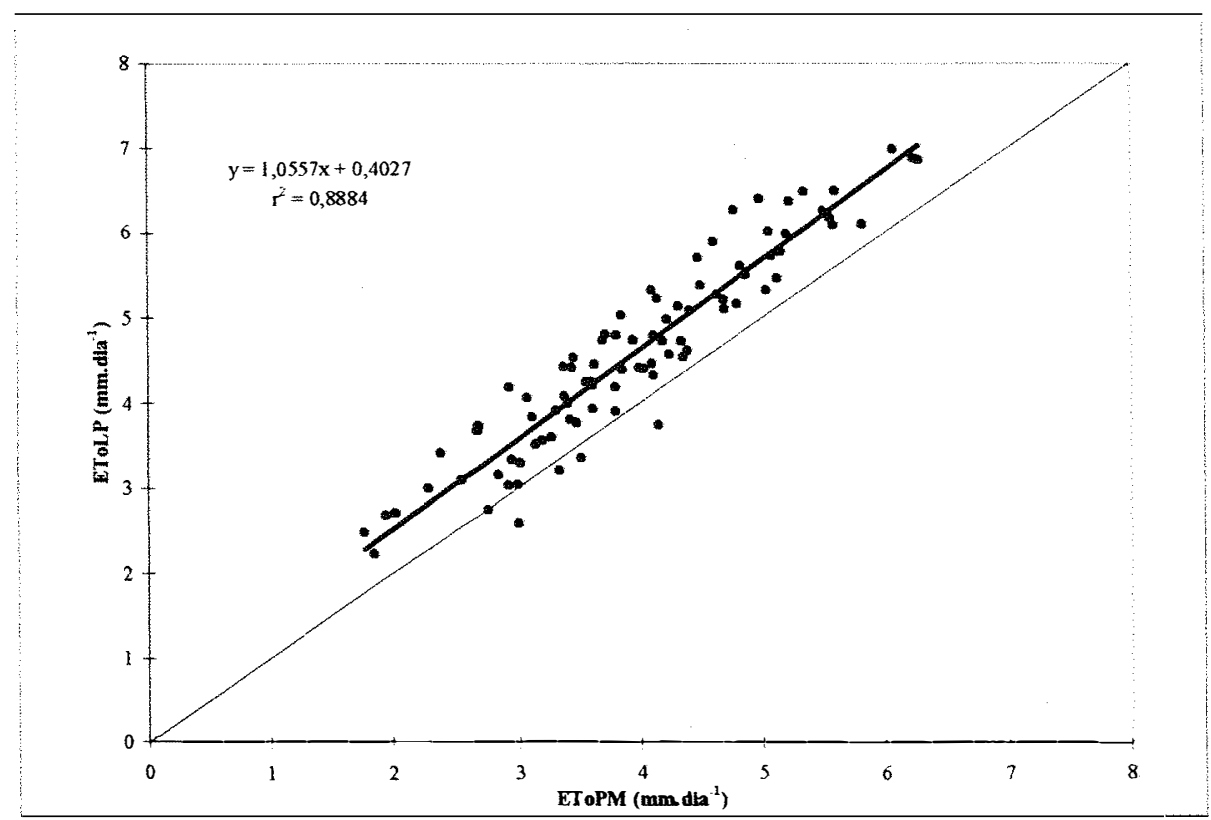

Figura 8- Evapotranspiração de referência no período de 24 horas, medida no lisímetro de pesagem (EToLP) versus a estimada pelo modelo de Penman-Monteith (EToPM), para a resistência do dossel de $80 \mathrm{~s} . \mathrm{m}^{-1}$. 
Tabela 3- Indicadores estatísticos de desempenho para a evapotranspiração medida no lisímetro de pesagem e estimada pelo modelo de Penman-Monteith para o período de 24 horas utilizando dados meteorológicos coletados em uma estação automática.

\begin{tabular}{lcccccc}
\hline & $\begin{array}{c}\text { Média } \\
\text { mm }\end{array}$ & Id & $\begin{array}{c}\text { Es } \\
\mathbf{m m}\end{array}$ & $\begin{array}{c}\text { Eu } \\
\mathbf{m m}\end{array}$ & $\begin{array}{c}\text { MAE } \\
\mathbf{m m}\end{array}$ & $\begin{array}{c}\text { RQEM } \\
\mathbf{m m}\end{array}$ \\
\hline Lisimetro Pesagem & 4,58 & & & & & \\
Penman-Monteith $\left(\mathrm{rc} 69 \mathrm{~s} \mathrm{~m}^{-1}\right)$ & 4,07 & 0,916 & 0,084 & 1,626 & 0,558 & 1,629 \\
Penman-Monteith $\left(\mathrm{rc} 80 \mathrm{~s} \mathrm{~m}^{-1}\right)$ & 3,96 & 0,893 & 0,190 & 3,295 & 0,649 & 3,300 \\
\hline
\end{tabular}

Uma das possíveis explicações para a tendência do modelo em subestimar a evapotranspiração em base diária, está relacionado aos valores adotados para a

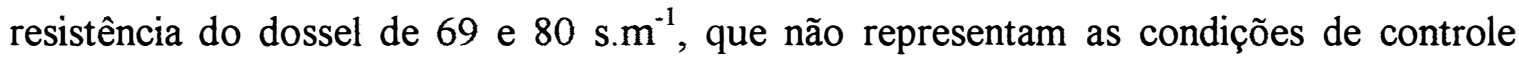
fisiológico estabelecidos pela cultura no período de 24 horas.

Como relatado anteriormente, a evapotranspiração é um processo físico, que ocorre fundamentalmente durante o período de luz. Desta maneira, o balanço de energia, o déficit de pressão de vapor e a resistência aerodinâmica em 24 horas, são menores que os ocorridos durante o período de luz. A associação destes fatores devem resultar em uma menor resistência do dossel, que traduza de maneira mais representativa o papel fisiológico da cultura na perda de água para a atmosfera.

Afim de comprovar esta suposição, estimou-se a resistência do dossel da grama, para os períodos de luz e 24 horas.

\section{5- Estimativa da resistência do dossel da grama}

Estimou-se a resistência do dossel da grama por meio da aplicação da equação (31) para os períodos de luz e de 24 horas, como resíduo da utilização do modelo de Penman-Monteith, a partir dos elementos meteorológicos médios de cada período e da evapotranspiração medida no lisímetro de pesagem. 


\subsection{1 - Resistência do dossel durante o período de luz}

Analisando-se a Figura 9, observou-se que a variação da resistência do dossel é bastante acentuada ao longo da período experimental, com valores de 304 a 8 s.m ${ }^{-1}$, tendo como média $92 \mathrm{s.m}^{-1}$. Esse valor médio, para a resistência do dossel, aproxima-se

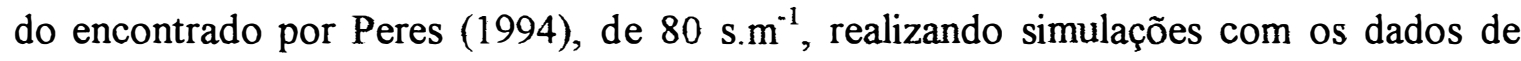
evapotranspiração média diária para o Estado de São Paulo. Deve-se salientar, entretanto, que os estudos realizados por Peres (1994) foram realizados na escala decendial e mensal, a partir dos valores de evapotranspiração medida em lisímetros de drenagem.

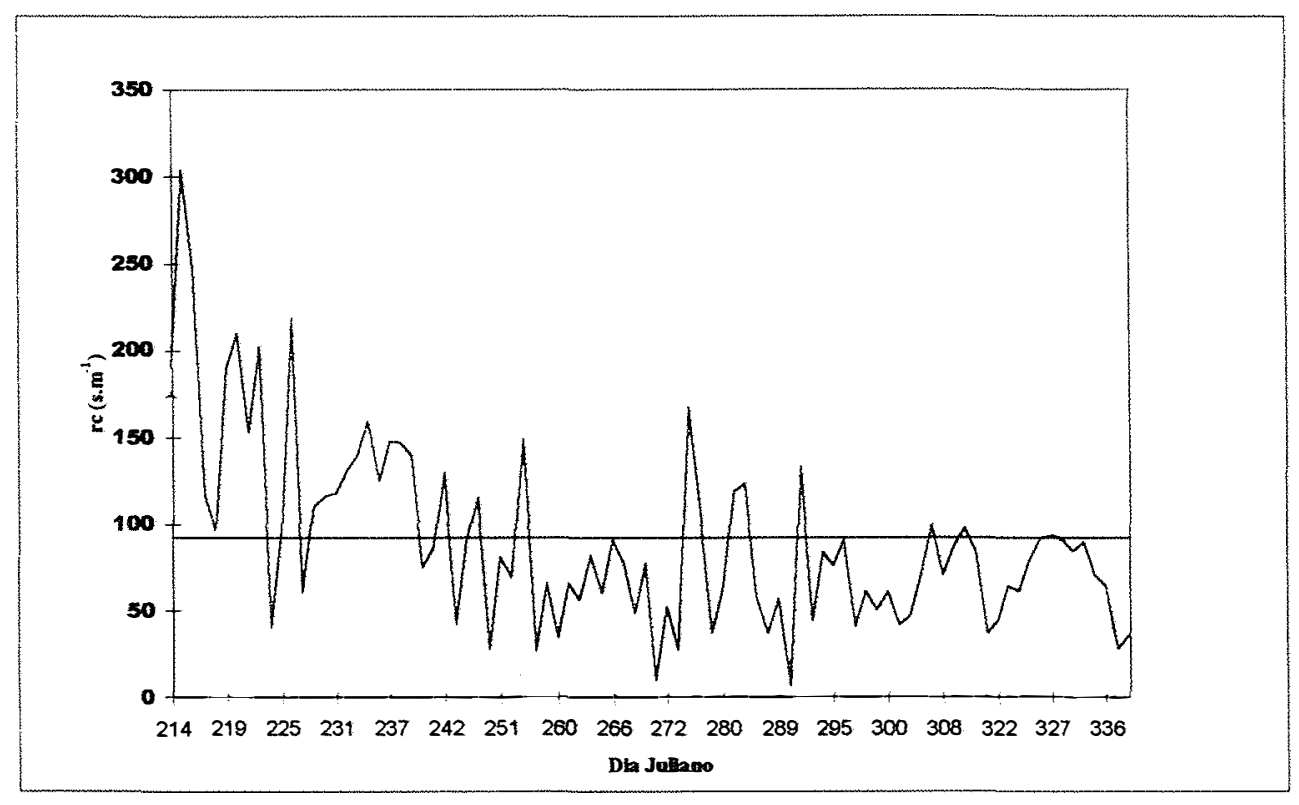

Figura 9 - Resistência do dossel da grama ( $\left.\mathrm{rc}_{\mathrm{res}}\right)$ para o período de luz, estimada como valor residual do modelo de Penman-Monteith ao longo do período experimental. 
Trabalhando em uma escala de tempo menor, com instrumentos de medida de melhor resolução, e medindo-se todos os elementos meteorológicos envolvidos no processo evapotranspirativo, Maggiotto (1996) encontrou valores de $\mathrm{rc}_{\mathrm{res}}$ variando de 146 a $496 \mathrm{s.m} \mathrm{m}^{-1}$, com média de $256 \mathrm{s.m} \mathrm{m}^{-1}$. Apesar da variação acentuada entre os resultados de Maggiotto (1996) e os encontrados neste trabalho, verificou-se uma maior consistência no valor médio de $92 \mathrm{s.m}^{-1}$, tendo em vista o excelente desempenho do modelo de Penman-Monteith no período de luz quando adotou-se a resistência de dossel de 80 s. $\mathrm{m}^{-1}$.

\subsection{2- Resistência do dossel durante o período de 24 horas}

Para o período de 24 horas, os valores estimados para a resistência do dossel, apresentaram uma menor amplitude que os observados durante o de luz, com valor médio da ordem de $41 \mathrm{~s} . \mathrm{m}^{-1}$, Figura 10.

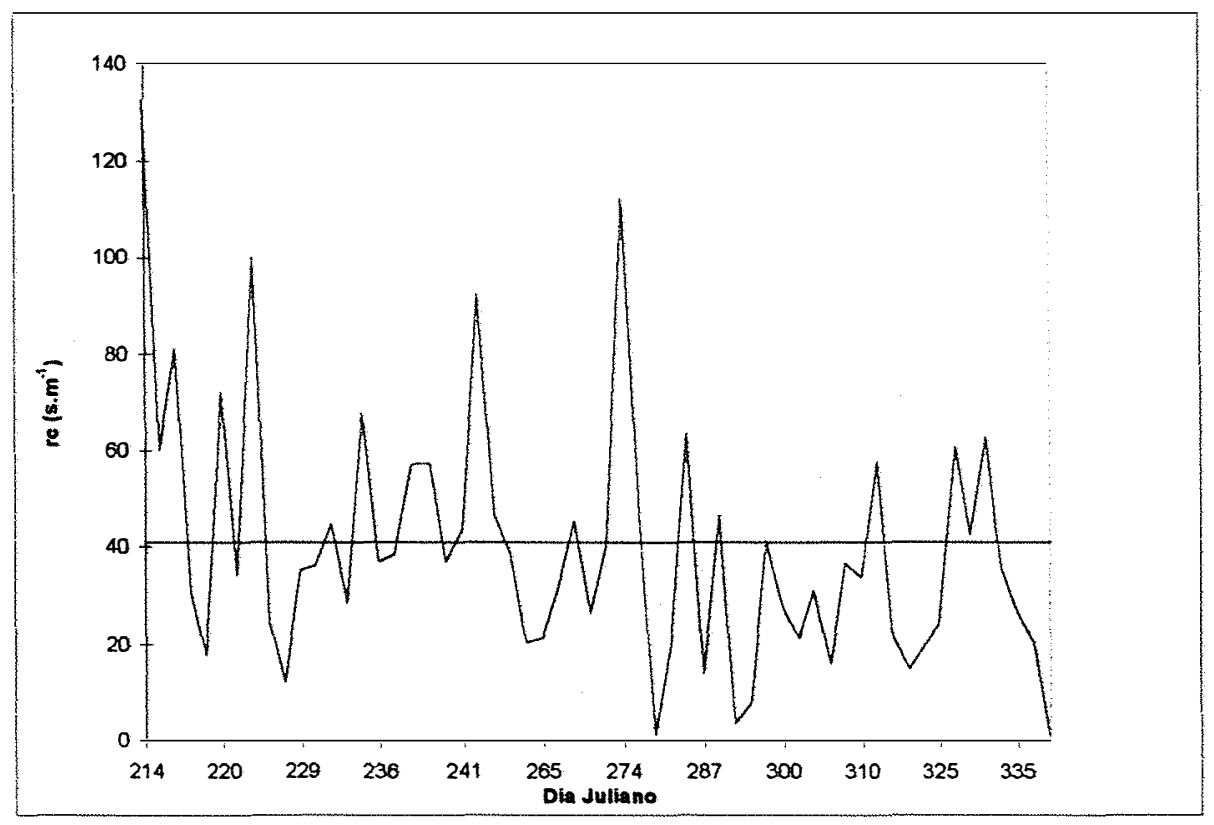

Figura 10 - Resistência do dossel da grama ( $\left(\mathrm{rc}_{\mathrm{res}}\right)$ para o período de 24 horas, estimada como valor residual do modelo de Penman-Monteith ao longo do período experimental. 
Este resultado aproxima-se dos valores propostos por Monteith (1985) e Hatfield (1988), que indicam as resistências de 20 e $50 \mathrm{s.m}^{-1}$,como as que melhor representam uma situação de evapotranspiração potencial. Esta situação fica evidenciada, quando se avalia o desempenho do modelo de Penman-Monteith, para o período de 24 horas, utilizando-se a resistência do dossel média de $40 \mathrm{~s} \cdot \mathrm{m}^{-1}$.

Analisando-se a Figura 11, constatou-se que o desempenho do modelo durante as 24 horas, melhora sensivelmente, em relação a adoção dos valores de rc de 69 e 80 s.m $\mathrm{m}^{-1}$, o que pode ser confirmado pelos indicadores de desempenho estatísticos, apresentados na Tabela 4.

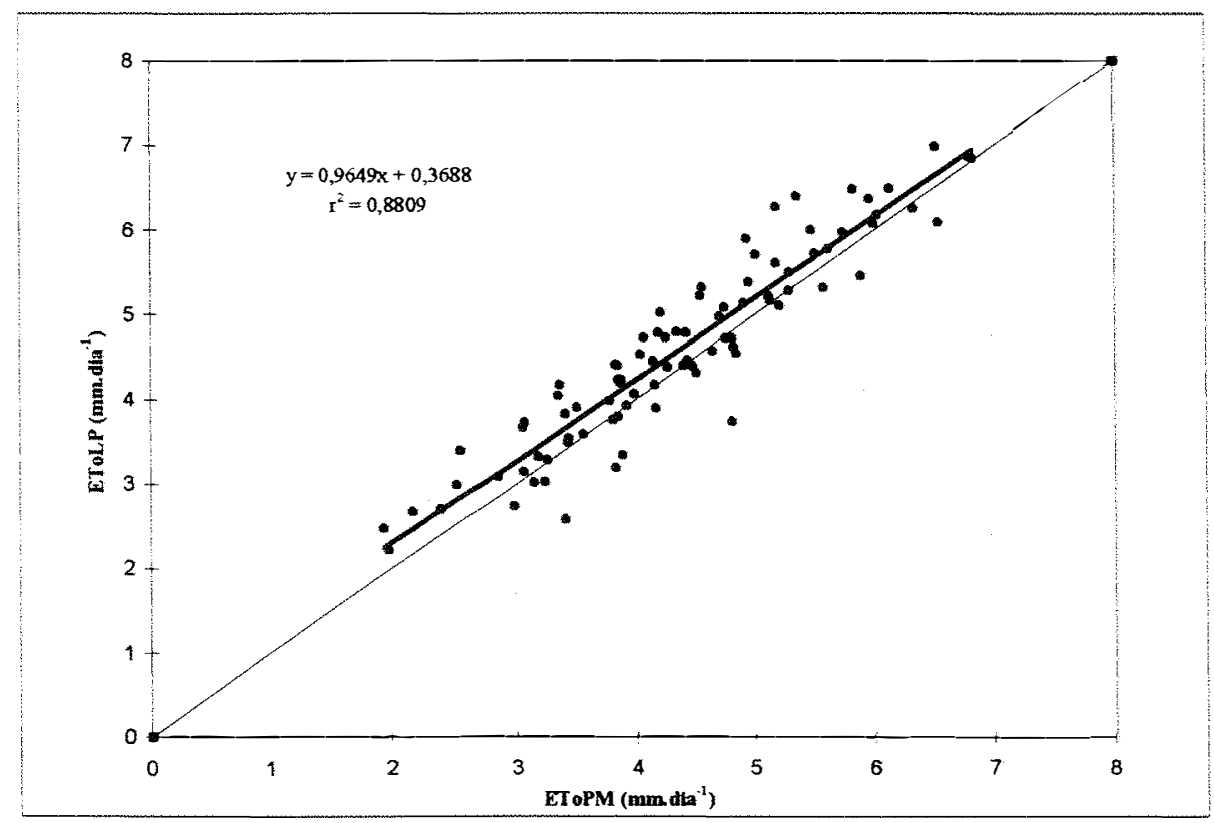

Figura 11 - Evapotranspiração de referência no período de 24 horas, medida no lisímetro de pesagem (EToLP) versus a estimada pelo modelo de Penman-Monteith (EToPM), para a resistência do dossel de $40 \mathrm{~s} \cdot \mathrm{m}^{-1}$. 
Deste modo, o erro médio em subestimar a evapotranspiração situa-se na ordem 4,4\%. Estes resultados, comprovam as afirmações de Allen (1986), Allen et al. (1989), Luchiari Jr. \& Riha (1991), de que uma vez estabelecido o valor da resistência da cobertura vegetal, o modelo de Penman-Monteith tem se apresentado como de melhor desempenho entre os métodos de estimativa da evapotranspiração de referência, para as mais diferentes condições de clima e local.

Tabela 4- Indicadores estatísticos de desempenho para a evapotranspiração medida no lisímetro de pesagem e estimada pelo modelo de Penman-Monteith para o período de 24 horas utilizando dados meteorológicos coletados em uma estação automática.

\begin{tabular}{lcccccc}
\hline & $\begin{array}{c}\text { Média } \\
\text { mm }\end{array}$ & Id & $\begin{array}{c}\text { Es } \\
\mathbf{m m}\end{array}$ & $\begin{array}{c}\text { Eu } \\
\mathbf{m m}\end{array}$ & $\begin{array}{c}\text { MAE } \\
\text { mm }\end{array}$ & $\begin{array}{c}\text { RQEM } \\
\mathbf{m m}\end{array}$ \\
\hline Lisímetro Pesagem & 4,58 & & & & & \\
Penman-Monteith $\left(\mathrm{rc} 40 \mathrm{~s} \mathrm{~m}^{-1}\right)$ & 4,37 & 0,959 & 0,002 & 0,109 & 0,356 & 0,109 \\
\hline
\end{tabular}

\section{6 - Estimativa da evapotranspiração de referência, utilizando os dados meteorológicos, medidos em uma estação convencional.}

Atualmente, no Brasil, a rede de estações meteorológicas de superfície é composta basicamente por estações convencionais, sendo constituída em sua grande maioria, por instrumentos de medida não automatizados. Esta situação, suscitou o interesse de avaliar o desempenho do modelo de Penman-Monteith, utilizando dados coletados por esses instrumentos, em dois horários de medida e estimando a radiação líquida pela metodologia proposta pela FAO.

Avaliando-se a Figura 12, verificou-se que o modelo de Penman-Monteith estimou com pequena margem de erro a evapotranspiração de referência, utilizando a resistência de dossel de $69 \mathrm{~s} . \mathrm{m}^{-1}$. Tomando por base a reta 1:1, verificou-se que o modelo subestima a evapotranspiração de referência em média de $7,8 \%$. Um dos fatores que proporcionaram este desempenho, foi a estimativa adequada da radiação líquida e a 
concordância entre os valores de temperatura e umidade relativa do ar, medidos pelos dois tipos de estação meteorológicas Figuras 13, 14 e 15. A velocidade do vento foi o elemento meteorológico que apresentou maior variação, sobretudo pelo fato que a sua medida, na estação convencional, foi realizada a $10 \mathrm{~m}$ de altura e na automática a $2,0 \mathrm{~m}$. Analisando-se o melhor desempenho do modelo em estimar a ETo, utilizando-se os dados da estação convencional, em relação aos da estação automática, para a resistência de dossel de $69 \mathrm{~s} . \mathrm{m}^{-1}$, verificou-se que estes resultados encontram-se associados a uma superestimativa da radiação líquida, temperatura e a umidade relativa do ar e a uma subestimativa da velocidade do vento. Entretanto, foi adotando-se a resistência de dossel $40 \mathrm{~s} . \mathrm{m}^{-1}$, que o modelo apresentou o seu melhor desempenho.

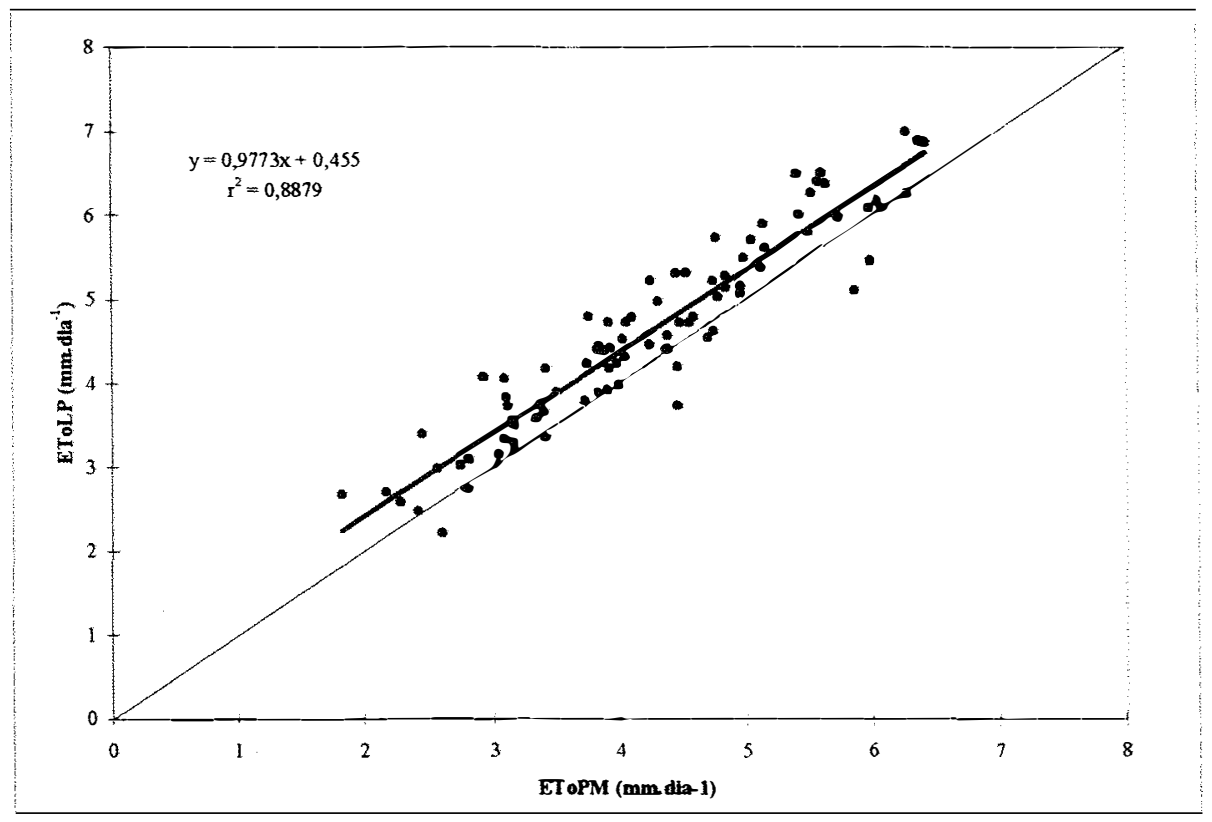

Figura 12 - Evapotranspiração de referência no período de 24 horas, medida no lisímetro de pesagem (EToLP) versus a estimada pelo modelo de Penman-Monteith (EToPM), para a resistência do dossel de 69 s.m $\mathrm{m}^{-1}$ utilizando dados medidos em uma estação meteorológica convencional. 


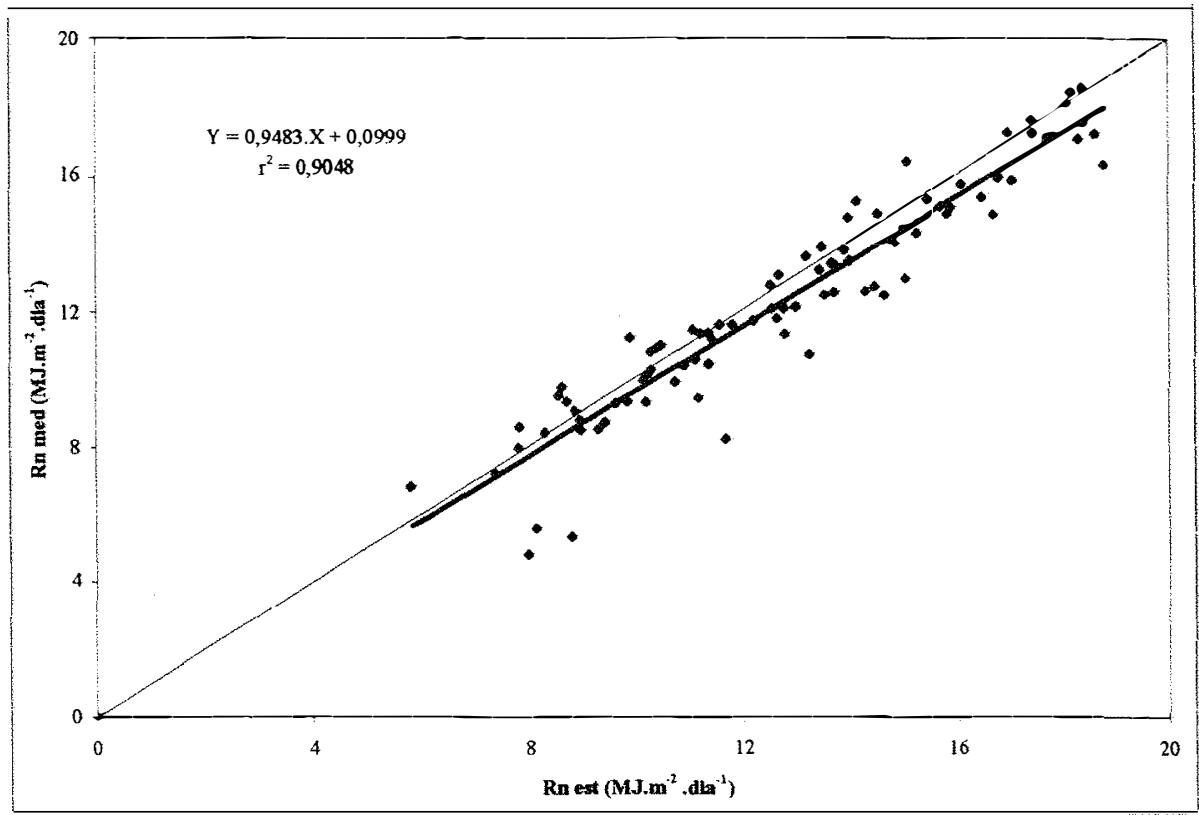

Figura 13- Relação entre a radiação líquida medida por um radiômetro líquido $\mathrm{Rn}$ med (MJ m ${ }^{-2}$ dia $^{-1}$ ) e estimada $\mathrm{Rn}$ est $\left(\mathrm{MJ} \mathrm{m}^{-2} \mathrm{dia}^{-1}\right)$ conforme parametrização proposta pela FAO.

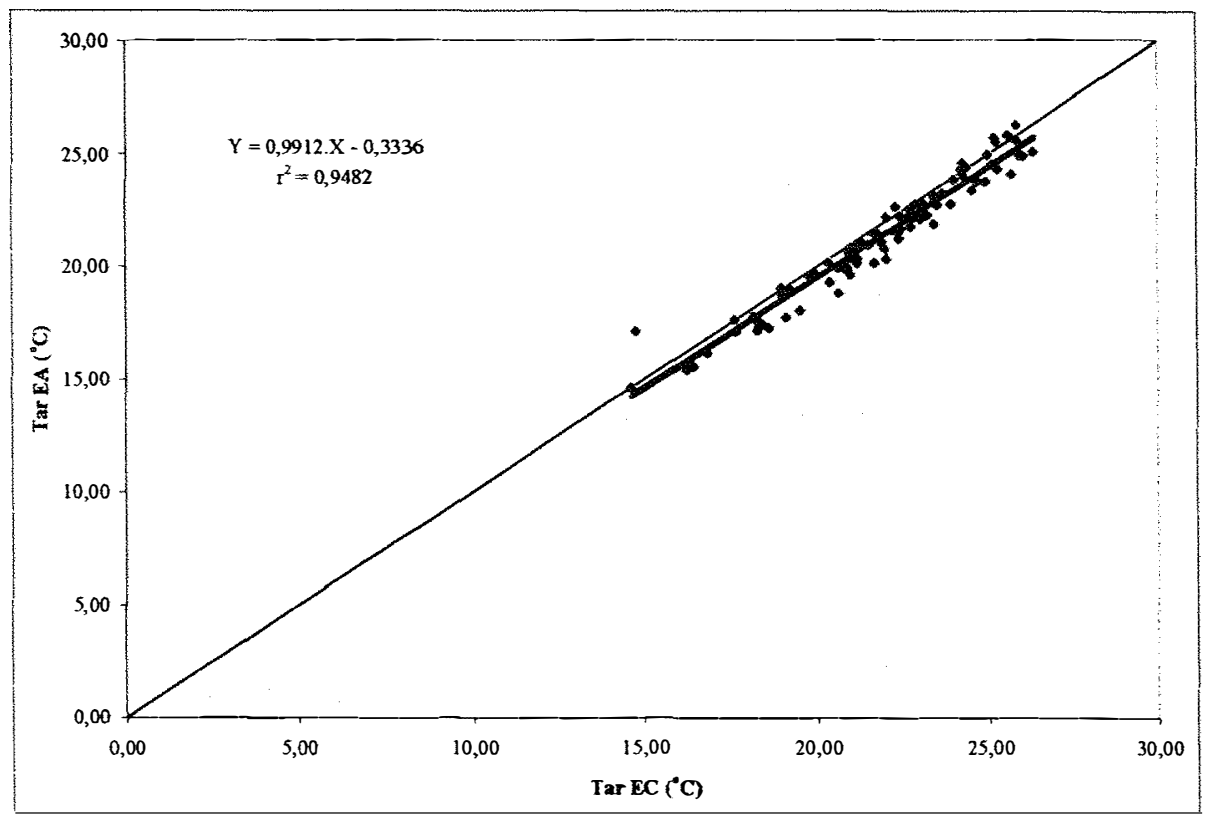

Figura 14- Relação entre a temperatura do ar medida em uma estação meteorológica automática Tar EA $\left({ }^{\circ} \mathrm{C}\right)$ e em uma estação convencional Tar EC $\left({ }^{\circ} \mathrm{C}\right)$. 


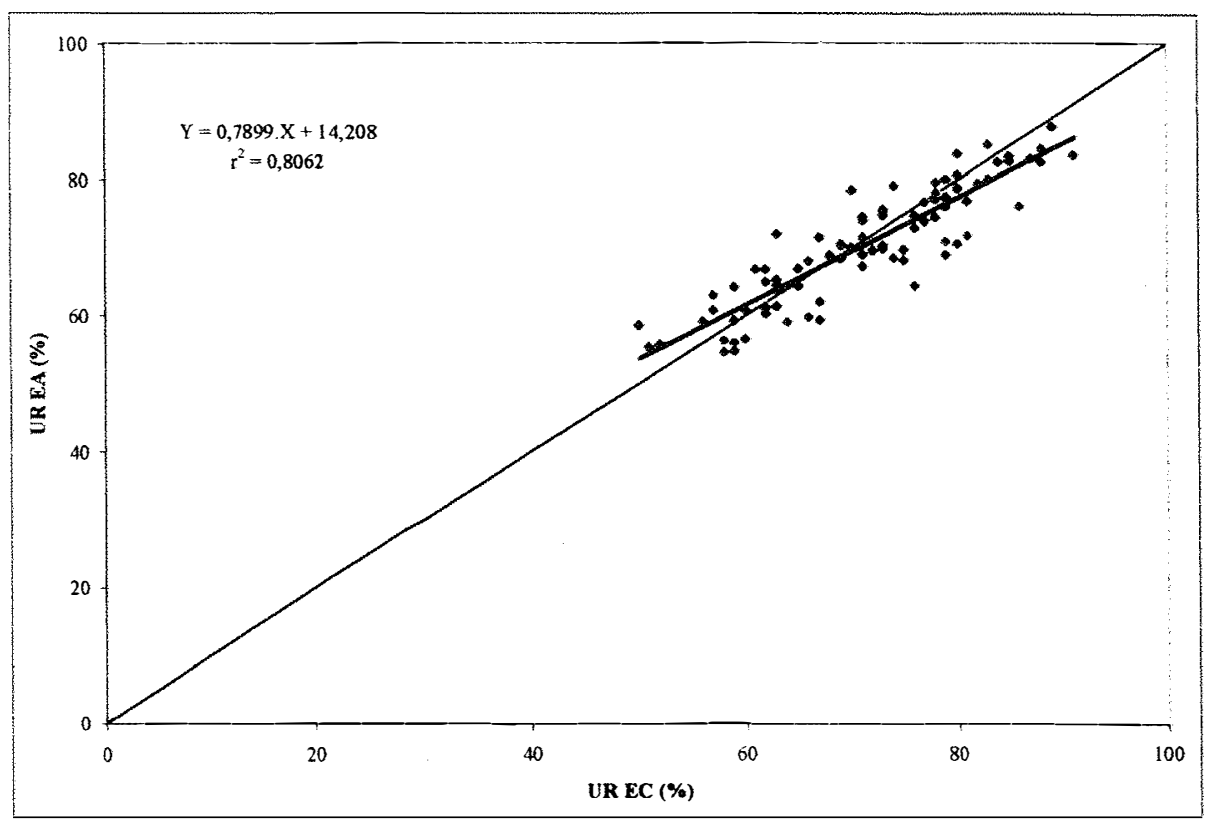

Figura 15- Relação entre a umidade relativa do ar mediada em uma estação meteorológica automática UR EA (\%) e em uma estação convencional UR EC (\%).

Avaliando-se a Figura 16 e a Tabela 5, verificou-se que a estimativa média do erro, em subestimar a evapotranspiração de referência situa-se em torno de $1,2 \%$. Este resultado evidencia que a resistência do dossel de $40 \mathrm{s.m} \mathrm{m}^{-1}$, representa melhor a resistência da cultura da grama à transferência de vapor de água para a atmosfera, durante o período de 24 horas. 
Tabela 5- Indicadores estatísticos de desempenho para a evapotranspiração medida no lisímetro de pesagem e estimada pelo modelo de Penman-Monteith para o período de 24 horas utilizando dados meteorológicos de uma estação convencional com a velocidade do vento corrigida para 2 metros.

\begin{tabular}{lcccccc}
\hline & $\begin{array}{c}\text { Média } \\
\text { mm }\end{array}$ & Id & $\begin{array}{c}\text { Es } \\
\text { mm }\end{array}$ & $\begin{array}{c}\text { Eu } \\
\text { mm }\end{array}$ & $\begin{array}{c}\text { MAE } \\
\text { mm }\end{array}$ & $\begin{array}{c}\text { RQEM } \\
\text { mm }\end{array}$ \\
\hline Lisimetro Pesagem & 4,58 & & & & & \\
Penman-Monteith (rc 69 s.m s. $\left.^{-1}\right)$ & 4,23 & 0,945 & 0,015 & 0,418 & 0,430 & 0,600 \\
Penman-Monteith (rc 40 s.m s. $\left.^{-1}\right)$ & 4,50 & 0,964 & 0,000 & 0,045 & 0,331 & 0,334 \\
\hline
\end{tabular}

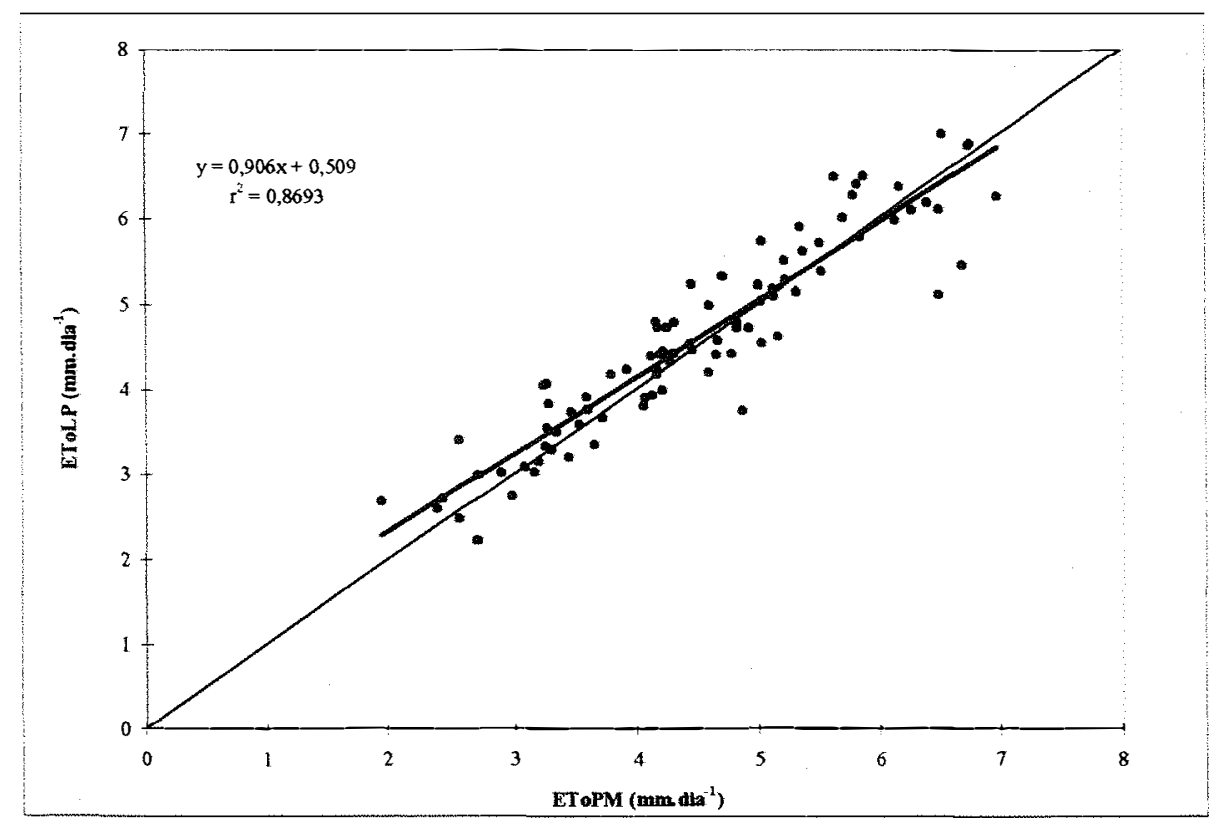

Figura 16 - Evapotranspiração de referência no período de 24 horas, medida no lisímetro de pesagem (EToLP) versus a estimada pelo modelo de Penman-Monteith

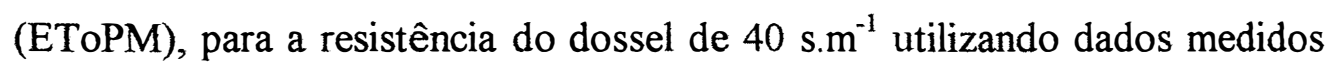
em uma estação meteorológica convencional. 


\section{7 - Evapotranspiração de referência estimada por meio da evaporação do tanque}

Classe A, utilizando diferentes modelos de coeficiente de tanque.

Devido a sua praticidade, baixo custo de aquisição e manutenção, o tanque Classe A é amplamente utilizado na estimativa da evapotranspiração de referência, em programas de planejamento e manejo da irrigação. Desta maneira, procurou-se avaliar a relação de dependência do coeficiente do tanque $(\mathrm{Kp})$ com os dados meteorológicos, visando adequar as medidas de evaporação às estimativas mais confiáveis de ETo.

Avaliando-se o coeficiente do tanque proposto por Pereira et al. (1995), para a estimativa da evapotranspiração de referência, a partir da evaporação do tanque Classe $\mathrm{A}$ em relação a um lisímetro de pesagem, apresentado na Figura 17, verificou-se que o Kp utilizado promoveu um ajuste bastante satisfatório, com um erro médio relativo da ordem de $0,08 \%$ em subestimar a ETo. A mesma tendência não foi verificada, com o Kp FAO, utilizando a da equação ajustada por Snyder (1992). A adoção do Kp FAO, conforme pode ser observado pela Figura 18, superestimou a evapotranspiração de referência em média de $15 \%$. Esta tendência em superestimar a ETo, utilizando o modelo FAO, também foi encontrada por Amorim et al. (1997), avaliando o utilização de diferentes modelos de coeficiente do tanque Classe A, na estimativa de ETo em Viçosa- MG. Os resultado encontrados por Amorim et al. (1997) permitiram hierarquizar sequencialmente os seguintes modelos por ordem de desempenho: Frevert et al. (1983), Snyder (1992), Cuenca (1989) e Pereira et al. (1995) respectivamente . Entretanto, os autores concluem que todos os modelos de coeficiente de tanque (Kp) estudados, permitiram uma conversão satisfatoria dos dados de evaporação do tanque Classe A em evapotranspiração de referência. 


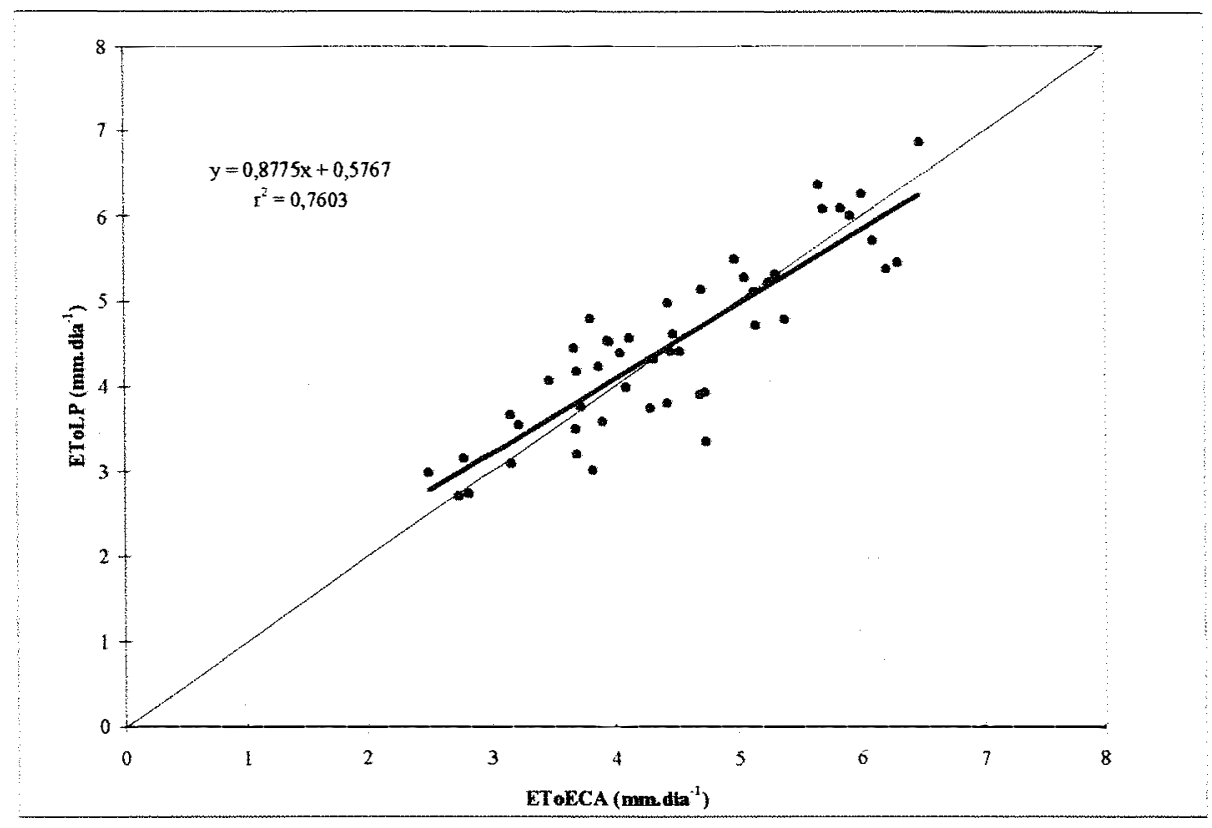

Figura 17- Evapotranspiração de referência no período de 24 horas, medida no lisímetro de pesagem (EToLP) versus a estimada pelo tanque Classe A (EToECA), utilizando o Kp proposto por Pereira et al. (1995).

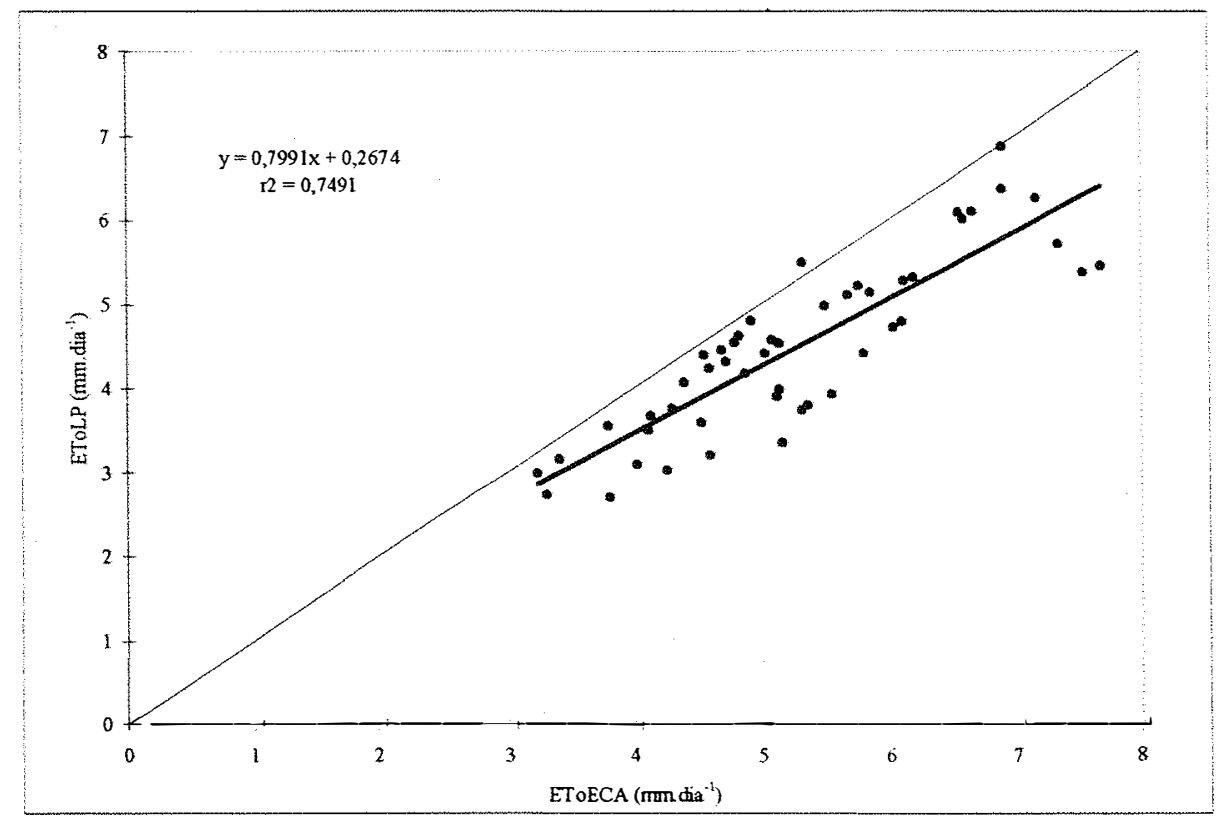

Figura 18- Evapotranspiração de referência no período de 24 horas, medida no lisímetro de pesagem (EToLP) versus a estimada pelo tanque Classe A (EToECA), utilizando o Kp proposto pela FAO (1977). 
Avaliando-se os indicadores de desempenho estatísticos apresentados na Tabela 6, verificou-se que o modelo de Kp proposto por Pereira et al. (1995), além de apresentar excelente desempenho, é o que possibilita a obtenção de menores erros sistemáticos e não sistemáticos de estimativa.

Tabela 6- Indicadores estatísticos de desempenho para a evapotranspiração medida no lisímetro de pesagem e estimada pela evaporação do tanque classe, para diferentes valores de Kp.

\begin{tabular}{lcccccc}
\hline & $\begin{array}{c}\text { Média } \\
\text { mm }\end{array}$ & Id & $\begin{array}{c}\text { Es } \\
\mathbf{m m}\end{array}$ & $\begin{array}{c}\text { Eu } \\
\mathbf{m m}\end{array}$ & $\begin{array}{c}\text { MAE } \\
\mathbf{m m}\end{array}$ & $\begin{array}{c}\text { RQEM } \\
\mathbf{m m}\end{array}$ \\
\hline Lisímetro Pesagem & 4,48 & & & & & \\
EToKp (Pereira et al.1995 ) & 4,45 & 0,933 & 0,062 & 0,000 & 0,419 & 0,062 \\
ETo Kp FAO & 5,27 & 0,818 & 0,068 & 0,457 & 0,799 & 0,462 \\
\hline
\end{tabular}

Estudando a relação de dependência do coeficiente do tanque Classe $\mathrm{A}(\mathrm{Kp})$ com os elementos meteorológicos, verificou-se um decréscimo do $\mathrm{Kp}$ com o aumento da velocidade do vento. Este efeito é evidenciado sobretudo na metodologia proposta por Pereira et al. (1995), onde pequenas variações na velocidade do vento, para uma mesma temperatura, provocam alterações significativas no valor do coeficiente do tanque, devido principalmente ao efeito linear que a relação $\mathbf{r c} / \mathbf{r a}$ assume com a velocidade do vento. Dessa maneira, as resistências de dossel e aerodinâmica, expressas na relação $\mathbf{r c / r a}$, substituiu com vantagens a natureza e tamanho da área tampão sugeridos por Doorenbos \& Pruitt (1977).

4.8- Estimativa da evapotranspiração de referência, a partir da evaporação de um atmômetro modificado SEEI.

Analisando-se a Figura 19, verificou-se que o atmômetro modificado estimou a evapotranspiração de referência medida no lisímetro de pesagem, satisfatoriamente para 
o agrupamento de dados diários. Estes resultados poderiam apresentar uma menor dispersão, se a escala de medida do atmômetro fosse mais precisa. Isto fica evidenciado, avaliando-se a Figura 19, onde vários valores do lisímetro correspondem a um único valor do atmômetro. Pereira (1997), trabalhando com atmômetros SEEI, utilizando dois tipos de escala de leitura, verificou que o efeito da mesma é significativo para períodos de tempo de 1 a 2 dias. Para períodos de tempo maiores ou iguais a três dias, a evaporação medida no atmômetro modificado com escala de leitura comercial, apresenta precisão equivalente ao que utiliza escala de leitura ampliada.

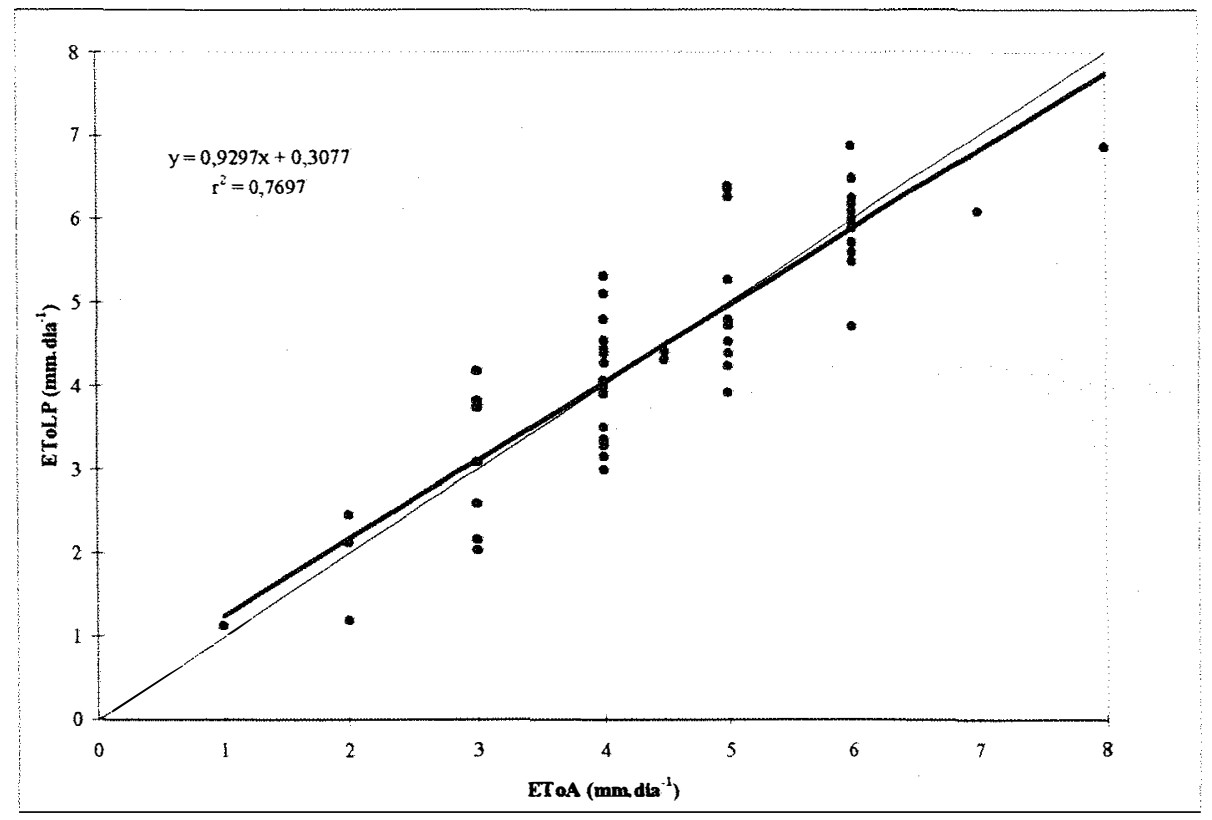

Figura 19- Evapotranspiração de referência no período de 24 horas, medida no lisímetro de pesagem (EToLP) versus a estimada pelo atmômetro modificado SEEI (EToA).

Entretanto, avaliando-se os indicadores estatísticos apresentados na Tabela 7, verificou-se que média entre os valores medidos e estimados de ETo, são praticamente coincidentes, com um elevado coeficiente de concordância Willmont aliado a um erro sistemático não mensurável e a erro não sistemático de pequeno valor. 
Tabela 7 - Indicadores estatísticos de desempenho para a evapotranspiração medida no lisímetro de pesagem e estimada pela atmômetro modificado SEEI em base diária.

\begin{tabular}{lcccccc}
\hline & $\begin{array}{c}\text { Média } \\
\mathbf{m m}\end{array}$ & Id & $\begin{array}{c}\text { Es } \\
\mathbf{m m}\end{array}$ & $\begin{array}{c}\text { Eu } \\
\mathbf{m m}\end{array}$ & $\begin{array}{c}\text { MAE } \\
\mathbf{m m}\end{array}$ & $\begin{array}{c}\text { RQEM } \\
\mathbf{m m}\end{array}$ \\
\hline $\begin{array}{l}\text { Lisímetro Pesagem } \\
\text { EToA }\end{array}$ & 4,50 & & & & & \\
\hline
\end{tabular}

De uma maneira geral, pode-se verificar que o agrupamento dos dados em períodos de três e cinco dias, possibilitaram uma melhor correlação entre os valores medidos e estimados, em função do amaciamento das flutuações diárias, Figuras 20 e 21.

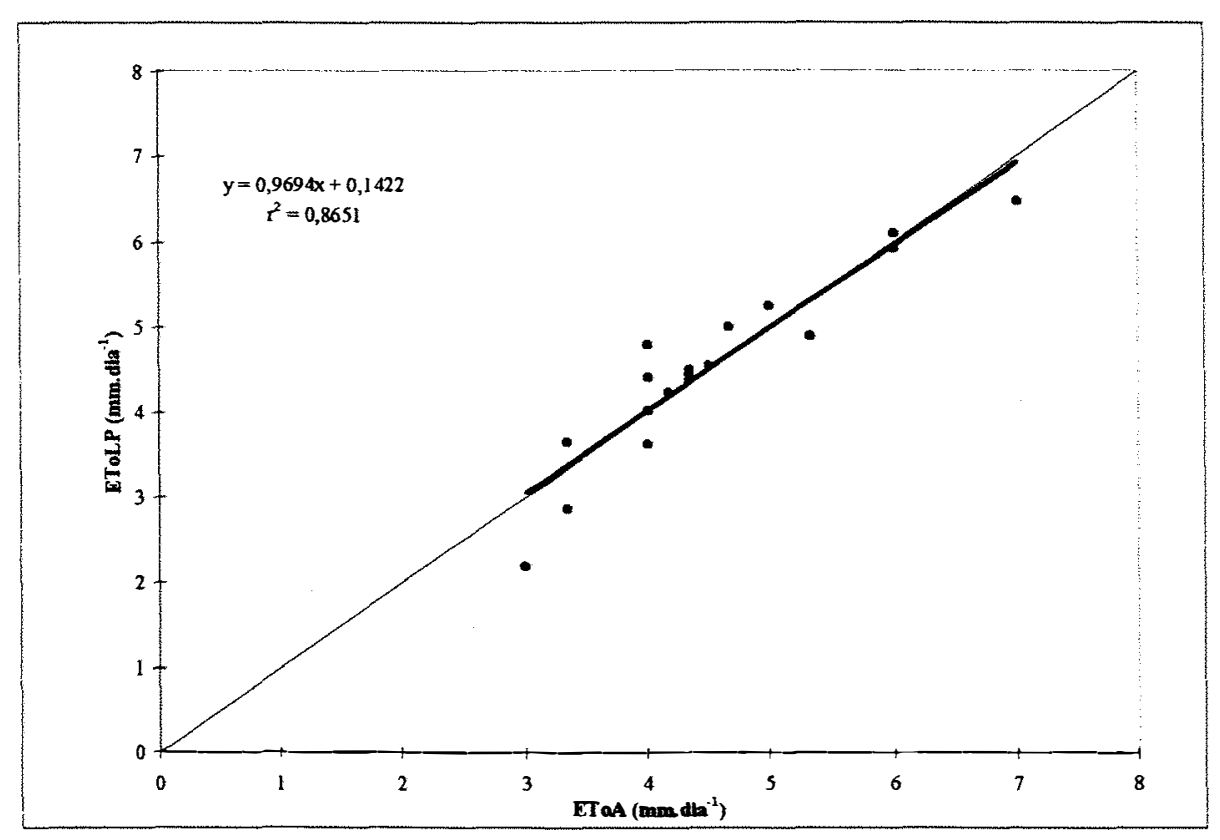

Figura 20- Evapotranspiração de referência no período de 24 horas, medida no lisímetro de pesagem (EToLP) versus a estimada pelo atmômetro modificado SEEI (EToA), com agrupamento dos dados em períodos de três dias. 


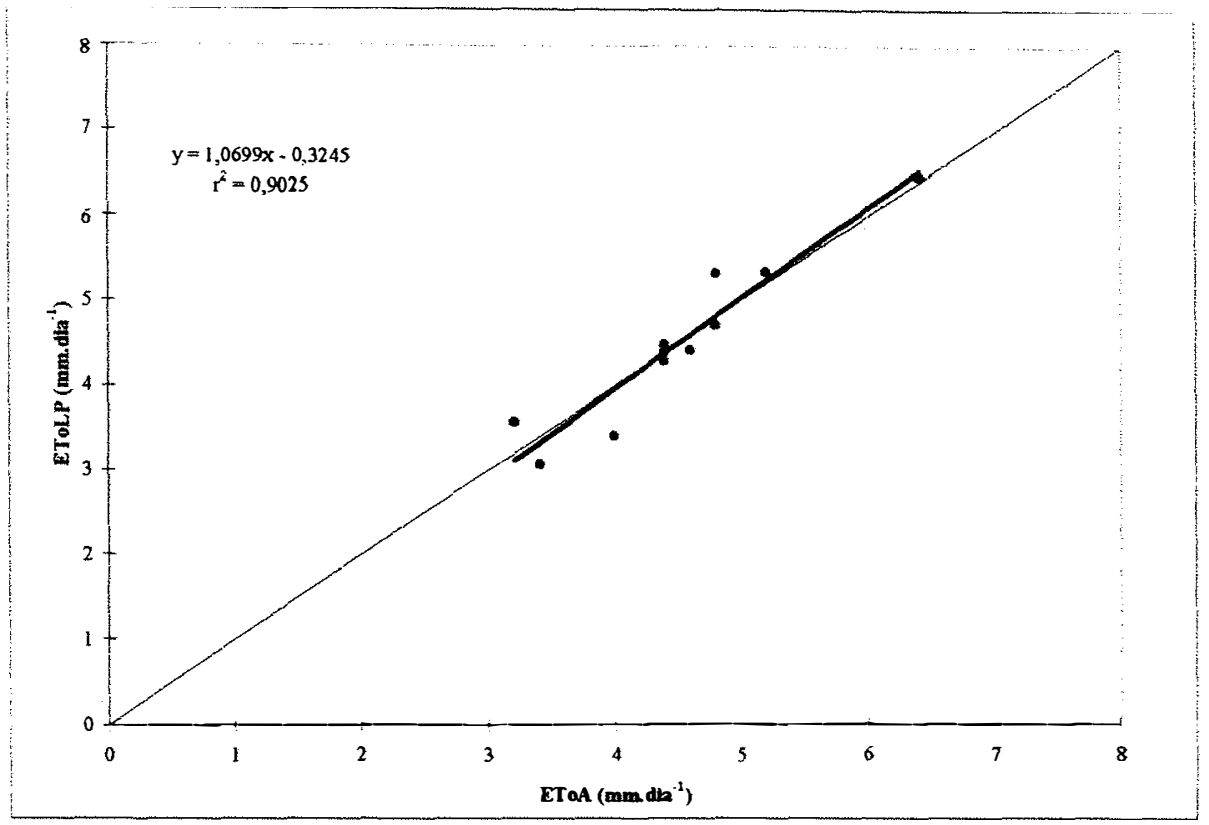

Figura 21 - Evapotranspiração de referência no período de 24 horas, medida no lisímetro de pesagem (EToLP) versus a estimada pelo atmômetro modificado SEEI (EToA), com agrupamento dos dados em períodos de cinco dias.

A análise conjunta das Figuras 20 e 21 com as Tabelas 8 e 9 evidenciam que $o$ desempenho do atmomêtro modificado SEEI melhora sensivelmente, com o agrupamento dos dados em períodos de tempo igual ou superior a três dias. Esta mesma tendência, também foi verificada por Pereira (1997), ao correlacionar a evapotranspiração estimada pelo atmômetro com o modelo de Penman-Monteith e a evaporação do tanque Classe A. 
Tabela 8 - Indicadores estatísticos de desempenho para a evapotranspiração medida no lisímetro de pesagem e estimada pela atmômetro modificado SEEI média de três dias.

\begin{tabular}{lcccccc}
\hline & $\begin{array}{c}\text { Média } \\
\mathbf{m m}\end{array}$ & Id & $\begin{array}{c}\text { Es } \\
\mathbf{m m}\end{array}$ & $\begin{array}{c}\text { Eu } \\
\mathbf{m m}\end{array}$ & $\begin{array}{c}\text { MAE } \\
\mathbf{m m}\end{array}$ & $\begin{array}{c}\text { RQEM } \\
\mathbf{m m}\end{array}$ \\
\hline $\begin{array}{l}\text { Lisímetro Pesagem } \\
\text { EToA }\end{array}$ & $\begin{array}{c}4,52 \\
4,52\end{array}$ & 0,964 & 0,000 & 0,020 & 0,299 & 0,020 \\
\hline
\end{tabular}

Tabela 9 - Indicadores estatísticos de desempenho para a evapotranspiração medida no lisímetro de pesagem e estimada pela atmômetro modificado SEEI média de cinco dias.

\begin{tabular}{lcccccc}
\hline & $\begin{array}{c}\text { Média } \\
\mathbf{m m}\end{array}$ & Id & $\begin{array}{c}\text { Es } \\
\mathbf{m m}\end{array}$ & $\begin{array}{c}\text { Eu } \\
\mathbf{m m}\end{array}$ & $\begin{array}{c}\text { MAE } \\
\mathbf{m m}\end{array}$ & $\begin{array}{c}\text { RQEM } \\
\mathbf{m m}\end{array}$ \\
\hline Lisímetro Pesagem & 4.50 & & & & & \\
EToA & 4,51 & 0,971 & 0,000 & 0,012 & 0,227 & 0,012 \\
\hline
\end{tabular}

Estes resultados diferem dos obtidos por Erthal (1994), que não encontrou correlação significativa na comparação entre os valores do atmômetro modificado com aqueles de um evapotranspirômetro de drenagem, devido possivelmente, à problemas de ordem operacional neste tipo de lisímetro.

Deve-se ressaltar, que frente aos resultados obtidos com esse evaporímetro e dada a sensibilidade e resolução do lisímetro de pesagem, que o atmômetro modificado pode ser utilizado com boa margem de segurança, quando se deseja utilizá-lo na estimativa de ETo, visando o manejo da irrigação. 


\section{CONCLUSÕES}

Com base nas informações coletadas e analisadas neste trabalho de pesquisa foram estabelecidas as seguintes conclusões:

a) aproximadamente $85 \%$ do total de perda de água no sistema solo-planta, ocorreu no período de luz (radiação líquida positiva);

b) o modelo de Penman-Monteith apresentou excelente desempenho na estimativa da evapotranspiração de referência no período de luz, com um erro médio em superestimar a evapotranspiração da ordem de $0,65 \%$, adotando-se a resistência do dossel de 80 s.m $\mathrm{m}^{-1}$;

c) o modelo de Penman-Monteith subestima a evapotranspiração de referência no período de 24 horas, na ordem de 12 a $15 \%$, para os valores de resistência do dossel de 69 e $80{\mathrm{~s} . \mathrm{m}^{-1}}^{-1}$, respectivamente;

d) a resistência do dossel da grama, estimada como resíduo da utilização do modelo de Penman-Monteith, apresentou um valor médio de $92 \mathrm{~s} . \mathrm{m}^{-1}$ para o período de luz e $41 \mathrm{~s} . \mathrm{m}^{-1}$ para o período de 24 horas;

e) o melhor desempenho do modelo de Penman-Monteith, entre os valores medidos e estimados da evapotranspiração de referência no período de 24 horas, foi 
obtido quando se utilizou a resistência de dossel de $40 \mathrm{s.m} \mathrm{m}^{-1}$, com um erro médio da ordem de $4,4 \%$ em subestimar a ETo;

f) a utilização de dados meteorológicos de uma estação convencional não alterou o desempenho do modelo de Penman-Monteith no período de 24 horas, adotando-se a resistência de dossel de $40 \mathrm{~s} . \mathrm{m}^{-1}$.

g) o emprego do coeficiente de tanque (Kp), proposto por Pereira et al. (1995) para estimativa da evapotranspiração de referência a partir da evaporação do tanque classe A, possibilitou uma boa correlação e uma excelente concordância em relação as medidas efetuadas no lisímetro de pesagem, com um erro médio relativo da ordem de 0,08\% em subestimar a ETo;

h) o atmômetro modificado apresentou uma excelente concordância com a evapotranspiração de referência, medida em um lisímetro de pesagem, para o agrupamento dos dados em períodos de tempo igual ou superior a três dias, em função do amaciamento das flutuações diárias. 
ANEXOS 
Tabela 10 -Dados meteorológicos médios, para o período de 24 horas medidos em estação meteorológica automática e no lisímetro de pesagem.

\begin{tabular}{|c|c|c|c|c|c|c|}
\hline Data & $\begin{array}{c}\mathbf{R n} \\
\mathrm{MJ} \mathrm{m}^{-2} \\
\end{array}$ & $\begin{array}{c}\mathbf{G} \\
\mathbf{M J ~ \mathbf { m } ^ { - 2 }} \\
\end{array}$ & $\begin{array}{c}\mathbf{T} \\
{ }^{\circ} \mathrm{C} \\
\end{array}$ & $\begin{array}{l}\text { UR } \\
\% \\
\end{array}$ & $\begin{array}{c}\mathrm{U} \\
\mathrm{m} \mathrm{s}^{-1}\end{array}$ & $\begin{array}{c}\text { EToLP } \\
\text { mm dia }\end{array}$ \\
\hline $01 / 08 / 96$ & 8,55 & $-0,08$ & 17,15 & 67,45 & 2,42 & 2,59 \\
\hline $02 / 08 / 96$ & 9,46 & 0,01 & 15,47 & 61,23 & 1,23 & 3,02 \\
\hline 03/08/96 & 9,29 & 0,10 & 15,62 & 68,16 & 1,36 & 2,74 \\
\hline 04/08/96 & 9,72 & 0,41 & 17,22 & 63,17 & 1,55 & 4,05 \\
\hline 05/08/96 & 9,03 & 0,11 & 17,63 & 59,41 & 1,61 & 3,50 \\
\hline 06/08/96 & 8,75 & 0,10 & 17,34 & 60,46 & 1,38 & 3,33 \\
\hline $07 / 08 / 96$ & 8,48 & 0,32 & 18,76 & 59,90 & 1,49 & 3,03 \\
\hline $08 / 08 / 96$ & 8,46 & 0,39 & 20,19 & 62,17 & 1,50 & 3,29 \\
\hline 09/08/96 & 7,19 & 0,14 & 22,25 & 54,77 & 2,22 & 3,35 \\
\hline $11 / 08 / 96$ & 6,80 & 0,29 & 17,33 & 83,50 & 2,05 & 2,68 \\
\hline $12 / 08 / 96$ & 8,38 & 0,42 & 18,08 & 83,93 & 1,93 & 2,99 \\
\hline $13 / 08 / 96$ & 9,92 & 0,47 & 19,99 & 80,16 & 1,47 & 3,15 \\
\hline $15 / 08 / 96$ & 8,69 & 0,05 & 17,81 & 80,17 & 2,08 & 3,09 \\
\hline $16 / 08 / 96$ & 10,21 & $-0,48$ & 14,64 & 64,60 & 3,13 & 4,07 \\
\hline $17 / 08 / 96$ & 10,74 & 0,07 & 16,20 & 70,13 & 1,55 & 3,83 \\
\hline $18 / 08 / 96$ & 10,85 & 0,14 & 17,15 & 67,12 & 1,52 & 3,59 \\
\hline $19 / 08 / 96$ & 11,16 & 0,13 & 17,85 & 65,41 & 1,65 & 3,76 \\
\hline $21 / 08 / 96$ & 10,92 & 0,19 & 19,57 & 59,28 & 1,98 & 4,39 \\
\hline $22 / 08 / 96$ & 10,12 & 0,31 & 20,64 & 56,07 & 1,85 & 3,90 \\
\hline $23 / 08 / 96$ & 10,52 & 0,29 & 20,87 & 59,24 & 1,81 & 4,18 \\
\hline $24 / 08 / 96$ & 11,39 & 0,21 & 20,52 & 61,00 & 1,98 & 4,41 \\
\hline $25 / 08 / 96$ & 11,26 & 0,22 & 20,92 & 56,68 & 1,87 & 4,32 \\
\hline $26 / 08 / 96$ & 11,12 & 0,29 & 22,75 & 54,90 & 2,07 & 4,62 \\
\hline $27 / 08 / 96$ & 10,36 & 0,44 & 24,06 & 56,46 & 1,80 & 4,46 \\
\hline $28 / 08 / 96$ & 9,41 & 0,35 & 21,95 & 70,75 & 2,66 & 3,80 \\
\hline 29/08/96 & 9,24 & 0,26 & 20,83 & 72,03 & 3,12 & 3,20 \\
\hline $30 / 08 / 96$ & 10,39 & 0,46 & 22,80 & 68,28 & 1,73 & 4,24 \\
\hline $31 / 08 / 96$ & 11,29 & 0,03 & 24,34 & 58,67 & 2,51 & 5,11 \\
\hline 02/09/96 & 11,54 & 0,13 & 20,21 & 70,65 & 1,61 & 3,93 \\
\hline 04/09/96 & 7,94 & 0,25 & 19,70 & 80,25 & 1,40 & 3,40 \\
\hline $07 / 09 / 96$ & 13,00 & 0,41 & 19,10 & 74,88 & 1,86 & 4,73 \\
\hline $12 / 09 / 96$ & 9,28 & 0,25 & 17,68 & 79,75 & 2,69 & 3,73 \\
\hline $13 / 09 / 96$ & 12,42 & 0,77 & 19,68 & 78,92 & 2,10 & 3,99 \\
\hline $14 / 09 / 96$ & 13,35 & 0,64 & 20,73 & 76,95 & 1,94 & 4,79 \\
\hline $15 / 09 / 96$ & 13,57 & 0,51 & 21,02 & 74,73 & 1,48 & 4,73 \\
\hline $17 / 09 / 96$ & 9,85 & $-0,11$ & 18,86 & 80,86 & 2,94 & 4,18 \\
\hline 18/09/96 & 12,70 & $-0,07$ & 17,50 & 73,07 & 3,13 & 4,80 \\
\hline $19 / 09 / 96$ & 13,84 & 0,40 & 19,93 & 69,02 & 1,78 & 5,23 \\
\hline $20 / 09 / 96$ & 13,29 & 0,46 & 21,14 & 66,94 & 1,44 & 4,79 \\
\hline $22 / 09 / 95$ & 13,14 & 0,37 & 23,89 & 55,51 & 1,86 & 5,50 \\
\hline 23/09/96 & 12,48 & 0,46 & 24,64 & 59,83 & 2,08 & 5,22 \\
\hline $24 / 09 / 96$ & 11,25 & 0,30 & 23,44 & 68,71 & 2,40 & 4,40 \\
\hline
\end{tabular}


$\frac{\text { Continuação }}{\text { Data }}$

\begin{tabular}{|c|c|c|c|c|c|c|}
\hline Data & $\begin{array}{c}\mathbf{R n} \\
\mathbf{M J ~ m ^ { - 2 }}\end{array}$ & $\begin{array}{c}\mathbf{G} \\
\mathbf{M J} \mathbf{~ m}^{-2}\end{array}$ & $\begin{array}{c}\mathrm{T} \\
{ }^{\circ} \mathrm{C}\end{array}$ & $\begin{array}{l}\text { UR } \\
\%\end{array}$ & $\begin{array}{c}\mathrm{U} \\
\mathrm{m} \mathrm{s}^{-1}\end{array}$ & $\begin{array}{c}\text { EToLP } \\
\text { mm dia }^{-1}\end{array}$ \\
\hline 26/09/96 & 13,75 & 0,26 & 22,18 & 74,25 & 2,95 & 5,14 \\
\hline 27/09/96 & 13,42 & 0,14 & 22,83 & 69,19 & 3,13 & 5,28 \\
\hline $28 / 09 / 96$ & 4,79 & $-0,26$ & 20,23 & 82,86 & 1,93 & 2,48 \\
\hline 29/09/96 & 11,68 & 0,33 & 22,32 & 75,83 & 1,57 & 4,24 \\
\hline $30 / 09 / 96$ & 13,96 & 0,13 & 22,34 & 71,78 & 2,48 & 5,71 \\
\hline 01/10/96 & 12,07 & $-0,16$ & 20,43 & 68,96 & 3,25 & 3,74 \\
\hline $04 / 10 / 96$ & 15,20 & 0,44 & 21,10 & 79,22 & 1,86 & 4,57 \\
\hline $07 / 10 / 96$ & 12,53 & 0,24 & 20,39 & 84,70 & 2,78 & 4,42 \\
\hline $08 / 10 / 96$ & 12,01 & 0,23 & 20,41 & 77,07 & 2,94 & 4,45 \\
\hline 09/10/96 & 14,27 & 0,47 & 22,32 & 74,09 & 2,36 & 4,54 \\
\hline $11 / 10 / 96$ & 12,67 & 0,59 & 23,84 & 85,29 & 1,58 & 4,20 \\
\hline $15 / 10 / 96$ & 10,67 & $-0,05$ & 19,35 & 74,71 & 3,41 & 4,53 \\
\hline $16 / 10 / 96$ & 14,38 & 0,45 & 19,96 & 74,90 & 2,14 & 5,32 \\
\hline $17 / 10 / 96$ & 15,82 & 0,67 & 22,73 & 75,50 & 1,45 & 5,90 \\
\hline $18 / 10 / 96$ & 14,79 & 0,74 & 25,05 & 70,38 & 1,91 & 6,27 \\
\hline $19 / 10 / 96$ & 12,02 & 0,29 & 24,99 & 69,87 & 2,51 & 4,72 \\
\hline $21 / 10 / 96$ & 8,19 & $-0,18$ & 21,30 & 83,15 & 3,02 & 3,67 \\
\hline $22 / 10 / 96$ & 15,31 & 0,71 & 22,81 & 77,65 & 1,55 & 5,09 \\
\hline $23 / 10 / 96$ & 14,75 & 0,61 & 24,37 & 77,31 & 2,27 & 5,38 \\
\hline $24 / 10 / 96$ & 12,40 & $-0,10$ & 21,70 & 71,17 & 2,84 & 4,72 \\
\hline $28 / 10 / 96$ & 12,92 & 0,34 & 22,21 & 78,56 & 1,94 & 5,03 \\
\hline $29 / 10 / 96$ & 15,25 & 0,44 & 23,31 & 66,92 & 1,49 & 5,61 \\
\hline $30 / 10 / 96$ & 14,95 & 0,42 & 24,47 & 63,97 & 1,82 & 6,01 \\
\hline $31 / 10 / 96$ & 15,81 & 0,42 & 25,80 & 61,40 & 1,95 & 6,18 \\
\hline $04 / 11 / 96$ & 11,72 & 0,25 & 22,23 & 82,68 & 2,51 & 4,41 \\
\hline $05 / 11 / 96$ & 17,03 & 0,32 & 21,82 & 69,79 & 3,01 & 6,37 \\
\hline 06/11/96 & 17,58 & 0,57 & 23,17 & 70,07 & 1,92 & 6,49 \\
\hline $07 / 11 / 96$ & 18,08 & 0,60 & 25,03 & 71,58 & 1,65 & 6,09 \\
\hline $08 / 11 / 96$ & 15,72 & 0,33 & 26,34 & 64,50 & 2,30 & 6,50 \\
\hline 09/11/96 & 18,40 & 0,29 & 25,68 & 60,95 & 1,98 & 6,86 \\
\hline $10 / 11 / 96$ & 17,22 & 0,10 & 25,59 & 55,87 & 2,04 & 6,88 \\
\hline $11 / 11 / 96$ & 14,70 & 0,34 & 25,15 & 69,15 & 2,50 & 5,32 \\
\hline $12 / 11 / 96$ & 9,30 & 0,04 & 24,15 & 76,35 & 1,64 & 3,55 \\
\hline $22 / 11 / 96$ & 5,56 & $-0,30$ & 19,04 & 83,72 & 3,79 & 2,71 \\
\hline $23 / 11 / 96$ & 14,82 & 0,34 & 20,40 & 76,25 & 2,22 & 4,98 \\
\hline $24 / 11 / 96$ & 17,07 & 0,34 & 21,48 & 72,05 & 1,47 & 6,40 \\
\hline $25 / 11 / 96$ & 17,16 & 0,42 & 22,46 & 70,52 & 2,17 & 5,98 \\
\hline 26/11/96 & 16,27 & 0,13 & 21,50 & 68,59 & 3,16 & 5,46 \\
\hline $27 / 11 / 96$ & 17,01 & 0,21 & 21,68 & 64,75 & 3,20 & 6,26 \\
\hline $28 / 11 / 96$ & 17,51 & 0,33 & 22,81 & 61,48 & 2,65 & 6,10 \\
\hline 29/11/96 & 14,97 & 0,22 & 22,71 & 65,05 & 1,44 & 5,17 \\
\hline $30 / 11 / 96$ & 5,31 & $-0,22$ & 21,12 & 82,70 & 1,40 & 2,22 \\
\hline $05 / 12 / 96$ & 17,20 & 0,36 & 24,60 & 78,20 & 2,01 & 5,78 \\
\hline $06 / 12 / 96$ & 16,35 & $-0,28$ & 24,98 & 79,64 & 1,89 & 5,73 \\
\hline $08 / 12 / 96$ & 11,54 & 0,35 & 23,82 & 87,89 & 1,28 & 3,91 \\
\hline $09 / 12 / 96$ & 18,55 & 0,51 & 25,89 & 64,36 & 1,66 & 6,99 \\
\hline
\end{tabular}


Tabela 11 - Dados meteorológicos médios, para o período de luz, medidos em estação meteorologica automática e no lisímetro de pesagem.

\begin{tabular}{|c|c|c|c|c|c|c|}
\hline Data & 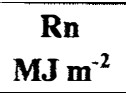 & $\begin{array}{c}\mathbf{G} \\
\mathbf{M J} \mathbf{m}^{-2}\end{array}$ & $\begin{array}{l}\mathrm{T} \\
{ }^{\circ} \mathrm{C}\end{array}$ & $\begin{array}{l}\mathbf{U R} \\
\%\end{array}$ & $\begin{array}{c}\mathrm{U} \\
\mathrm{m} \mathrm{s}^{-1}\end{array}$ & $\begin{array}{c}\text { EToLP } \\
\text { mm pluz }{ }^{-1}\end{array}$ \\
\hline $01 / 08 / 96$ & 9,91 & 0,68 & 20,77 & 57,18 & 2,86 & 2,10 \\
\hline $02 / 08 / 96$ & 10,80 & 0,73 & 19,10 & 48,14 & 1,43 & 2,10 \\
\hline 03/08/96 & 10,15 & 0,71 & 18,79 & 58,05 & 1,42 & 2,05 \\
\hline $04 / 08 / 96$ & 10,92 & 0,91 & 21,25 & 49,70 & 1,86 & 2,89 \\
\hline $05 / 08 / 96$ & 10,45 & 0,74 & 21,55 & 47,99 & 1,85 & 2,99 \\
\hline 06/08/96 & 9,99 & 0,73 & 21,67 & 45,55 & 1,62 & 2,48 \\
\hline 07/08/96 & 9,54 & 0,81 & 22,79 & 44,26 & 1,54 & 2,42 \\
\hline 08/08/96 & 9,49 & 0,81 & 24,15 & 46,90 & 1,60 & 2,68 \\
\hline 09/08/96 & 8,25 & 0,59 & 26,28 & 42,32 & 2,63 & 2,48 \\
\hline $11 / 08 / 96$ & 7,60 & 0,63 & 19,45 & 74,91 & 2,21 & 2,21 \\
\hline $12 / 08 / 96$ & 9,21 & 0,76 & 20,31 & 75,60 & 1,66 & 2,26 \\
\hline $13 / 08 / 96$ & 10,73 & 0,87 & 22,93 & 70,19 & 1,68 & 2,32 \\
\hline $15 / 08 / 96$ & 9,91 & 0,58 & 19,75 & 74,13 & 2,19 & 2,65 \\
\hline $16 / 08 / 96$ & 12,49 & 0,43 & 17,36 & 52,46 & 4,11 & 2,85 \\
\hline $17 / 08 / 96$ & 11,99 & 0,79 & 20,04 & 54,45 & 1,73 & 3,04 \\
\hline $18 / 08 / 96$ & 12,00 & 0,80 & 20,40 & 55,44 & 1,66 & 3,05 \\
\hline $19 / 08 / 96$ & 12,32 & 0,78 & 21,30 & 53,12 & 2,24 & 3,10 \\
\hline $21 / 08 / 96$ & 12,31 & 0,82 & 23,71 & 44,95 & 2,22 & 3,37 \\
\hline $22 / 08 / 96$ & 11,42 & 0,88 & 24,47 & 43,60 & 1,73 & 3,14 \\
\hline $23 / 08 / 96$ & 11,89 & 0,86 & 24,85 & 45,63 & 2,05 & 3,45 \\
\hline $24 / 08 / 96$ & 12,61 & 0,82 & 24,19 & 48,19 & 2,60 & 3,39 \\
\hline $25 / 08 / 96$ & 12,69 & 0,87 & 25,09 & 42,97 & 2,08 & 3,55 \\
\hline $26 / 08 / 96$ & 12,35 & 0,89 & 27,27 & 41,34 & 2,51 & 3,74 \\
\hline $27 / 08 / 96$ & 11,23 & 0,87 & 28,21 & 42,42 & 2,16 & 3,97 \\
\hline $28 / 08 / 96$ & 10,06 & 0,84 & 24,49 & 62,99 & 3,16 & 3,00 \\
\hline 29/08/96 & 10,01 & 0,62 & 23,31 & 62,64 & 3,39 & 2,61 \\
\hline $30 / 08 / 96$ & 11,19 & 0,81 & 25,72 & 57,83 & 2,01 & 3,72 \\
\hline $31 / 08 / 96$ & 12,47 & 0,57 & 27,51 & 45,89 & 3,06 & 4,30 \\
\hline $02 / 09 / 96$ & 12,50 & 0,70 & 23,23 & 59,23 & 1,86 & 3,38 \\
\hline 04/09/96 & 8,67 & 0,53 & 21,50 & 69,60 & 1,70 & 2,72 \\
\hline 07/09/96 & 14,11 & 0,88 & 21,82 & 65,01 & 2,35 & 3,74 \\
\hline $12 / 09 / 96$ & 10,38 & 0,55 & 20,32 & 69,88 & 3,35 & 2,85 \\
\hline $13 / 09 / 96$ & 13,48 & 1,06 & 23,16 & 67,31 & 1,95 & 3,18 \\
\hline 14/09/96 & 14,32 & 0,97 & 23,70 & 64,41 & 1,95 & 4,45 \\
\hline $15 / 09 / 96$ & 14,49 & 0,89 & 23,73 & 61,83 & 1,62 & 4,18 \\
\hline $17 / 09 / 96$ & 10,86 & 0,38 & 21,67 & 70,50 & 3,58 & 3,53 \\
\hline $18 / 09 / 96$ & 14,08 & 0,46 & 20,18 & 63,13 & 3,93 & 3,86 \\
\hline $19 / 09 / 96$ & 15,03 & 0,82 & 22,50 & 59,79 & 2,00 & 4,41 \\
\hline 20/09/96 & 14,28 & 0,92 & 24,39 & 55,98 & 1,59 & 4,14 \\
\hline $22 / 09 / 96$ & 14,39 & 0,79 & 28,14 & 41,67 & 2,02 & 5,02 \\
\hline 23/09/96 & 13,54 & 0,83 & 28,56 & 43,56 & 2,14 & 4,52 \\
\hline $24 / 09 / 96$ & 12,04 & 0,65 & 25,74 & 60,18 & 2,06 & 3,72 \\
\hline
\end{tabular}


Continuação

\begin{tabular}{|c|c|c|c|c|c|c|}
\hline Data & $\begin{array}{c}\mathbf{R n} \\
\mathrm{MJ} \mathrm{m}^{-2}\end{array}$ & $\begin{array}{c}\mathbf{G} \\
\mathrm{MJ} \mathrm{m}^{-2}\end{array}$ & $\begin{array}{c}\mathrm{T} \\
{ }^{\circ} \mathrm{C} \\
\end{array}$ & $\begin{array}{l}\text { UR } \\
\%\end{array}$ & $\begin{array}{c}\mathrm{U} \\
\mathrm{m} \mathrm{s}^{-1}\end{array}$ & $\begin{array}{c}\text { EToLP } \\
\text { mm pluz }{ }^{-1}\end{array}$ \\
\hline $26 / 09 / 96$ & 14,54 & 0,56 & 24,16 & 64,89 & 2,98 & 4,53 \\
\hline 27/09/96 & 14,45 & 0,53 & 25,83 & 57,19 & 3,32 & 4,51 \\
\hline $28 / 09 / 96$ & 5,51 & 0,04 & 21,47 & 76,45 & 2,83 & 2,18 \\
\hline 29/09/96 & 12,38 & 0,61 & 24,54 & 65,88 & 1,83 & 3,83 \\
\hline $30 / 09 / 96$ & 15,00 & 0,59 & 25,23 & 61,86 & 2,30 & 5,03 \\
\hline $01 / 10 / 96$ & 13,63 & 0,46 & 23,30 & 58,40 & 3,44 & 3,13 \\
\hline $04 / 10 / 96$ & 16,05 & 0,85 & 23,48 & 71,01 & 2,42 & 4,00 \\
\hline $07 / 10 / 96$ & 13,54 & 0,64 & 22,72 & 77,61 & 3,24 & 3,97 \\
\hline $08 / 10 / 96$ & 13,14 & 0,64 & 23,16 & 68,84 & 3,38 & 3,84 \\
\hline $09 / 10 / 96$ & 15,20 & 0,79 & 24,41 & 67,12 & 2,38 & 3,92 \\
\hline $11 / 10 / 96$ & 13,27 & 0,87 & 26,26 & 75,04 & 1,72 & 3,52 \\
\hline $15 / 10 / 96$ & 11,81 & 0,47 & 21,21 & 66,28 & 3,38 & 3,53 \\
\hline $16 / 10 / 96$ & 15,51 & 0,94 & 22,60 & 66,31 & 2,25 & 4,62 \\
\hline $17 / 10 / 96$ & 16,62 & 1,07 & 25,91 & 63,48 & 1,63 & 4,96 \\
\hline $18 / 10 / 96$ & 15,63 & 1,14 & 28,17 & 57,31 & 2,11 & 5,64 \\
\hline $19 / 10 / 96$ & 12,65 & 0,81 & 28,74 & 53,92 & 2,37 & 3,89 \\
\hline $21 / 10 / 96$ & 8,96 & 0,28 & 23,06 & 77,62 & 3,33 & 2,91 \\
\hline $22 / 10 / 96$ & 16,23 & 1,08 & 25,27 & 68,75 & 1,52 & 4,55 \\
\hline $23 / 10 / 96$ & 15,41 & 1,08 & 27,22 & 68,53 & 2,03 & 4,55 \\
\hline $24 / 10 / 96$ & 13,42 & 0,52 & 24,40 & 62,76 & 2,83 & 3,91 \\
\hline $28 / 10 / 96$ & 13,87 & 0,72 & 24,10 & 70,95 & 2,19 & 4,24 \\
\hline $29 / 10 / 96$ & 16,16 & 0,88 & 25,63 & 57,33 & 1,51 & 4,97 \\
\hline $30 / 10 / 96$ & 15,86 & 0,90 & 27,58 & 54,70 & 1,86 & 5,23 \\
\hline $31 / 10 / 96$ & 16,59 & 0,90 & 29,12 & 51,10 & 2,23 & 5,58 \\
\hline $04 / 11 / 96$ & 12,46 & 0,63 & 24,03 & 77,01 & 2,85 & 3,77 \\
\hline $05 / 11 / 96$ & 18,14 & 0,88 & 24,55 & 59,28 & 3,22 & 5,71 \\
\hline $06 / 11 / 96$ & 18,58 & 1,06 & 25,84 & 60,27 & 1,96 & 5,50 \\
\hline $07 / 11 / 96$ & 18,68 & 1,03 & 27,90 & 60,07 & 2,11 & 5,45 \\
\hline 08/11/96 & 16,49 & 0,84 & 28,97 & 54,89 & 2,34 & 5,43 \\
\hline $09 / 11 / 96$ & 19,29 & 0,87 & 28,66 & 49,83 & 2,51 & 6,14 \\
\hline $10 / 11 / 96$ & 18,12 & 0,78 & 29,68 & 42,47 & 2,41 & 5,96 \\
\hline $11 / 11 / 96$ & 15,12 & 0,77 & 26,89 & 63,21 & 2,78 & 4,59 \\
\hline $12 / 11 / 96$ & 9,72 & 0,44 & 25,93 & 70,03 & 1,83 & 3,30 \\
\hline $22 / 11 / 96$ & 6,20 & 0,04 & 19,91 & 82,35 & 4,25 & 2,05 \\
\hline $23 / 11 / 96$ & 15,94 & 0,71 & 22,69 & 68,12 & 2,40 & 4,50 \\
\hline $24 / 11 / 96$ & 18,04 & 0,81 & 24,37 & 58,51 & 1,68 & 5,39 \\
\hline $25 / 11 / 96$ & 18,36 & 0,86 & 25,30 & 57,46 & 2,03 & 5,37 \\
\hline $26 / 11 / 96$ & 17,97 & 0,67 & 24,03 & 59,46 & 3,25 & 4,97 \\
\hline $27 / 11 / 96$ & 18,68 & 0,74 & 24,88 & 51,28 & 3,47 & 5,37 \\
\hline $28 / 11 / 96$ & 19,03 & 0,79 & 25,57 & 51,02 & 2,76 & 5,59 \\
\hline $29 / 11 / 96$ & 16,01 & 0,69 & 25,18 & 54,11 & 1,52 & 4,85 \\
\hline $30 / 11 / 96$ & 5,93 & 0,11 & 22,25 & 77,22 & 1,55 & 1,78 \\
\hline $05 / 12 / 96$ & 17,71 & 0,61 & 26,89 & 67,03 & 2,61 & 5,34 \\
\hline $06 / 12 / 96$ & 16,80 & 0,21 & 26,86 & 71,24 & 2,57 & 5,20 \\
\hline $08 / 12 / 96$ & 12,07 & 0,73 & 25,72 & 80,13 & 1,49 & 3,70 \\
\hline $09 / 12 / 96$ & 19,25 & 0,99 & 28,27 & 55,26 & 1,69 & 6,42 \\
\hline
\end{tabular}


Tabela 12 - Dados meteorológicos médios, para o período de 24 horas, estimados e medidos em um estação meteorologica convencional.

\begin{tabular}{|c|c|c|c|c|}
\hline Data & $\begin{array}{c}\text { Rn } \\
M^{\prime} \mathbf{~ m}^{-2}\end{array}$ & $\begin{array}{l}\mathrm{T} \\
{ }^{\circ} \mathrm{C}\end{array}$ & $\begin{array}{l}\text { UR } \\
\%\end{array}$ & $\begin{array}{c}\mathrm{U} \\
\mathrm{m} \mathrm{s}^{-1}\end{array}$ \\
\hline $01 / 08 / 96$ & 7,83 & 14,80 & 71,00 & 1,31 \\
\hline $02 / 08 / 96$ & 8,60 & 16,25 & 62,00 & 1,44 \\
\hline 03/08/96 & 8,75 & 16,45 & 66,00 & 1,78 \\
\hline $04 / 08 / 96$ & 8,66 & 18,30 & 57,00 & 1,64 \\
\hline 05/08/96 & 8,90 & 18,30 & 59,00 & 1,83 \\
\hline 06/08/96 & 8,98 & 18,35 & 62,00 & 1,75 \\
\hline 07/08/96 & 9,33 & 19,05 & 66,00 & 1,39 \\
\hline 08/08/96 & 9,00 & 21,70 & 67,00 & 1,61 \\
\hline 09/08/96 & 7,35 & 22,05 & 58,00 & 2,67 \\
\hline $11 / 08 / 96$ & 5,82 & 18,65 & 85,00 & 2,22 \\
\hline $12 / 08 / 96$ & 8,33 & 19,55 & 80,00 & 1,81 \\
\hline $13 / 08 / 96$ & 10,17 & 20,90 & 83,00 & 1,83 \\
\hline $15 / 08 / 96$ & 9,46 & 19,15 & 83,00 & 3,25 \\
\hline $16 / 08 / 96$ & 10,30 & 14,65 & 76,00 & 3,64 \\
\hline $17 / 08 / 96$ & 10,30 & 16,85 & 70,00 & 1,75 \\
\hline $18 / 08 / 96$ & 10,42 & 17,70 & 65,00 & 1,86 \\
\hline $19 / 08 / 96$ & 9,92 & 18,20 & 63,00 & 2,11 \\
\hline $21 / 08 / 96$ & 10,49 & 19,85 & 56,00 & 2,17 \\
\hline $22 / 08 / 96$ & 10,25 & 20,95 & 59,00 & 2,19 \\
\hline $23 / 08 / 96$ & 11,12 & 21,10 & 64,00 & 2,25 \\
\hline $24 / 08 / 96$ & 11,08 & 21,10 & 60,00 & 3,42 \\
\hline $25 / 08 / 96$ & 11,22 & 21,00 & 60,00 & 2,17 \\
\hline $26 / 08 / 96$ & 11,43 & 23,05 & 59,00 & 3,47 \\
\hline $27 / 08 / 96$ & 10,92 & 24,30 & 58,00 & 2,00 \\
\hline $28 / 08 / 96$ & 11,18 & 23,45 & 80,00 & 3,69 \\
\hline $29 / 08 / 96$ & 9,66 & 22,00 & 81,00 & 3,36 \\
\hline $30 / 08 / 96$ & 11,36 & 23,55 & 75,00 & 1,81 \\
\hline $31 / 08 / 96$ & 11,36 & 24,20 & 50,00 & 4,81 \\
\hline 02/09/96 & 11,81 & 21,20 & 69,00 & 2,08 \\
\hline 04/09/96 & 7,81 & 20,00 & 79,00 & 1,56 \\
\hline 07/09/96 & 12,69 & 19,00 & 73,00 & 2,97 \\
\hline $12 / 09 / 96$ & 10,23 & 17,65 & 78,00 & 3,89 \\
\hline $13 / 09 / 96$ & 13,54 & 21,00 & 80,00 & 2,00 \\
\hline $14 / 09 / 96$ & 13,66 & 21,10 & 77,00 & 1,78 \\
\hline $15 / 09 / 96$ & 13,20 & 21,55 & 71,00 & 1,06 \\
\hline $17 / 09 / 96$ & 10,75 & 20,65 & 80,00 & 4,19 \\
\hline $18 / 09 / 96$ & 12,54 & 18,45 & 76,00 & 3,75 \\
\hline 19/09/96 & 13,48 & 20,85 & 68,00 & 1,67 \\
\hline 20/09/96 & 13,72 & 21,35 & 61,00 & 1,86 \\
\hline $22 / 09 / 96$ & 13,44 & 24,00 & 51,00 & 1,75 \\
\hline 23/09/96 & 13,71 & 24,25 & 67,00 & 2,14 \\
\hline $24 / 09 / 96$ & 12,79 & 24,55 & 74,00 & 2,64 \\
\hline
\end{tabular}




\begin{tabular}{|c|c|c|c|c|}
\hline Data & $\begin{array}{c}\mathrm{Rn} \\
\mathrm{MJ} \mathbf{~ m}^{-2}\end{array}$ & $\begin{array}{c}\mathrm{T} \\
{ }^{\circ} \mathrm{C}\end{array}$ & $\begin{array}{l}\text { UR } \\
\%\end{array}$ & $\begin{array}{c}U \\
\mathrm{~m} \mathrm{~s}^{-1}\end{array}$ \\
\hline $26 / 09 / 96$ & 13,90 & 23,05 & 71,00 & 4,00 \\
\hline $27 / 09 / 96$ & 14,00 & 23,95 & 71,00 & 3,19 \\
\hline 28/09/96 & 8,01 & 20,35 & 85,00 & 2,11 \\
\hline 29/09/96 & 12,20 & 22,95 & 73,00 & 1,78 \\
\hline $30 / 09 / 96$ & 14,84 & 23,25 & 71,00 & 3,72 \\
\hline $01 / 10 / 96$ & 13,00 & 21,00 & 68,00 & 3,42 \\
\hline $04 / 10 / 96$ & 14,13 & 21,30 & 74,00 & 2,39 \\
\hline $07 / 10 / 96$ & 14,30 & 22,05 & 88,00 & 3,89 \\
\hline $08 / 10 / 96$ & 12,78 & 21,05 & 81,00 & 3,89 \\
\hline 09/10/96 & 15,27 & 22,45 & 77,00 & 2,69 \\
\hline $11 / 10 / 96$ & 14,47 & 24,95 & 83,00 & 1,25 \\
\hline $15 / 10 / 96$ & 13,25 & 20,40 & 78,00 & 3,83 \\
\hline $16 / 10 / 96$ & 15,00 & 20,65 & 76,00 & 2,06 \\
\hline $17 / 10 / 96$ & 16,80 & 22,80 & 73,00 & 1,42 \\
\hline $18 / 10 / 96$ & 16,72 & 25,00 & 69,00 & 1,94 \\
\hline $19 / 10 / 96$ & 12,55 & 26,05 & 75,00 & 3,64 \\
\hline $21 / 10 / 96$ & 11,70 & 22,40 & 87,00 & 3,67 \\
\hline $22 / 10 / 96$ & 16,50 & 23,15 & 79,00 & 1,19 \\
\hline $23 / 10 / 96$ & 15,82 & 25,30 & 78,00 & 3,33 \\
\hline $24 / 10 / 96$ & 14,65 & 22,45 & 79,00 & 3,00 \\
\hline $28 / 10 / 96$ & 15,04 & 22,50 & 70,00 & 1,83 \\
\hline 29/10/96 & 15,47 & 23,70 & 62,00 & 1,56 \\
\hline $30 / 10 / 96$ & 15,88 & 24,35 & 63,00 & 2,00 \\
\hline $31 / 10 / 96$ & 17,09 & 25,20 & 62,00 & 2,58 \\
\hline $04 / 11 / 96$ & 12,66 & 22,85 & 84,00 & 3,94 \\
\hline $05 / 11 / 96$ & 17,71 & 22,75 & 72,00 & 3,89 \\
\hline $06 / 11 / 96$ & 17,44 & 23,45 & 73,00 & 1,61 \\
\hline $07 / 11 / 96$ & 18,12 & 25,00 & 67,00 & 2,03 \\
\hline $08 / 11 / 96$ & 16,11 & 25,85 & 65,00 & 2,08 \\
\hline $09 / 11 / 96$ & 18,18 & 25,85 & 57,00 & 2,06 \\
\hline $10 / 11 / 96$ & 16,98 & 25,25 & 52,00 & 2,50 \\
\hline $11 / 11 / 96$ & 13,98 & 26,35 & 79,00 & 1,61 \\
\hline $12 / 11 / 96$ & 9,90 & 25,70 & 86,00 & 1,56 \\
\hline $22 / 11 / 96$ & 8,16 & 19,25 & 91,00 & 4,44 \\
\hline $23 / 11 / 96$ & 14,54 & 21,20 & 79,00 & 2,47 \\
\hline $24 / 11 / 96$ & 17,85 & 21,70 & 63,00 & 1,58 \\
\hline $25 / 11 / 96$ & 18,64 & 22,75 & 73,00 & 2,78 \\
\hline $26 / 11 / 96$ & 18,80 & 21,80 & 69,00 & 4,81 \\
\hline $27 / 11 / 96$ & 18,32 & 22,25 & 63,00 & 4,58 \\
\hline $28 / 11 / 96$ & 18,41 & 22,90 & 63,00 & 2,69 \\
\hline $29 / 11 / 96$ & 15,70 & 22,30 & 62,00 & 1,11 \\
\hline $30 / 11 / 96$ & 8,84 & 21,90 & 88,00 & 1,25 \\
\hline $05 / 12 / 96$ & 17,46 & 25,15 & 78,00 & 2,67 \\
\hline $06 / 12 / 96$ & 15,08 & 25,95 & 82,00 & 2,33 \\
\hline $08 / 12 / 96$ & 11,56 & 24,70 & 89,00 & 0,97 \\
\hline $09 / 12 / 96$ & 18,41 & 25,60 & 59,00 & 1,67 \\
\hline
\end{tabular}


Tabela 13- Valores de evapotranspiração de referência medidos no lisímetro de pesagem e estimados pelo modelo de Penman Monteith utilizando os dados meteorológicos medidos em uma estação automática, para diferentes valores de resistência do dossel no período de 24 horas.

\begin{tabular}{|c|c|c|c|c|}
\hline Data & EToLP (mm) & $\begin{array}{l}\text { EToPM (mm) } \\
\text { rc } 69 \mathrm{~s} \mathrm{~m}^{-1}\end{array}$ & $\begin{array}{l}\text { EToPM (mm) } \\
\text { rc } 80 \mathrm{~s} \mathrm{~m}^{-1}\end{array}$ & $\begin{array}{l}\text { EToPM (mm) } \\
\text { rc } 40 \mathrm{~s} \mathrm{~m}^{-1}\end{array}$ \\
\hline $01 / 08 / 96$ & 2,59 & 3,10 & 3,00 & 3,40 \\
\hline $02 / 08 / 96$ & 3,02 & 2,97 & 2,91 & 3,14 \\
\hline 03/08/96 & 2,74 & 2,81 & 2,75 & 2,98 \\
\hline $04 / 08 / 96$ & 4,05 & 3,14 & 3,07 & 3,35 \\
\hline 05/08/96 & 3,50 & 3,21 & 3,13 & 3,43 \\
\hline 06/08/96 & 3,33 & 3,00 & 2,94 & 3,18 \\
\hline 07/08/96 & 3,03 & 3,05 & 2,99 & 3,24 \\
\hline 08/08/96 & 3,29 & 3,07 & 3,01 & 3,25 \\
\hline 09/08/96 & 3,35 & 3,61 & 3,51 & 3,89 \\
\hline $11 / 08 / 96$ & 2,68 & 2,00 & 1,94 & 2,17 \\
\hline $12 / 08 / 96$ & 2,99 & 2,35 & 2,28 & 2,53 \\
\hline $13 / 08 / 96$ & 3,15 & 2,89 & 2,83 & 3,05 \\
\hline $15 / 08 / 96$ & 3,09 & 2,62 & 2,55 & 2,84 \\
\hline $16 / 08 / 96$ & 4,07 & 3,52 & 3,37 & 3,99 \\
\hline $17 / 08 / 96$ & 3,83 & 3,18 & 3,11 & 3,40 \\
\hline $18 / 08 / 96$ & 3,59 & 3,34 & 3,27 & 3,56 \\
\hline $19 / 08 / 96$ & 3,76 & 3,56 & 3,48 & 3,81 \\
\hline $21 / 08 / 96$ & 4,39 & 3,96 & 3,85 & 4,26 \\
\hline $22 / 08 / 96$ & 3,90 & 3,89 & 3,80 & 4,16 \\
\hline $23 / 08 / 96$ & 4,18 & 3,89 & 3,80 & 4,15 \\
\hline $24 / 08 / 96$ & 4,41 & 4,09 & 3,99 & 4,40 \\
\hline $25 / 08 / 96$ & 4,32 & 4,21 & 4,11 & 4,50 \\
\hline $26 / 08 / 96$ & 4,62 & 4,50 & 4,39 & 4,82 \\
\hline $27 / 08 / 96$ & 4,46 & 4,18 & 4,09 & 4,43 \\
\hline $28 / 08 / 96$ & 3,80 & 3,53 & 3,42 & 3,85 \\
\hline $29 / 08 / 96$ & 3,20 & 3,46 & 3,33 & 3,83 \\
\hline $30 / 08 / 96$ & 4,24 & 3,63 & 3,56 & 3,85 \\
\hline $31 / 08 / 96$ & 5,11 & 4,82 & 4,69 & 5,21 \\
\hline 02/09/96 & 3,93 & 3,69 & 3,61 & 3,92 \\
\hline 04/09/96 & 3,40 & 2,42 & 2,38 & 2,56 \\
\hline 07/09/96 & 4,73 & 3,79 & 3,69 & 4,06 \\
\hline $12 / 09 / 96$ & 3,73 & 2,77 & 2,67 & 3,06 \\
\hline $13 / 09 / 96$ & 3,99 & 3,50 & 3,40 & 3,78 \\
\hline $14 / 09 / 96$ & 4,79 & 3,90 & 3,80 & 4,18 \\
\hline $15 / 09 / 96$ & 4,73 & 4,02 & 3,94 & 4,25 \\
\hline $17 / 09 / 96$ & 4,18 & 3,03 & 2,92 & 3,36 \\
\hline $18 / 09 / 96$ & 4,80 & 3,87 & 3,72 & 4,34 \\
\hline 19/09/96 & 5,23 & 4,25 & 4,15 & 4,54 \\
\hline 20/09/96 & 4,79 & 4,19 & 4,11 & 4,41 \\
\hline $22 / 09 / 96$ & 5,50 & 4,98 & 4,87 & 5,28 \\
\hline $23 / 09 / 96$ & 5,22 & 4,80 & 4,68 & 5,12 \\
\hline $24 / 09 / 96$ & 4,40 & 4,14 & 4,03 & 4,47 \\
\hline
\end{tabular}


Continuação

\begin{tabular}{|c|c|c|c|c|}
\hline & EToLP (mm) & $\begin{array}{l}\text { EToPM (mm) } \\
\operatorname{rc~} 69 \mathrm{~s} \mathrm{~m}^{-1}\end{array}$ & $\begin{array}{l}\text { EToPM (mm) } \\
\text { rc } 80 \mathrm{~s} \mathrm{~m}^{-1}\end{array}$ & $\begin{array}{c}\text { EToPM (mm) } \\
\text { rc } 40 \mathrm{~s} \mathrm{~m}^{-1}\end{array}$ \\
\hline $26 / 09 / 96$ & 5,14 & 4,46 & 4,32 & 4,91 \\
\hline $27 / 09 / 96$ & 5,28 & 4,79 & 4,63 & 5,28 \\
\hline 28/09/96 & 2,48 & 1,81 & 1,77 & 1,94 \\
\hline 29/09/96 & 4,24 & 3,67 & 3,60 & 3,88 \\
\hline $30 / 09 / 96$ & 5,71 & 4,61 & 4,48 & 5,00 \\
\hline $01 / 10 / 96$ & 3,74 & 4,31 & 4,15 & 4,81 \\
\hline $04 / 10 / 96$ & 4,57 & 4,35 & 4,24 & 4,65 \\
\hline 07/10/96 & 4,42 & 3,48 & 3,37 & 3,83 \\
\hline $08 / 10 / 96$ & 4,45 & 3,75 & 3,62 & 4,14 \\
\hline 09/10/96 & 4,54 & 4,48 & 4,35 & 4,84 \\
\hline $11 / 10 / 96$ & 4,20 & 3,68 & 3,61 & 3,87 \\
\hline $15 / 10 / 96$ & 4,53 & 3,59 & 3,45 & 4,03 \\
\hline $16 / 10 / 96$ & 5,32 & 4,21 & 4,09 & 4,55 \\
\hline $17 / 10 / 96$ & 5,90 & 4,69 & 4,60 & 4,93 \\
\hline $18 / 10 / 96$ & 6,27 & 4,88 & 4,77 & 5,17 \\
\hline $19 / 10 / 96$ & 4,72 & 4,46 & 4,34 & 4,81 \\
\hline $21 / 10 / 96$ & 3,67 & 2,76 & 2,67 & 3,05 \\
\hline $22 / 10 / 96$ & 5,09 & 4,50 & 4,41 & 4,74 \\
\hline $23 / 10 / 96$ & 5,38 & 4,61 & 4,50 & 4,95 \\
\hline $24 / 10 / 96$ & 4,72 & 4,32 & 4,18 & 4,75 \\
\hline $28 / 10 / 96$ & 5,03 & 3,94 & 3,84 & 4,21 \\
\hline $29 / 10 / 96$ & 5,61 & 4,92 & 4,83 & 5,17 \\
\hline $30 / 10 / 96$ & 6,01 & 5,16 & 5,05 & 5,47 \\
\hline $31 / 10 / 96$ & 6,18 & 5,68 & 5,56 & 6,02 \\
\hline $04 / 11 / 96$ & 4,41 & 3,54 & 3,43 & 3,84 \\
\hline $05 / 11 / 96$ & 6,37 & 5,40 & 5,22 & 5,96 \\
\hline $06 / 11 / 96$ & 6,49 & 5,46 & 5,34 & 5,82 \\
\hline $07 / 11 / 96$ & 6,09 & 5,69 & 5,58 & 5,99 \\
\hline $08 / 11 / 96$ & 6,50 & 5,73 & 5,60 & 6,13 \\
\hline $09 / 11 / 96$ & 6,86 & 6,42 & 6,28 & 6,82 \\
\hline $10 / 11 / 96$ & 6,88 & 6,38 & 6,24 & 6,79 \\
\hline $11 / 11 / 96$ & 5,32 & 5,17 & 5,04 & 5,57 \\
\hline $12 / 11 / 96$ & 3,55 & 3,25 & 3,19 & 3,43 \\
\hline $22 / 11 / 96$ & 2,71 & 2,11 & 2,02 & 2,40 \\
\hline $23 / 11 / 96$ & 4,98 & 4,34 & 4,22 & 4,70 \\
\hline $24 / 11 / 96$ & 6,40 & 5,08 & 4,98 & 5,35 \\
\hline $25 / 11 / 96$ & 5,98 & 5,34 & 5,20 & 5,74 \\
\hline $26 / 11 / 96$ & 5,46 & 5,32 & 5,13 & 5,89 \\
\hline $27 / 11 / 96$ & 6,26 & 5,71 & 5,50 & 6,32 \\
\hline $28 / 11 / 96$ & 6,10 & 6,00 & 5,82 & 6,53 \\
\hline $29 / 11 / 96$ & 5,17 & 4,88 & 4,80 & 5,13 \\
\hline $30 / 11 / 96$ & 2,22 & 1,88 & 1,85 & 1,98 \\
\hline $05 / 12 / 96$ & 5,78 & 5,27 & 5,15 & 5,61 \\
\hline $06 / 12 / 96$ & 5,73 & 5,19 & 5,08 & 5,50 \\
\hline $08 / 12 / 96$ & 3,91 & 3,36 & 3,30 & 3,50 \\
\hline $09 / 12 / 96$ & 6,99 & 6,19 & 6,07 & 6,51 \\
\hline Média & 4,58 & 4,07 & 3,96 & 4,37 \\
\hline
\end{tabular}


Tabela 14- Valores de evapotranspiração de referência medidos no lisímetro de pesagem e estimados pelo modelo de Penman Monteith utilizando os dados meteorológicos medidos em uma estação automática, para diferentes valores de resistência do dossel no período de luz.

\begin{tabular}{|c|c|c|c|}
\hline Data & EToLP (mm) & $\begin{array}{c}\text { EToPM (mm) } \\
\text { rc } 69 \mathrm{~s} \mathrm{~m}^{-1}\end{array}$ & $\begin{array}{l}\text { EToPM (mm) } \\
\text { rc } 80 \mathrm{~s} \mathrm{~m}^{-1}\end{array}$ \\
\hline $01 / 08 / 96$ & 2,10 & 2,91 & 2,81 \\
\hline $02 / 08 / 96$ & 2,10 & 3,03 & 2,96 \\
\hline 03/08/96 & 2,05 & 2,74 & 2,69 \\
\hline $04 / 08 / 96$ & 2,89 & 3,20 & 3,12 \\
\hline 05/08/96 & 2,99 & 3,17 & 3,10 \\
\hline 06/08/96 & 2,48 & 3,06 & 3,00 \\
\hline 07/08/96 & 2,42 & 3,03 & 2,97 \\
\hline 08/08/96 & 2,68 & 3,08 & 3,02 \\
\hline $09 / 08 / 96$ & 2,48 & 3,31 & 3,22 \\
\hline $11 / 08 / 96$ & 2,21 & 2,04 & 1,98 \\
\hline $12 / 08 / 96$ & 2,26 & 2,39 & 2,34 \\
\hline $13 / 08 / 96$ & 2,32 & 2,98 & 2,92 \\
\hline $15 / 08 / 96$ & 2,65 & 2,60 & 2,52 \\
\hline $16 / 08 / 96$ & 2,85 & 3,39 & 3,23 \\
\hline $17 / 08 / 96$ & 3,04 & 3,35 & 3,27 \\
\hline $18 / 08 / 96$ & 3,05 & 3,36 & 3,29 \\
\hline $19 / 08 / 96$ & 3,10 & 3,60 & 3,50 \\
\hline $21 / 08 / 96$ & 3,37 & 3,94 & 3,84 \\
\hline $22 / 08 / 96$ & 3,14 & 3,67 & 3,60 \\
\hline $23 / 08 / 96$ & 3,45 & 3,86 & 3,77 \\
\hline $24 / 08 / 96$ & 3,39 & 4,10 & 3,99 \\
\hline $25 / 08 / 96$ & 3,55 & 4,14 & 4,05 \\
\hline $26 / 08 / 96$ & 3,74 & 4,36 & 4,26 \\
\hline $27 / 08 / 96$ & 3,97 & 4,02 & 3,94 \\
\hline $28 / 08 / 96$ & 3,00 & 3,16 & 3,06 \\
\hline $29 / 08 / 96$ & 2,61 & 3,14 & 3,03 \\
\hline $30 / 08 / 96$ & 3,72 & 3,52 & 3,45 \\
\hline $31 / 08 / 96$ & 4,30 & 4,58 & 4,45 \\
\hline $02 / 09 / 96$ & 3,38 & 3,71 & 3,63 \\
\hline $04 / 09 / 96$ & 2,72 & 2,50 & 2,44 \\
\hline $07 / 09 / 96$ & 3,74 & 3,86 & 3,76 \\
\hline $12 / 09 / 96$ & 2,85 & 2,86 & 2,75 \\
\hline $13 / 09 / 96$ & 3,18 & 3,73 & 3,64 \\
\hline $14 / 09 / 96$ & 4,45 & 4,06 & 3,97 \\
\hline $15 / 09 / 96$ & 4,18 & 4,16 & 4,08 \\
\hline $17 / 09 / 96$ & 3,53 & 3,10 & 2,98 \\
\hline $18 / 09 / 96$ & 3,86 & 3,82 & 3,66 \\
\hline $19 / 09 / 96$ & 4,41 & 4,29 & 4,19 \\
\hline $20 / 09 / 96$ & 4,14 & 4,24 & 4,16 \\
\hline $22 / 09 / 96$ & 5,02 & 4,94 & 4,84 \\
\hline $23 / 09 / 96$ & 4,52 & 4,72 & 4,62 \\
\hline $24 / 09 / 96$ & 3,72 & 3,79 & 3,71 \\
\hline
\end{tabular}




\begin{tabular}{|c|c|c|c|}
\hline Data & EToLP (mm) & $\begin{array}{c}\text { EToPM (mm) } \\
\text { rc } 69 \mathrm{~s} \mathrm{~m}^{-1}\end{array}$ & $\begin{array}{c}\text { EToPM (mm) } \\
\text { rc } 80 \mathrm{~s} \mathrm{~m}^{-1}\end{array}$ \\
\hline $26 / 09 / 96$ & 4,53 & 4,26 & 4,13 \\
\hline $27 / 09 / 96$ & 4,51 & 4,64 & 4,49 \\
\hline $28 / 09 / 96$ & 2,18 & 1,79 & 1,73 \\
\hline $29 / 09 / 96$ & 3,83 & 3,71 & 3,63 \\
\hline $30 / 09 / 96$ & 5,03 & 4,56 & 4,45 \\
\hline $01 / 10 / 96$ & 3,13 & 4,18 & 4,03 \\
\hline $04 / 10 / 96$ & 4,00 & 4,40 & 4,28 \\
\hline 07/10/96 & 3,97 & 3,57 & 3,44 \\
\hline $08 / 10 / 96$ & 3,84 & 3,76 & 3,62 \\
\hline 09/10/96 & 3,92 & 4,40 & 4,29 \\
\hline $11 / 10 / 96$ & 3,52 & 3,85 & 3,78 \\
\hline $15 / 10 / 96$ & 3,53 & 3,39 & 3,27 \\
\hline $16 / 10 / 96$ & 4,62 & 4,26 & 4,15 \\
\hline $17 / 10 / 96$ & 4,96 & 4,87 & 4,78 \\
\hline $18 / 10 / 96$ & 5,64 & 4,97 & 4,86 \\
\hline $19 / 10 / 96$ & 3,89 & 4,42 & 4,32 \\
\hline $21 / 10 / 96$ & 2,91 & 2,68 & 2,58 \\
\hline $22 / 10 / 96$ & 4,55 & 4,66 & 4,58 \\
\hline $23 / 10 / 96$ & 4,55 & 4,62 & 4,52 \\
\hline $24 / 10 / 96$ & 3,91 & 4,16 & 4,03 \\
\hline $28 / 10 / 96$ & 4,24 & 3,97 & 3,87 \\
\hline $29 / 10 / 96$ & 4,97 & 4,92 & 4,83 \\
\hline $30 / 10 / 96$ & 5,23 & 5,06 & 4,97 \\
\hline $31 / 10 / 96$ & 5,58 & 5,50 & 5,38 \\
\hline $04 / 11 / 96$ & 3,77 & 3,48 & 3,38 \\
\hline $05 / 11 / 96$ & 5,71 & 5,34 & 5,17 \\
\hline $06 / 11 / 96$ & 5,50 & 5,53 & 5,41 \\
\hline $07 / 11 / 96$ & 5,45 & 5,78 & 5,66 \\
\hline $08 / 11 / 96$ & 5,43 & 5,45 & 5,33 \\
\hline $09 / 11 / 96$ & 6,14 & 6,39 & 6,24 \\
\hline $10 / 11 / 96$ & 5,96 & 6,32 & 6,18 \\
\hline $11 / 11 / 96$ & 4,59 & 4,78 & 4,65 \\
\hline $12 / 11 / 96$ & 3,30 & 3,11 & 3,05 \\
\hline $22 / 11 / 96$ & 2,05 & 1,84 & 1,75 \\
\hline $23 / 11 / 96$ & 4,50 & 4,45 & 4,33 \\
\hline $24 / 11 / 96$ & 5,39 & 5,32 & 5,22 \\
\hline $25 / 11 / 96$ & 5,37 & 5,49 & 5,37 \\
\hline $26 / 11 / 96$ & 4,97 & 5,33 & 5,15 \\
\hline $27 / 11 / 96$ & 5,37 & 5,81 & 5,60 \\
\hline $28 / 11 / 96$ & 5,59 & 5,92 & 5,75 \\
\hline $29 / 11 / 96$ & 4,85 & 4,98 & 4,89 \\
\hline $30 / 11 / 96$ & 1,78 & 1,85 & 1,81 \\
\hline $05 / 12 / 96$ & 5,34 & 5,37 & 5,23 \\
\hline $06 / 12 / 96$ & 5,20 & 5,15 & 5,02 \\
\hline $08 / 12 / 96$ & 3,70 & 3,47 & 3,41 \\
\hline $09 / 12 / 96$ & 6,42 & 6,09 & 5,98 \\
\hline Média & 3,90 & 4,04 & 3,94 \\
\hline
\end{tabular}


Tabela 15 - Valores de evapotranspiração de referência medidos no lisímetro de pesagem e estimados pelo modelo de Penman Monteith utilizando os dados meteorológicos medidos em uma estação convencional, para diferentes valores de resistência do dossel no período de 24 horas.

\begin{tabular}{|c|c|c|c|}
\hline Data & EToLP (mm) & $\begin{array}{l}\text { EToPM (mm) } \\
\text { rc } 69 \mathrm{~s} \mathrm{~m}^{-1}\end{array}$ & $\begin{array}{c}\text { EToPM (mm) } \\
\text { rc } 40 \mathrm{~s} \mathrm{~m}^{-1}\end{array}$ \\
\hline $01 / 08 / 96$ & 2,59 & 2,30 & 2,40 \\
\hline 02/08/96 & 3,02 & 2,76 & 2,89 \\
\hline 03/08/96 & 2,74 & 2,81 & 2,98 \\
\hline 04/08/96 & 4,05 & 3,09 & 3,24 \\
\hline 05/08/96 & 3,50 & 3,17 & 3,34 \\
\hline 06/08/96 & 3,33 & 3,09 & 3,26 \\
\hline 07/08/96 & 3,03 & 3,03 & 3,16 \\
\hline 08/08/96 & 3,29 & 3,16 & 3,30 \\
\hline 09/08/96 & 3,35 & 3,42 & 3,65 \\
\hline $11 / 08 / 96$ & 2,68 & 1,82 & 1,94 \\
\hline $12 / 08 / 96$ & 2,99 & 2,57 & 2,71 \\
\hline $13 / 08 / 96$ & 3,15 & 3,04 & 3,20 \\
\hline $15 / 08 / 96$ & 3,09 & 2,82 & 3,08 \\
\hline $16 / 08 / 96$ & 4,07 & 2,93 & 3,27 \\
\hline $17 / 08 / 96$ & 3,83 & 3,10 & 3,28 \\
\hline $18 / 08 / 96$ & 3,59 & 3,34 & 3,54 \\
\hline $19 / 08 / 96$ & 3,76 & 3,38 & 3,60 \\
\hline $21 / 08 / 96$ & 4,39 & 3,88 & 4,12 \\
\hline $22 / 08 / 96$ & 3,90 & 3,84 & 4,07 \\
\hline $23 / 08 / 96$ & 4,18 & 3,92 & 4,17 \\
\hline $24 / 08 / 96$ & 4,41 & 4,39 & 4,78 \\
\hline $25 / 08 / 96$ & 4,32 & 4,04 & 4,28 \\
\hline $26 / 08 / 96$ & 4,62 & 4,75 & 5,15 \\
\hline $27 / 08 / 96$ & 4,46 & 4,25 & 4,46 \\
\hline $28 / 08 / 96$ & 3,80 & 3,73 & 4,06 \\
\hline 29/08/96 & 3,20 & 3,17 & 3,44 \\
\hline $30 / 08 / 96$ & 4,24 & 3,75 & 3,92 \\
\hline $31 / 08 / 96$ & 5,11 & 5,86 & 6,49 \\
\hline 02/09/96 & 3,93 & 3,91 & 4,13 \\
\hline 04/09/96 & 3,40 & 2,46 & 2,58 \\
\hline 07/09/96 & 4,73 & 3,92 & 4,25 \\
\hline $12 / 09 / 96$ & 3,73 & 3,12 & 3,46 \\
\hline $13 / 09 / 96$ & 3,99 & 4,00 & 4,22 \\
\hline $14 / 09 / 96$ & 4,79 & 4,11 & 4,31 \\
\hline $15 / 09 / 96$ & 4,73 & 4,06 & 4,18 \\
\hline $17 / 09 / 96$ & 4,18 & 3,42 & 3,79 \\
\hline $18 / 09 / 96$ & 4,80 & 3,76 & 4,16 \\
\hline $19 / 09 / 96$ & 5,23 & 4,25 & 4,45 \\
\hline $20 / 09 / 96$ & 4,79 & 4,59 & 4,82 \\
\hline $22 / 09 / 96$ & 5,50 & 5,00 & 5,22 \\
\hline $23 / 09 / 96$ & 5,22 & 4,75 & 5,00 \\
\hline 24/09/96 & 4,40 & 4,38 & 4,65 \\
\hline
\end{tabular}




\begin{tabular}{|c|c|c|c|}
\hline Data & EToLP (mm) & $\begin{array}{l}\text { EToPM (mm) } \\
\text { rc } 69 \mathrm{~s} \mathrm{~m}^{-1}\end{array}$ & $\begin{array}{c}\text { EToPM (mm) } \\
\text { rc } 40 \mathrm{~s} \mathrm{~m}^{-1}\end{array}$ \\
\hline $26 / 09 / 96$ & 5,14 & 4,84 & 5,31 \\
\hline 27/09/96 & 5,28 & 4,85 & 5,22 \\
\hline 28/09/96 & 2,48 & 2,43 & 2,57 \\
\hline 29/09/96 & 4,24 & 3,98 & 4,16 \\
\hline $30 / 09 / 96$ & 5,71 & 5,05 & 5,51 \\
\hline $01 / 10 / 96$ & 3,74 & 4,46 & 4,86 \\
\hline 04/10/96 & 4,57 & 4,39 & 4,67 \\
\hline 07/10/96 & 4,42 & 3,93 & 4,31 \\
\hline 08/10/96 & 4,45 & 3,84 & 4,23 \\
\hline 09/10/96 & 4,54 & 4,70 & 5,02 \\
\hline $11 / 10 / 96$ & 4,20 & 4,46 & 4,60 \\
\hline $15 / 10 / 96$ & 4,53 & 4,03 & 4,44 \\
\hline $16 / 10 / 96$ & 5,32 & 4,45 & 4,71 \\
\hline $17 / 10 / 96$ & 5,90 & 5,15 & 5,34 \\
\hline $18 / 10 / 96$ & 6,27 & 5,53 & 5,78 \\
\hline $19 / 10 / 96$ & 4,72 & 4,56 & 4,92 \\
\hline $21 / 10 / 96$ & 3,67 & 3,41 & 3,72 \\
\hline $22 / 10 / 96$ & 5,09 & 4,96 & 5,12 \\
\hline $23 / 10 / 96$ & 5,38 & 5,13 & 5,52 \\
\hline $24 / 10 / 96$ & 4,72 & 4,48 & 4,82 \\
\hline $28 / 10 / 96$ & 5,03 & 4,78 & 5,02 \\
\hline 29/10/96 & 5,61 & 5,16 & 5,36 \\
\hline $30 / 10 / 96$ & 6,01 & 5,43 & 5,70 \\
\hline $31 / 10 / 96$ & 6,18 & 6,04 & 6,40 \\
\hline $04 / 11 / 96$ & 4,41 & 3,83 & 4,19 \\
\hline $05 / 11 / 96$ & 6,37 & 5,64 & 6,17 \\
\hline $06 / 11 / 96$ & 6,49 & 5,41 & 5,63 \\
\hline 07/11/96 & 6,09 & 5,98 & 6,27 \\
\hline $08 / 11 / 96$ & 6,50 & 5,60 & 5,87 \\
\hline 09/11/96 & 6,86 & 6,43 & 6,73 \\
\hline $10 / 11 / 96$ & 6,88 & 6,38 & 6,75 \\
\hline $11 / 11 / 96$ & 5,32 & 4,54 & 4,71 \\
\hline $12 / 11 / 96$ & 3,55 & 3,15 & 3,27 \\
\hline $22 / 11 / 96$ & 2,71 & 2,18 & 2,44 \\
\hline $23 / 11 / 96$ & 4,98 & 4,31 & 4,60 \\
\hline $24 / 11 / 96$ & 6,40 & 5,58 & 5,82 \\
\hline $25 / 11 / 96$ & 5,98 & 5,74 & 6,14 \\
\hline $26 / 11 / 96$ & 5,46 & 5,99 & 6,69 \\
\hline $27 / 11 / 96$ & 6,26 & 6,29 & 6,98 \\
\hline $28 / 11 / 96$ & 6,10 & 6,08 & 6,50 \\
\hline $29 / 11 / 96$ & 5,17 & 4,96 & 5,11 \\
\hline $30 / 11 / 96$ & 2,22 & 2,61 & 2,70 \\
\hline $05 / 12 / 96$ & 5,78 & 5,50 & 5,84 \\
\hline $06 / 12 / 96$ & 5,73 & 4,77 & 5,02 \\
\hline $08 / 12 / 96$ & 3,91 & 3,50 & 3,59 \\
\hline $09 / 12 / 96$ & 6,99 & 6,27 & 6,52 \\
\hline Média & 4,58 & 4,23 & 4,50 \\
\hline
\end{tabular}


Tabela 16 -Valores de evaporação de tanque Classe A e evapotranspiração de referência estimados por meio de coeficientes de tanque $(\mathrm{Kp})$, propostos por Pereira et al. 1995 e FAO (1977) e medida em lisímetro de pesagem.

\begin{tabular}{|c|c|c|c|c|c|c|}
\hline Dia & $\underset{\text { mm.dia }^{-1}}{\text { ECA }}$ & $\mathbf{K p}^{*}$ & $\begin{array}{c}\text { EToECA } \\
\text { mm.dia }^{*-1}\end{array}$ & $K_{p}^{* *}$ & $\begin{array}{c}\text { mmoECA }^{* *} \\
\text { mm.dia }^{-1}\end{array}$ & $\begin{array}{c}\text { EToLP } \\
\text { mm.dia }^{-1}\end{array}$ \\
\hline $02 / 08 / 96$ & 5,14 & 0,74 & 3,81 & 0,83 & 4,26 & 3,02 \\
\hline 03/08/96 & 3,86 & 0,73 & 2,83 & 0,86 & 3,30 & 2,74 \\
\hline $05 / 08 / 96$ & 5,09 & 0,72 & 3,68 & 0,81 & 4,11 & 3,50 \\
\hline 09/08/96 & 6,72 & 0,71 & 4,74 & 0,77 & 5,15 & 3,35 \\
\hline $12 / 08 / 96$ & 3,56 & 0,70 & 2,51 & 0,91 & 3,23 & 2,99 \\
\hline $13 / 08 / 96$ & 3,76 & 0,74 & 2,79 & 0,91 & 3,40 & 3,15 \\
\hline $15 / 08 / 96$ & 4,54 & 0,69 & 3,15 & 0,89 & 4,02 & 3,09 \\
\hline $16 / 08 / 96$ & 5,62 & 0,62 & 3,46 & 0,78 & 4,39 & 4,07 \\
\hline $18 / 08 / 96$ & 5,36 & 0,73 & 3,90 & 0,85 & 4,53 & 3,59 \\
\hline $19 / 08 / 96$ & 5,16 & 0,72 & 3,72 & 0,83 & 4,30 & 3,76 \\
\hline $21 / 08 / 96$ & 5,72 & 0,71 & 4,05 & 0,79 & 4,55 & 4,39 \\
\hline $22 / 08 / 96$ & 6,52 & 0,72 & 4,69 & 0,78 & 5,12 & 3,90 \\
\hline $24 / 08 / 96$ & 6,26 & 0,71 & 4,46 & 0,80 & 5,02 & 4,41 \\
\hline $25 / 08 / 96$ & 6,00 & 0,72 & 4,32 & 0,79 & 4,72 & 4,32 \\
\hline $26 / 08 / 96$ & 6,25 & 0,72 & 4,48 & 0,77 & 4,83 & 4,62 \\
\hline $28 / 08 / 96$ & 6,50 & 0,68 & 4,43 & 0,82 & 5,36 & 3,80 \\
\hline $29 / 08 / 96$ & 5,64 & 0,65 & 3,68 & 0,82 & 4,60 & 3,20 \\
\hline $31 / 08 / 96$ & 7,32 & 0,70 & 5,13 & 0,77 & 5,67 & 5,11 \\
\hline $02 / 09 / 96$ & 6,46 & 0,73 & 4,73 & 0,86 & 5,54 & 3,93 \\
\hline $13 / 09 / 96$ & 5,84 & 0,70 & 4,09 & 0,88 & 5,14 & 3,99 \\
\hline $17 / 09 / 96$ & 5,66 & 0,65 & 3,68 & 0,86 & 4,87 & 4,18 \\
\hline $18 / 09 / 96$ & 6,00 & 0,63 & 3,79 & 0,82 & 4,92 & 4,80 \\
\hline $20 / 09 / 96$ & 7,20 & 0,75 & 5,38 & 0,85 & 6,10 & 4,79 \\
\hline $22 / 09 / 96$ & 6,80 & 0,73 & 4,98 & 0,78 & 5,32 & 5,50 \\
\hline $23 / 09 / 96$ & 7,25 & 0,72 & 5,25 & 0,79 & 5,76 & 5,22 \\
\hline $26 / 09 / 96$ & 7,04 & 0,67 & 4,71 & 0,83 & 5,85 & 5,14 \\
\hline $27 / 09 / 96$ & 7,62 & 0,66 & 5,06 & 0,80 & 6,11 & 5,28 \\
\hline $29 / 09 / 96$ & 5,20 & 0,74 & 3,86 & 0,88 & 4,59 & 4,24 \\
\hline $30 / 09 / 96$ & 8,80 & 0,69 & 6,10 & 0,83 & 7,35 & 5,71 \\
\hline $01 / 10 / 96$ & 6,66 & 0,64 & 4,29 & 0,80 & 5,31 & 3,74 \\
\hline $04 / 10 / 96$ & 5,72 & 0,72 & 4,13 & 0,89 & 5,08 & 4,57 \\
\hline $08 / 10 / 96$ & 5,56 & 0,66 & 3,66 & 0,84 & 4,69 & 4,45 \\
\hline $09 / 10 / 96$ & 5,64 & 0,70 & 3,94 & 0,85 & 4,79 & 4,54 \\
\hline $15 / 10 / 96$ & 6,28 & 0,63 & 3,95 & 0,82 & 5,14 & 4,53 \\
\hline $19 / 10 / 96$ & 7,31 & 0,70 & 5,15 & 0,83 & 6,03 & 4,72 \\
\hline $21 / 10 / 96$ & 4,76 & 0,66 & 3,14 & 0,87 & 4,13 & 3,67 \\
\hline $23 / 10 / 96$ & 8,70 & 0,71 & 6,20 & 0,87 & 7,54 & 5,38 \\
\hline $30 / 10 / 96$ & 8,02 & 0,74 & 5,91 & 0,82 & 6,59 & 6,01 \\
\hline $04 / 11 / 96$ & 6,56 & 0,69 & 4,53 & 0,88 & 5,79 & 4,41 \\
\hline $05 / 11 / 96$ & 8,52 & 0,66 & 5,65 & 0,81 & 6,89 & 6,37 \\
\hline $07 / 11 / 96$ & 7,60 & 0,75 & 5,69 & 0,86 & 6,54 & 6,09 \\
\hline
\end{tabular}


Continuação

\begin{tabular}{ccccccc} 
Dia & $\begin{array}{c}\text { ECA } \\
\text { mm.dia }^{-1}\end{array}$ & Kp $^{*}$ & $\begin{array}{c}\text { EToECA }^{*} \\
\text { mm.dia }^{-1}\end{array}$ & Kp $^{* *}$ & $\begin{array}{c}\text { EToECA }^{* *} \\
\text { mm.dia }^{-1}\end{array}$ & $\begin{array}{c}\text { EToLP } \\
\text { mm.dia }^{-1}\end{array}$ \\
$10 / 11 / 96$ & 8,86 & 0,73 & $\mathbf{6 , 4 7}$ & 0,78 & $\mathbf{6 , 8 9}$ & $\mathbf{6 , 8 8}$ \\
$11 / 11 / 96$ & 7,52 & 0,71 & $\mathbf{5 , 3 0}$ & 0,82 & $\mathbf{6 , 1 9}$ & $\mathbf{5 , 3 2}$ \\
$12 / 11 / 96$ & 4,30 & 0,75 & $\mathbf{3 , 2 1}$ & 0,88 & $\mathbf{3 , 8 0}$ & $\mathbf{3 , 5 5}$ \\
$22 / 11 / 96$ & 4,50 & 0,61 & $\mathbf{2 , 7 5}$ & 0,85 & $\mathbf{3 , 8 1}$ & $\mathbf{2 , 7 1}$ \\
$23 / 11 / 96$ & 6,36 & 0,70 & $\mathbf{4 , 4 4}$ & 0,86 & $\mathbf{5 , 4 9}$ & $\mathbf{4 , 9 8}$ \\
$26 / 11 / 96$ & 9,62 & 0,65 & $\mathbf{6 , 3 0}$ & 0,80 & $\mathbf{7 , 6 8}$ & $\mathbf{5 , 4 6}$ \\
$27 / 11 / 96$ & 9,18 & 0,65 & $\mathbf{6 , 0 0}$ & 0,78 & $\mathbf{7 , 1 6}$ & $\mathbf{6 , 2 6}$ \\
$28 / 11 / 96$ & $\mathbf{8 , 5 0}$ & 0,69 & $\mathbf{5 , 8 3}$ & 0,78 & $\mathbf{6 , 6 6}$ & $\mathbf{6 , 1 0}$ \\
\hline Média & $\mathbf{6 , 3 9}$ & $\mathbf{0 , 7 0}$ & $\mathbf{4 , 4 5}$ & $\mathbf{0 , 8 3}$ & $\mathbf{5 , 2 7}$ & $\mathbf{4 . 4 8}$ \\
\hline
\end{tabular}

$\mathrm{Kp}^{*}$ - Coeficiente de tanque proposto por Pereira et al. 1995

ETo ${ }^{*}$ - Evapotranspiração de referência estimada com base na evaporação do tanque Classe A com o Kp proposto por Pereira et al. 1995.

$\mathrm{Kp}^{* *}$ - Coeficiente de tanque FAO (1977), calculado pela equação proposta por Snyder (1985).

ETo** - Evapotranspiração de referência estimada com base na evaporação do tanque Classe A com o Kp proposto pela FAO (1977). 
Tabela 17- Valores de evapotranspiração de referência estimada em atmômetro modificado SEEI e medida em lisímetro de pesagem.

\begin{tabular}{|c|c|c|}
\hline Dia & $\begin{array}{c}\text { EToA } \\
\text { mm.dia }^{-1}\end{array}$ & $\begin{array}{c}\text { EToLP } \\
\text { mm.dia }^{-1}\end{array}$ \\
\hline $04 / 08 / 96$ & 4,00 & 4,05 \\
\hline $05 / 08 / 96$ & 4,00 & 3,50 \\
\hline $06 / 08 / 96$ & 4,00 & 3,33 \\
\hline $12 / 08 / 96$ & 4,00 & 2,99 \\
\hline $13 / 08 / 96$ & 4,00 & 3,15 \\
\hline $14 / 08 / 96$ & 2,00 & 2,46 \\
\hline $15 / 08 / 96$ & 3,00 & 3,09 \\
\hline $16 / 08 / 96$ & 4,00 & 4,07 \\
\hline $17 / 08 / 96$ & 3,00 & 3,83 \\
\hline $21 / 08 / 96$ & 4,00 & 4,39 \\
\hline $22 / 08 / 96$ & 4,00 & 3,90 \\
\hline $24 / 08 / 96$ & 4,50 & 4,41 \\
\hline $25 / 08 / 96$ & 4,50 & 4,32 \\
\hline $30 / 08 / 96$ & 5.00 & 4,24 \\
\hline $31 / 08 / 96$ & 4,00 & 5,11 \\
\hline $03 / 09 / 96$ & 3,00 & 2,03 \\
\hline 08/09/96 & 4,00 & 3,36 \\
\hline 09/09/96 & 2,00 & 1,20 \\
\hline $13 / 09 / 96$ & 4,00 & 3,99 \\
\hline $14 / 09 / 96$ & 4,00 & 4,79 \\
\hline $15 / 09 / 96$ & 5,00 & 4,73 \\
\hline $16 / 09 / 96$ & 5,00 & 4,39 \\
\hline $17 / 09 / 96$ & 3,00 & 4,18 \\
\hline $20 / 09 / 96$ & 5,00 & 4,79 \\
\hline $22 / 09 / 96$ & 6,00 & 5,50 \\
\hline $27 / 09 / 96$ & 5,00 & 5,28 \\
\hline $02 / 10 / 96$ & 5,00 & 3,92 \\
\hline $05 / 10 / 96$ & 4,00 & 4,27 \\
\hline $08 / 10 / 96$ & 4,00 & 4,45 \\
\hline 09/10/96 & 4,00 & 4,54 \\
\hline $12 / 10 / 96$ & 5,00 & 4,53 \\
\hline $16 / 10 / 96$ & 4,00 & 5,32 \\
\hline $17 / 10 / 96$ & 6,00 & 5,90 \\
\hline $18 / 10 / 96$ & 5,00 & 6,27 \\
\hline $19 / 10 / 96$ & 6,00 & 4,72 \\
\hline $27 / 10 / 96$ & 2,00 & 2,13 \\
\hline $29 / 10 / 96$ & 6,00 & 5,61 \\
\hline $30 / 10 / 96$ & 6,00 & 6,01 \\
\hline $31 / 10 / 96$ & 6,00 & 6,18 \\
\hline $02 / 11 / 96$ & 3,00 & 2,16 \\
\hline $05 / 11 / 96$ & 5,00 & 6,37 \\
\hline
\end{tabular}


Continuação

\begin{tabular}{ccc}
\hline Dia & $\begin{array}{c}\text { EToA } \\
\text { mm.dia }^{-1}\end{array}$ & $\begin{array}{c}\text { EToLP } \\
\text { mm.dia }^{-1}\end{array}$ \\
\hline $06 / 11 / 96$ & 6,00 & 6,49 \\
$07 / 11 / 96$ & 7,00 & 6,09 \\
$08 / 11 / 96$ & 6,00 & 6,50 \\
$09 / 11 / 96$ & 8,00 & 6,86 \\
$10 / 11 / 96$ & 6,00 & 6,88 \\
$14 / 11 / 96$ & 1,00 & 1,13 \\
$24 / 11 / 96$ & 5,00 & 6,40 \\
$25 / 11 / 96$ & 6,00 & 5,98 \\
$27 / 11 / 96$ & 6,00 & 6,26 \\
$28 / 11 / 96$ & 6,00 & 6,10 \\
$04 / 12 / 96$ & 3,00 & 2,60 \\
$06 / 12 / 96$ & 6,00 & 5,73 \\
$11 / 12 / 96$ & 3,00 & 3,74 \\
$12 / 12 / 96$ & 4,00 & 3,28 \\
\hline Média & 4,51 & $\mathbf{4 , 5 0}$ \\
\hline
\end{tabular}




\section{REFERÊNCIAS BIBLIOGRÁFICAS}

ABOUKHALED, A.; ALFARO, A. SMITH, M. Lysimeters. Rome: FAO, 1982. 68p. (FAO. Irrigation and Drainage Paper, 39).

ALLEN, R. G. Daily reference evapotranspiration in arid and humid environment. In: NATIONAL CONFERENCE ON ADVANCES IN EVAPOTRANSPIRATION, Chicago, 1985 Proceedings. St. Joseph: ASAE, 1985. p. 4-12.

ALLEN, R. G. A Penman for all seasons. Journal of Irrigation and Drainage. Engineering, v.112, n.4, p. 348-368, 1986.

ALLEN, R. G.; JENSEN, M. E.; WRIGHT, J.L.; BURMAN, R. D. Operation estimates of reference evapotranspiration. Agronomy Journal, v.81, p.650-662, 1989.

ALTENHOFEN, J. A Modifield atmometer for on-farm evapotranspiration determination. In: CONFERENCE ON ADVANCES IN EVAPOTRANSPIRATION, Chicago, 1985 Proceedings. St. Joseph: ASAE, 1985. p.177-184. 
AMORIM, M. C.; SEDIYAMA, G. S.; SOBRINHO, J. E.; RODRIGUES, L.N. Avaliação da evapotranspiração de referência estimada por diferentes modelos de coeficiente de tanque classe A. In: CONGRESSO BRASILEIRO DE AGROMETEOROLOGIA,10. , Piracicaba, 1997. Anais. Piracicaba: SBA, 1997. p.683-685.

ANGELOCCI, L. R.; MINAMI, K. Consumo hídrico de espécies hortícolas. Piracicaba: ESALQ, 1992. 36p. (Relatório de Projeto de Pesquisa).

BARBIERI, V. Medidas e estimativas de consumo hídrico em cana-de-açúcar. Piracicaba, 1981. 82 p. Dissertação (Mestrado) - Escola Superior de Agricultura "Luiz de Queiroz", Universidade de São Paulo.

BARRADA, Y. Water balance studies. In: FAO/UNDP REGIONAL SEMINAR ON EFFECTIVE USE OF IRRIGATION WATER AT THE FARM LEVEL, Damascus, 1971. Rome: FAO, 1972. p.60-90. ( FAO. Irrigation and Drainage Paper, 13).

BERLATO, M. A.; MOLION,L.C.D. Evaporação e evapotranspiração. Porto Alegre: IPAGRO, 1981. 95p. (Boletim Técnico, 7).

BERNARDO, S. Manual de irrigação. 5. ed. Viçosa: UFV, Imprensa Universitária, 1989. $596 \mathrm{p}$.

BRUTSAERT, W. Evaporation into the atmosphere: theory, history and aplications. Dordrecht: Kluwer Academic, 1982. 299p. (Environmental Fluid Mechanics, 1).

BURMAN, R. D.; NIXON, P. R.; WRIGTH, J. L.; PRUITT, W. O. Water requeriment. In: JENSEN, M. E. Desing and operation of farm irrigation system. St. Joseph: ASAE, 1980. cap. 6, p. 189-232. 
COSTA, A. C. S. Balanço hídrico das culturas de feijão (Phaseolus vulgaris L.) e de milho (Zea mays L.) sob condições de campo. Piracicaba, 1986. 166p. Dissertação (Mestrado) - Escola Superior de Agricultura "Luiz de Queiroz", Universidade de São Paulo.

CUENCA, R. H. Irrigation system desing: engineering approach. Englewood Cliffs: Prentice-Hall, 1989. 133p.

CURY, D. M.; VILLA NOVA, N. A. A utilização de um evapotranspirômetro de lençol freático fixo na determinação da demanda de água em hortaliças. Engenharia Agrícola, v.11, p.33-39, 1987.

DOORENBOS, J.; PRUITT, J. O. Guidlines for predicting crop water requirements. Rome: FAO, 1977. 179p .(FAO. Irrigation and Drainage Paper, 24).

ENCARNAÇÃO, C. R. F. Estudo da demanda de água do feijoeiro (Phaseolus vulgaris L.) var. goiano precoce. Piracicaba, 1980. 62p. Dissertação (Mestrado) - Escola Superior de Agricultura "Luiz de Queiroz", Universidade de São Paulo.

ENCARNAÇÃO, C. R. F.; VILA NOVA, N. A. ; ANGELOCCI, L. R. Exigências hídricas e coeficientes culturais da batata (Solanum tuberosum L.). In: CONGRESSO BRASILEIRO DE AGROMETEOROLOGIA, 5., Belém, 1987. Anais. Belém: SBA, 1987. p.143-147.

ERTHAL, V. J. T. Avaliação da estimativa da evapotranspiração de referência, utilizando o atmômetro modificado, na região de Viçosa-MG. Viçosa, 1994. 44p. Dissertação (Mestrado) - Universidade Federal de Viçosa. 
FERREIRA, E. J. Determinação da evapotranspiração e do coeficiente de cultura (Kc) para aveia preta (Avena strigosa Sckreb) irrigada. Viçosa, 1988. 70p. Dissertação (Mestrado) - Universidade Federal de Viçosa.

FREVERT, D. R.; HILL, W. R.; BRAATEN, B. C. Estimation of FAO evapotranspiration coefficients. Journal of Irrigation and Drainage Engineering, ASCE, v. 109 p. 265-270, 1983.

GLOVER, J.; McCULLOCH, J. S. F., The empirical ralation between solar radiation and hours of sunshine. Quarterly Journal of the Royal Meteorological. Society, v. 84 p.172-175, 1958.

GUANDIQUE, M.E.G. Balanço hídrico no solo e consumo de água pela cultura de feijão (Phaseolus vulgaris L.) irrigado. Piracicaba, 1993. 94p. Dissertação (Mestrado) Escola Superior de Agricultura "Luiz de Queiroz", Universidade de São Paulo.

HATFIELD, J. L. Research priorities in ET: evolving methods. Transactions of the ASAE, v. 31, n.2, p. 491-495, Mar./Apr. 1988.

JANSEN, M. E. Evaluating irrigation efficiency. Journal of Irrigation and Drainage Division, v. 93, p.88-98, 1967.

JANSEN, M. E.Water consumption by agricultural plants. In: KOSLOWSKY, T.T. Water deficits and plant growth. New York: Academic Press, 1968. v.2, p.1-22.

LAW, R.A.P.; ISRAELI, I. Evaluation of atmometer performance as a tool for irrigation scheduling. St. Joseph: ASEA, 1988. 26p. 
LUCHIARI JUNIOR, A. Determinação do coeficiente de cultura $(\mathrm{Kc})$ para feijão (Phaseolus vulgaris L. ) pelo método do balanço hídrico. Piracicaba, 1978. 59p. Dissertação (Mestrado) - Escola Superior de Agricultura "Luiz de Queiroz", Universidade de São Paulo.

LUCHIARI JUNIOR, A.; RIHA, S. J. Bulk surface resistance and its effect on evapotranspiration rates in irragated wheat. Agronomy Journal, v. 83 , n. 5 , p. 888895, Sept./Nov. 1991.

MAGGIOTTO, S. R. Estimativa da evapotranspiração de referência pelo uso da termometria ao infravermelho. Piracicaba, 1996. 71 p. Dissertação (Mestrado) Escola Superior de Agricultura "Luiz de Queiroz", Universidade de São Paulo.

MARTORANO, L. G.; MARIANO, Z. F.; BARBIERI, V.; SANTOS, R.M.N.; SILVA; J. G. Caracterização climática de Piracicaba, SP: uma análise das tendências de elementos meteorológicos. In: REUNIÃO ARGENTINA, LATINOAMERICANA de AGROMETEOROLOGIA, 7.,1., Buenos Aires, 1997. Resumos. Buenos Aires: 1997. p.31-32.

MONTEITH, J.L. Evaporation and environment. In: SYMPOSIUM OF THE SOCIETY FOR EXPERIMENTAL BIOLOGY, 19., London, 1964. Cambridge: Cambridge University Press, p.205-234. 1965.

MONTEITH, J.L. The development and extension of Penman's evaporation formula. In: HIllLL, D. (Ed.) Applications of soil physics. New York: Academic Press, 1980. p.247-253.

MONTEITH, J.L. Evaporation and suface temperature. Quarterly Journal of the Royal Meteorological Society of London, v. 107, n.451 p. 1-27, 1981. 
MONTEITH, J.L. Evaporation from land surfaces: progress in analysis and prediction since 1948. In: NATIONAL CONFERENCE ON ADVANCES IN EVAPOTRANSPIRATION, Chicago, 1985. Proceeedings. St Joseph: ASAE, 1985. p.4-12.

OKE, T. R. Boundary layer climates. 2. ed. London: Routledge, 1992. 435p.

OMETTO, J. C. Registros e estimativas dos parâmetros meteorológicos da região de Piracicaba, SP. Piracicaba: FEALQ, 1991. 76p.

PENMAN, H. L. Natural evaporation from open water, bare soil and grass. Proceedings of the Royal Society, v.198, p.116-140, 1948.

PENMAN, H. L. Evaporation: introduction survey. Netherland Journal of Agricultural Science, v.4, n.1, p.9-29, 1956.

PEREIRA, A. R.; VILLA NOVA, N.A.; SEDIYAMA G. C. Evapo(transpi)ração. Piracicaba: FEALQ, 1997. 183p.

PEREIRA, A. R.; VILLA NOVA, N.A.; PEREIRA, A. S.; BARBIERI, V. A model for the Class A pan coefficient. Agricultural and Forest Meteorology, v. 76, p.75-88, 1995.

PEREIRA, A. S. Avaliação do desempenho de um atmômetro modificado na estimativa da evapotranspiração potencial. Piracicaba, 1997. 90p. Dissertação (Mestrado) Escola Superior de Agricultura "Luiz de Queiroz", Universidade de São Paulo. 
PEREIRA, A. S.; COELHO, R. D. Determinação da evapotranpiração de referência (ETo) através de atmômetros modificados em condições tropicais. In: CONGRESSO BRASILEIRO DE ENGENHARIA AGRÍCOLA, 21., Santa Maria, 1992. Anais. Santa Maria: SBEA, 1992. p.637-647.

PEREIRA, F.A.C. Efeitos de diferentes profundidades do lençol freático sobre a evapotranspiração, o coeficiente de cultura, a produção e os componentes de produção da alface (Lactuca sativa L.) Viçosa, 1993, 55p. Dissertação (Mestrado) Universidade Federal de Viçosa.

PERES, J. G. Avaliação do modelo de Penman-Monteith, padrão FAO, para estimar a evapotranspiração de referência nas condições climáticas do estado de São Paulo. Piracicaba, 1994. 116p. Tese (Doutorado) - Escola Superior de Agricultura "Luiz de Queiroz", Universidade de São Paulo.

REICHARDT, K. Processos de transferência no sistema solo-planta-atmosfera. Campinas: Fundação Cargill, 1985. 445p.

REICHARDT, K. A água em sistemas agrícolas. São Paulo: Editora Manole, 1987. $187 \mathrm{p}$.

REICHARDT, K.; LIBARDI, P.L.; SAUNDERS, L.C.V.; CADIMA,Z. A. Dinâmica da água em solo cultivado com milho. Revista Brasileira de Ciência do Solo, v.3, p.1-5, 1979.

ROSE, C. W.; STERN, W. R. Determination of withdrawal of water from soil by crops roots as a function of depth and time. Australian Journal of Soil Research, v.5, p.11-19, 1967. 
SAAD, A. M. Uso do tensiômetro no controle da irrigação por pivô central em cultura do feijoeiro (Phaseolus vulgaris L.) Piracicaba, 1991. 144p. Dissertação (Mestrado) Escola Superior de Agricultura "Luiz de Queiroz", Universidade de São Paulo.

SAKAI, E. Balanço hídrico e energético na cultura do feijoeiro em latossolo roxo. Piracicaba, 1989. 121p. Dissertação (Mestrado) - Escola Superior de Agricultura "Luiz de Queiroz", Universidade de São Paulo.

SEDIYAMA, G. C. A versão proposta para o conceito de evapotranspiração de referência. In: CONGRESSO BRASILEIRO DE AGROMETEOROLOGIA 9.,. Campina Grande,1995. Palestra. Campina Grande: SBA, 1995. p.1-14.

SEDIYAMA, G. C. Necessidade de água para os cultivos. Brasília: ABEAS, 1987. 143p. (ABEAS. Curso de Engenharia de irrigação. Módulo 4).

SHARMA, M. L. Estimating evapotranspiration. In: HILLEL, D. (Ed) Advances in irrigation. New York: Academic Press, 1983. v.3, p. 213-281.

SILVA, A.A.G. da. Avaliação da eficiência de métodos de estimativa da evapotranspiração de referência para o município de Parnaiba-Pi. Piracicaba, 1989. 80p. Dissertação (Mestrado) - Escola Superior de Agricultura "Luiz de Queiroz", Universidade de São Paulo.

SILVA, F.C. Uso de dispositivos lisimétricos para determinação da evapotranspiração de referência. Piracicaba, 1996. 68p. Dissertação (Mestrado) - Escola Superior de Agricultura "Luiz de Queiroz", Universidade de São Paulo.

SMITH, M. (Ed.) Guidelines for prediction of crop water requirements. Rome: FAO, 1991. 45p. 
SNYDER, R. L. Equation for evaporation pan to evapotranspiration conversions. Journal. of Irrrigation and Drainage Engineering ASCE v.118, p.977-980, 1992.

TANNER, C. B. Evaporation of water from plants and soil. In: KOZLWSKI, T. T. (Ed.) Water deficits and plant growth. New York: Academic Press, 1968. v.1, p.73-106.

THORNTHWAITE, W. C. An approch toward a rational classification of climate. Geographical Review, v.38, n.1, p.55-94, 1948.

THORNTHWAITE, W. C. ; HOLZMAN, B. Measurement of evaporation from land and water surface. Washington: USDA, 1944. p.4-11. (USDA. Technical Bulletin. $817 \mathrm{~B})$

VIEIRA, D. B. As técnicas de irrigação. São Paulo: Globo, 1989. 259p.

WILLMONT, C. J. On the validation of models. Physical Geography, v.2, p.184-194, 1981.

WITHERS, B.; VIPOND, S. Irrigation: design and paractive. London: B.T. Batsford, 1974. 306p. 